AperTO - Archivio Istituzionale Open Access dell'Università di Torino

\title{
Elimination from Wastewater of Antibiotics Reserved for Hospital Settings, with a Fenton Process Based on Zero-Valent Iron
}

\section{This is the author's manuscript}

Original Citation:

Availability:

This version is available http://hdl.handle.net/2318/1795019

since 2021-07-26T12:09:55Z

Published version:

DOI:10.1016/j.chemosphere.2021.131170

Terms of use:

Open Access

Anyone can freely access the full text of works made available as "Open Access". Works made available under a Creative Commons license can be used according to the terms and conditions of said license. Use of all other works requires consent of the right holder (author or publisher) if not exempted from copyright protection by the applicable law. 


\section{SUPPLEMENTARY MATERIAL}

\section{Elimination from Wastewater of Antibiotics Reserved for Hospital Settings, with a Fenton Process Based on Zero-Valent Iron (ZVI-Fenton)}

Francesco Furia, ${ }^{a}$ Marco Minella, ${ }^{a}$ Fabio Gosetti, ${ }^{b}$ Raffaella Sabatino, ${ }^{\mathrm{c}}$ Andrea Di Cesare, ${ }^{\mathrm{c}}$ Gianluca Corno, ${ }^{\mathrm{c}}$ Davide Vione ${ }^{\mathrm{a} *}$

${ }^{a}$ Dipartimento di Chimica, Università di Torino, Via Pietro Giuria 5, 10125 Torino, Italy.

${ }^{b}$ Dipartimento di Scienze dell'Ambiente e della Terra, Università di Milano - Bicocca, Piazza della Scienza 1, 20126 Milano, Italy.

${ }^{c}$ Molecular Ecology Group, National Research Council of Italy, Water Research Institute, Largo Tonolli 50, 28922, Verbania (VCO), Italy.

* Corresponding author. E-mail: davide.vione@unito.it 


\section{Table of contents}

Paragraph S1 (Reagents), Paragraph S2 (WW characterization) page S3

Table S1 (WW characterization), Paragraph S3, Table S2 (Instrumentation details) page S4

$\begin{array}{ll}\text { Figure S1 (Example of repeatability test) } & \text { page S8 }\end{array}$

Figure $\mathrm{S} 2$ ( $\mathrm{pH}$ trend of degradation, $\mathrm{CFZ}) \quad$ page S9

Figure S3 (pH trend of degradation, VNM) page S10

Figure S4 (pH trend of degradation, IMI) page S11

Table S3 (Preliminary experiments, ultra-pure water, $\mathrm{pH} 5-7$ ) page S12

$\begin{array}{ll}\text { Figure S5 (EPR measurements) } & \text { page S13 }\end{array}$

Table S4 (Degradation conditions) page S14

Figure S6 (Degradation in WWa\&b, pH 6) page S15

$\begin{array}{ll}\text { Figure S7 (Wastewater titration) } & \text { page S16 }\end{array}$

$\begin{array}{ll}\text { Figure S8 (Time trends of conductivity) } & \text { page S17 }\end{array}$

Figure $\mathrm{S} 9$ (Time trends of $\mathrm{H}_{2} \mathrm{O}_{2}$ ) page $\mathrm{S} 18$

$\begin{array}{ll}\text { Table S5 (Optimized degradation conditions) } & \text { page S19 }\end{array}$

Table S6 (Structures of intermediates, complete table) pages S20-S25

Figures S10-S12 (LC-MS/MS spectra, original antibiotics) pages S26-S28

Figures S13-S30 (LC-MS/MS spectra, CFZ intermediates) pages S29-S46

Figures S31-S35 (LC-MS/MS spectra, IMI intermediates) pages S47-S51

Figures S36-S43 (LC-MS/MS spectra, VNM intermediates) pages S52-S59

Figure S44 (Trends of normalized peak areas, antibiotics and intermediates) $\quad$ page S60 


\section{S1. Reagents}

Cefazolin (CFZ, EP reference standard), imipenem (IMI, reference standard), vancomycin (VNM, pharmaceutical secondary standard), $\mathrm{HClO}_{4}(70 \% \mathrm{w} / \mathrm{w}), \mathrm{NaOH}(\geq 90 \%)$, methanol (gradient grade), $\mathrm{H}_{2} \mathrm{SO}_{4}\left(96 \%\right.$ w/w), $\mathrm{H}_{3} \mathrm{PO}_{4}\left(85 \%\right.$ w/w), $\mathrm{FeCl}_{3} \cdot 6 \mathrm{H}_{2} \mathrm{O}(99 \%)$, ampyrone (4-amino-2,3dimethyl-1-phenyl-3-pyrazol-5-one; reagent grade), $\mathrm{NaH}_{2} \mathrm{PO}_{4}(\geq 99.9 \%), \mathrm{Na}_{2} \mathrm{HPO}_{4}(\geq 98 \%), \mathrm{ZVI}$ ( $\geq 99.5 \%$, powder $<10 \mu \mathrm{m}$, product number 44890), 1,10-phenanthroline (>99\%), ascorbic acid (reagent grade), 5,5-dimethyl-1-pyrrolidine-N-oxide (DMPO, 97\%), catalase and horseradish peroxidase were purchased from Sigma-Aldrich; KSCN ( $\geq 98 \%)$ and $\mathrm{FeSO}_{4} \cdot 7 \mathrm{H}_{2} \mathrm{O}$ (99.5\%) from Merck; $\mathrm{H}_{2} \mathrm{O}_{2}(30 \% \mathrm{w} / \mathrm{v})$ from Applichem PanReac; formalin, SYBRgreen and propidium iodide from Thermo-Fisher Scientific. These reagents were used as received, without further purification, with the exception of DMPO that was stored at $-15^{\circ} \mathrm{C}$, diluted to $0.15 \mathrm{~mol} \mathrm{~L}{ }^{-1}$ in ultra-pure water before use, and filtered on activated carbon to eliminate impurities and degradation products. The water used was of Milli-Q quality.

\section{S2. Wastewater characterization}

The wastewater samples WWa and WWb were characterized for conductivity (HI2030 Multiparameter probe, Hanna Instruments), pH (Checker HI98103, Hanna Instruments), total carbon (TC), inorganic carbon (IC), total organic carbon (computed as TOC $=$ TC - IC) and total nitrogen (TN, Shimadzu ON-LINE TOC-VCSH instrument, equipped with an ASI-V autosampler and fed with zero-grade air), as well as the anions $\mathrm{Cl}^{-}, \mathrm{NO}_{3}^{-}$and $\mathrm{SO}_{4}{ }^{2-}$ (Dionex $\mathrm{DX} 500$ ion chromatograph, Dionex Ion Pac AS9-HC column, elution with $9 \mathrm{mM} \mathrm{K}_{2} \mathrm{CO}_{3}$ at $1 \mathrm{~mL} \mathrm{~min}^{-1}$ ). The results are reported in Table $\mathbf{S 1}$ below. 
Table S1. Physico-chemical features of the studied wastewater samples. TC $=$ total carbon, TOC $=$ total organic carbon, $\mathrm{IC}=$ inorganic carbon, $\mathrm{TN}=$ total nitrogen. The error bounds represent the standard error of replicate measurements.

\begin{tabular}{lcc}
\hline Parameter & WWa & WWb \\
\hline Conductivity, $\mu \mathrm{S} \mathrm{cm}^{-1}$ & $267 \pm 9$ & $914 \pm 22$ \\
$\mathrm{pH}$ & $7.5 \pm 0.1$ & $7.8 \pm 0.1$ \\
$\mathrm{TC}, \mathrm{mgC}^{-1}$ & $10.5 \pm 0.4$ & $44.6 \pm 0.8$ \\
$\mathrm{TOC}, \mathrm{mg}_{\mathrm{C}} \mathrm{L}^{-1}$ & $7.8 \pm 0.6$ & $38.9 \pm 1.1$ \\
$\mathrm{IC}, \mathrm{mg}_{\mathrm{C}} \mathrm{L}^{-1}$ & $2.7 \pm 0.2$ & $5.7 \pm 0.3$ \\
$\mathrm{TN}, \mathrm{mg}_{\mathrm{N}} \mathrm{L}^{-1}$ & $5.8 \pm 0.7$ & $6.5 \pm 0.6$ \\
Chloride $\left(\mathrm{Cl}^{-}\right), \mathrm{mg} \mathrm{L}^{-1}$ & $35.6 \pm 2.2$ & $109.5 \pm 5.4$ \\
Nitrate $\left(\mathrm{NO}_{3}{ }^{-}\right), \mathrm{mg} \mathrm{L}^{-1}$ & $34.7 \pm 2.8$ & $37.9 \pm 1.9$ \\
Sulfate $\left(\mathrm{SO}_{4}{ }^{2-}\right), \mathrm{m} \mathrm{L}^{-1}$ & $19.6 \pm 1.2$ & $151 \pm 2.1$ \\
\hline
\end{tabular}

\section{S3. Instrumentation details}

\section{Liquid chromatography}

It was used a VWR-Hitachi Elite LaChrom instrument equipped with L2455 diode array detector (DAD), L2130 quaternary pump module, L2300 column oven (set at $40{ }^{\circ} \mathrm{C}$ ), L2200 autosampler (sample injection volume $60 \mu \mathrm{L}$ ), Duratec vacuum degasser and reverse-phase column Merck LiChroCART, packed with LiChrospher $100 \mathrm{RP} 18(125 \mathrm{~mm} \times 4 \mathrm{~mm} \times 5 \mu \mathrm{m})$. The chromatographic elution and detection conditions are reported in Table S2 below (flow rate was 1.0 $\mathrm{mL} \min ^{-1}$.

Table S2. Chromatographic conditions used for the elution, separation (where relevant) and detection of the antibiotics under study.

\begin{tabular}{|c|c|c|c|c|c|}
\hline Compound & Eluent A & Eluent B & Conditions & $t_{R}, \min$ & $\lambda_{\text {detection, }} \mathbf{n m}$ \\
\hline \multirow{3}{*}{$\begin{array}{l}\text { CFZ+VNM } \\
+\mathrm{IMI}\end{array}$} & \multirow{3}{*}{ Methanol } & \multirow{3}{*}{$\begin{array}{l}\mathrm{H}_{2} \mathrm{PO}_{4}{ }^{-} / \mathrm{HPO}_{4}{ }^{2-}, \\
\mathrm{pH} 7\end{array}$} & 0-1.50 min: $4 \% \mathrm{~A}$; & 2.60 (IMI) & 299 (IMI) \\
\hline & & & 2.00-9.00 min: $26 \% \mathrm{~A}$; & 6.45 (CFZ) & 271 (CFZ) \\
\hline & & & $9.50-15.00 \mathrm{~min}: 4 \% \mathrm{~A}$ & $9.00(\mathrm{VNM})$ & 281 (VNM) \\
\hline
\end{tabular}


At scheduled reaction times, samples were withdrawn from the reaction mixture and filtered $(0.45$ $\mu \mathrm{m})$ to remove suspended ZVI. In these experiments methanol was not used as quencher to avoid analytical biases, thus the following determinations were done soon after sample withdrawal. Absorbance measurements were carried out with a Varian Cary 100 Scan double-beam UV-Vis spectrophotometer, using Hellma quartz cuvettes with $1 \mathrm{~cm}$ optical path length. Dissolved Fe(II) was determined by exploiting its reaction with o-phenanthroline $\left(4 \times 10^{-3} \mathrm{~mol} \mathrm{~L}^{-1}\right.$, $\mathrm{pH} 3$ by $4 \times 10^{-3}$ mol L $\mathrm{L}^{-1} \mathrm{H}_{3} \mathrm{PO}_{4} / \mathrm{H}_{2} \mathrm{PO}_{4}^{-}$), which yields a red-orange complex with molar absorption coefficient $\varepsilon_{510 \mathrm{~nm}}=1.1 \times 10^{4} \mathrm{~L} \mathrm{~mol}^{-1} \mathrm{~cm}^{-1}$. Total Fe $($ Fетот) was determined on another sample aliquot, after $\mathrm{Fe}(\mathrm{III})$ reduction to $\mathrm{Fe}(\mathrm{II})$ upon addition of ascorbic acid $\left(4 \times 10^{-4} \mathrm{~mol} \mathrm{~L}^{-1}\right)$ for a reaction time of 20 min. Dissolved Fe(III) was then calculated as $\mathrm{Fe}(\mathrm{III})=\mathrm{Fe}$ тот $-\mathrm{Fe}(\mathrm{II})$. Hydrogen peroxide was determined with the peroxidase - 4-aminoantipyrine method, which is based on the formation of a colored quinoneimine dye that absorbs at $505 \mathrm{~nm}$.

\section{Identification of degradation intermediates by UHPLC-MS/MS}

A liquid chromatograph Nexera Shimadzu (Kyoto, Japan) was used, equipped with a DGU-20A3R Degasser, two LC-30AD Pumps, a SIL-30AC Autosampler, a CTO-20AC column compartment and a CMB-20A Lite system controller. The system was interfaced with a 3200 QTrap $^{\mathrm{TM}}$ mass spectrometer (Sciex, Concord, Canada) by a Turbo $\mathrm{V}^{\mathrm{TM}}$ interface equipped with an ESI probe. The 3200 QTrap ${ }^{\text {TM }}$ data were processed by Analyst 1.5.2 (Toronto, Canada) and Peakview 1.2 (Toronto, Canada) software.

The stationary phase was a Kinetex C18 column $(3.0 \mathrm{~mm} \times 100 \mathrm{~mm}, 1.7 \mu \mathrm{m})$ (Phenomenex, Bologna, Italy). The mobile phase was a mixture of water (A) and methanol (B), both with the addition of $0.1 \%$ formic acid, eluting at a flow rate of $0.400 \mathrm{~mL} \mathrm{~min}{ }^{-1}$. The final gradient conditions of UHPLC-MS/MS, working in selected reaction monitoring (SRM) mode, were the following: 0.0- 
$1.0 \min 5 \% \mathrm{~B}, 1.0-15.0 \min 50 \% \mathrm{~B}, 15.0-15.1 \mathrm{~min} 98 \% \mathrm{~B}, 15.1-17.0 \mathrm{~min} 98 \% \mathrm{~B}, 17.0-17.1 \mathrm{~min}$

$5 \% \mathrm{~B}$, the latter kept till $20.0 \mathrm{~min}$. The injection volume was $10.0 \mu \mathrm{L}$ and the oven temperature was set at $40{ }^{\circ} \mathrm{C}$.

The turbo ion spray ionization (TIS) was obtained using the Turbo $\mathrm{V}^{\mathrm{TM}}$ interface working in positive ion (PI) mode. The instrumental parameters were set as follows: curtain gas $\left(\mathrm{N}_{2}\right)$ at 40 psig, nebulizer gas GS1 $\left(\mathrm{N}_{2}\right)$ and $\mathrm{GS} 2\left(\mathrm{~N}_{2}\right)$ at 75 and 70 psig, respectively, desolvation temperature (TEM) at $500{ }^{\circ} \mathrm{C}$, collision activated dissociation gas (CAD) at 6 units (arbitrary scale), and ion spray voltage (IS) at $+5000 \mathrm{~V}$. The declustering potential (DP) and the entrance potential (EP) were set at $+40 \mathrm{~V}$ and $+4 \mathrm{~V}$, respectively, in both the MS and MS/MS experiments. The collision energy (CE) was set at +10 in MS experiment, and at $+45 \mathrm{~V}$ with the addition of $\pm 15 \mathrm{~V}$ due to the collision energy spread (CES) in the Enhanced Product Ion (EPI) experiments. Unit mass resolution was established and maintained in each mass-resolving quadrupole, by keeping a full width at half maximum (FWHM) of about $0.7 \mathrm{u}$.

In order to identify the unknown degradation products of the antibiotics investigated, the hybrid quadrupole-ion trap (QLIT) mass analyzer was used in dual mode. First, the analyzer worked in data-dependent mode using the third quadrupole as linear ion trap, in order to identify the characteristic $\mathrm{m} / \mathrm{z}$ signals of the corresponding antibiotic precursors. Secondly, the precursorproduct ion transitions were chosen to build a more sensitive SRM method using the analyzer as triple quadrupole. The non-target screening was carried out with Enhanced MS experiment (EMS), i.e., a full scan mode as a survey scan. When the signal of a detected compound exceeded a defined threshold, the survey scan automatically triggered the acquisition of both Enhanced Resolution (ER) and Enhanced Product Ion (EPI). The MS worked cyclizing an Enhanced MS experiment (EMS) as survey scan at $1000 \mathrm{Da} / \mathrm{s}$ between $\mathrm{m} / \mathrm{z}, 100$ and $\mathrm{m} / \mathrm{z}$ 650, using dynamic background subtraction of survey scan.

The data-dependent acquisition conditions that had to be satisfied in order to trigger the dependent scans were as follows: the survey scan ion must be greater than $\mathrm{m} / \mathrm{z} 100$ and smaller than $\mathrm{m} / \mathrm{z} 650$, 
and it must exceed the threshold of 100,000 cps. The ion could be monitored 3 times (number of occurrences) before it was excluded from future scans for $5 \mathrm{~s}$. If these conditions were satisfied, then two different dependent scans were performed on the most intense ion: the Enhanced Resolution (ER) experiment as first dependent scan at $250 \mathrm{Da} / \mathrm{s}$, and the EPI experiment as second dependent scan at $1000 \mathrm{Da} / \mathrm{s}$ (number of scans to sum =2). The total cycle time of the analysis was $1.7 \mathrm{~s}$. The SRM method was defined once the precursor/product ion transitions were assigned to each chromatographic peak. 


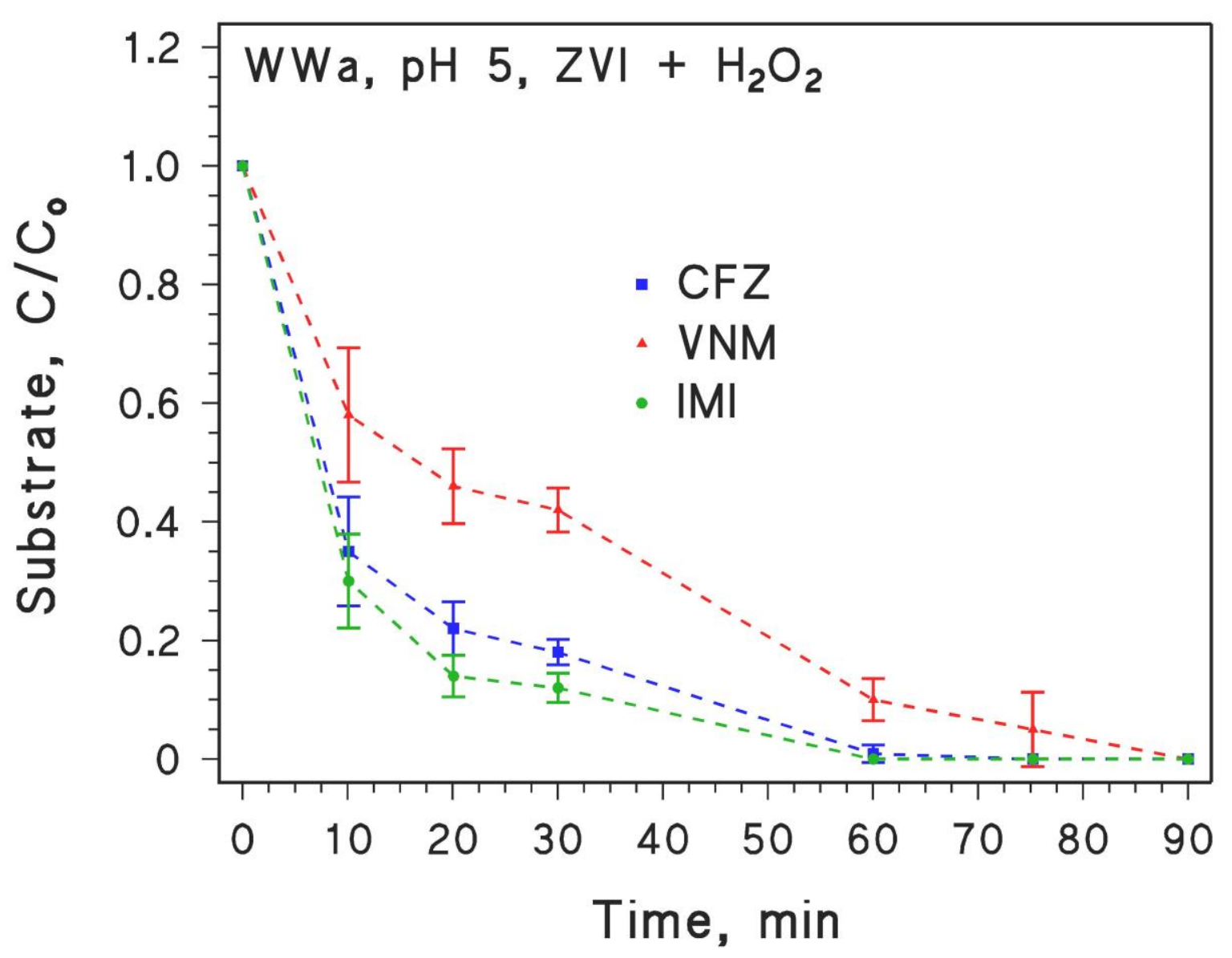

Figure S1. Repeatability test on the degradation of a mixture of $4 \mu \mathrm{mol} \mathrm{L}{ }^{-1}$ cefazolin (CFZ) +4 $\mu \mathrm{mol} \mathrm{L}{ }^{-1}$ vancomycin $(\mathrm{VNM})+4 \mu \mathrm{mol} \mathrm{L}-1$ imipenem (IMI) in secondary wastewater (WWa) at $\mathrm{pH}$ 5, adjusted with $\mathrm{H}_{2} \mathrm{SO}_{4}$ before the beginning of the reaction and corrected again at $30 \mathrm{~min}$. Other conditions: $0.02 \mathrm{~g} \mathrm{~L}^{-1} \mathrm{ZVI} ; 400 \mu \mathrm{mol} \mathrm{L}{ }^{-1} \mathrm{H}_{2} \mathrm{O}_{2}$ added in three aliquots $\left(300 \mu \mathrm{mol} \mathrm{L}{ }^{-1}\right.$ at $0 \mathrm{~min}, 50$

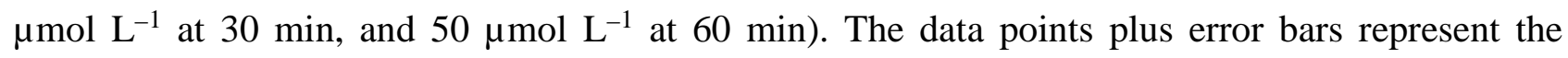
average values and standard deviation of experiments carried out in triplicate. 

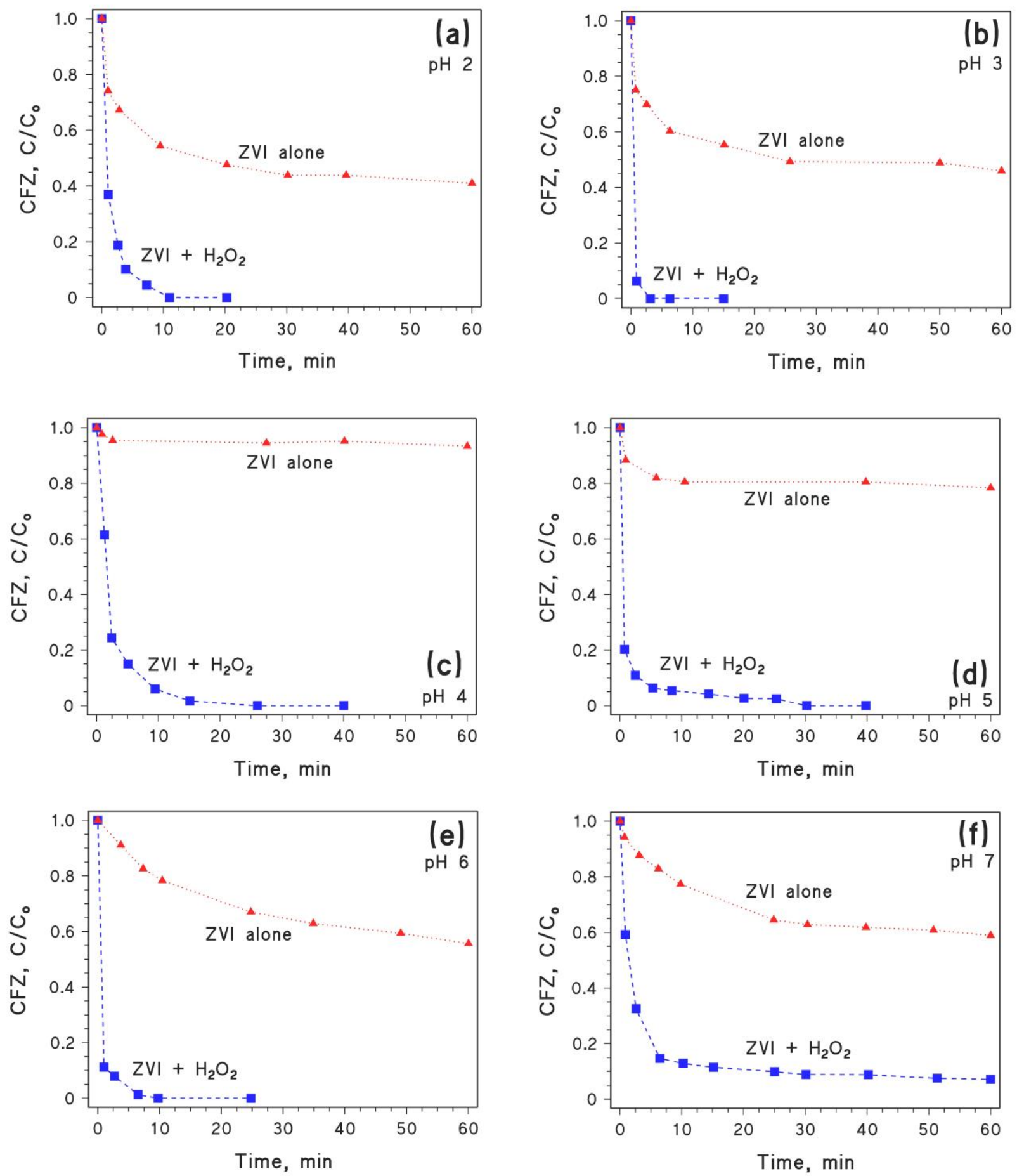

Figure S2. Degradation of $10 \mu \mathrm{mol} \mathrm{L} \mathrm{L}^{-1}$ cefazolin (CFZ) in the presence of ZVI $+\mathrm{H}_{2} \mathrm{O}_{2}$ and of ZVI

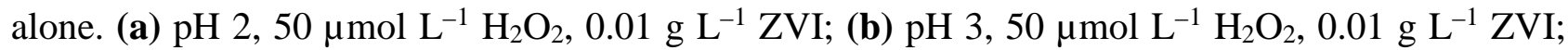
(c) $\mathrm{pH}$ 4, $50 \mu \mathrm{mol} \mathrm{L} \mathrm{H}_{2} \mathrm{O}_{2}, 0.01 \mathrm{~g} \mathrm{~L}^{-1} \mathrm{ZVI}$; (d) $\mathrm{pH} 5,100 \mu \mathrm{mol} \mathrm{L}^{-1} \mathrm{H}_{2} \mathrm{O}_{2}, 0.01 \mathrm{~g} \mathrm{~L}^{-1} \mathrm{ZVI}$; (e) $\mathrm{pH}$ 6, $400 \mu \mathrm{mol} \mathrm{L}{ }^{-1} \mathrm{H}_{2} \mathrm{O}_{2}, 0.02 \mathrm{~g} \mathrm{~L}^{-1} \mathrm{ZVI}$; (f) $\mathrm{pH}$ 7, $400 \mu \mathrm{mol} \mathrm{L}^{-1} \mathrm{H}_{2} \mathrm{O}_{2}, 0.03 \mathrm{~g} \mathrm{~L}^{-1} \mathrm{ZVI}$. 

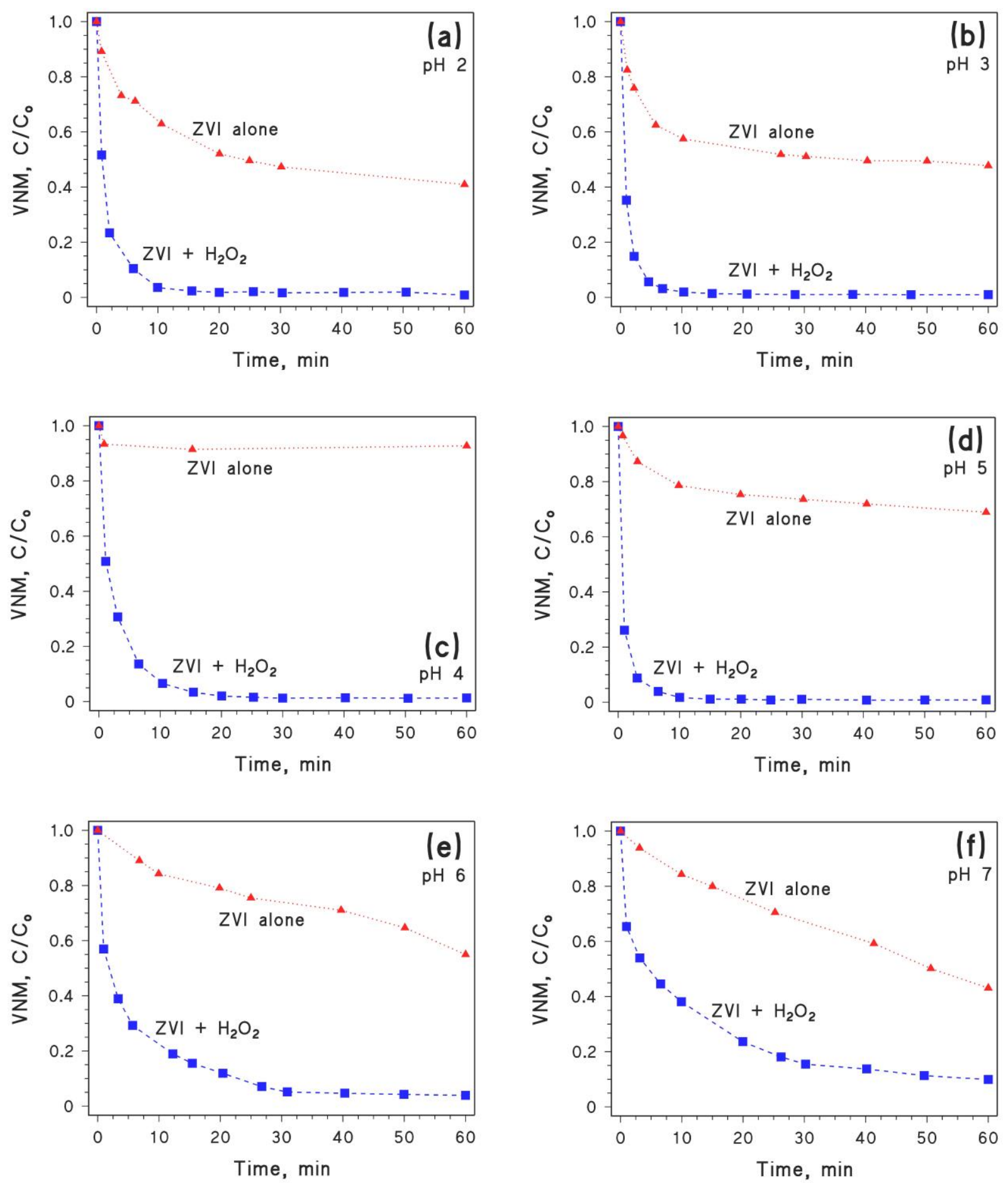

Figure S3. Degradation of $10 \mu \mathrm{mol} \mathrm{L}{ }^{-1}$ vancomicin (VNM) in the presence of ZVI $+\mathrm{H}_{2} \mathrm{O}_{2}$ and of

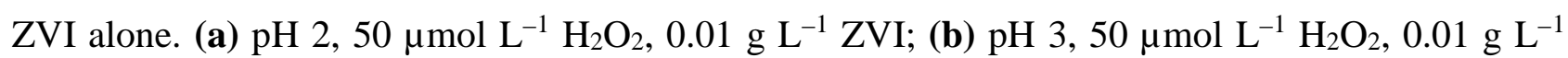
ZVI; (c) pH 4, $80 \mu \mathrm{mol} \mathrm{L}-1 \mathrm{H}_{2} \mathrm{O}_{2}, 0.01 \mathrm{~g} \mathrm{~L}^{-1} \mathrm{ZVI}$; (d) pH 5, $200 \mu \mathrm{mol} \mathrm{L}-1 \mathrm{H}_{2} \mathrm{O}_{2}, 0.02 \mathrm{~g} \mathrm{~L}^{-1} \mathrm{ZVI}$; (e) $\mathrm{pH} \mathrm{6,} 400 \mu \mathrm{mol} \mathrm{L}-1 \mathrm{H}_{2} \mathrm{O}_{2}, 0.03 \mathrm{~g} \mathrm{~L}^{-1} \mathrm{ZVI}$; (f) $\mathrm{pH} 7,200 \mu \mathrm{mol} \mathrm{L}^{-1} \mathrm{H}_{2} \mathrm{O}_{2}, 0.03 \mathrm{~g} \mathrm{~L}^{-1} \mathrm{ZVI}$. 

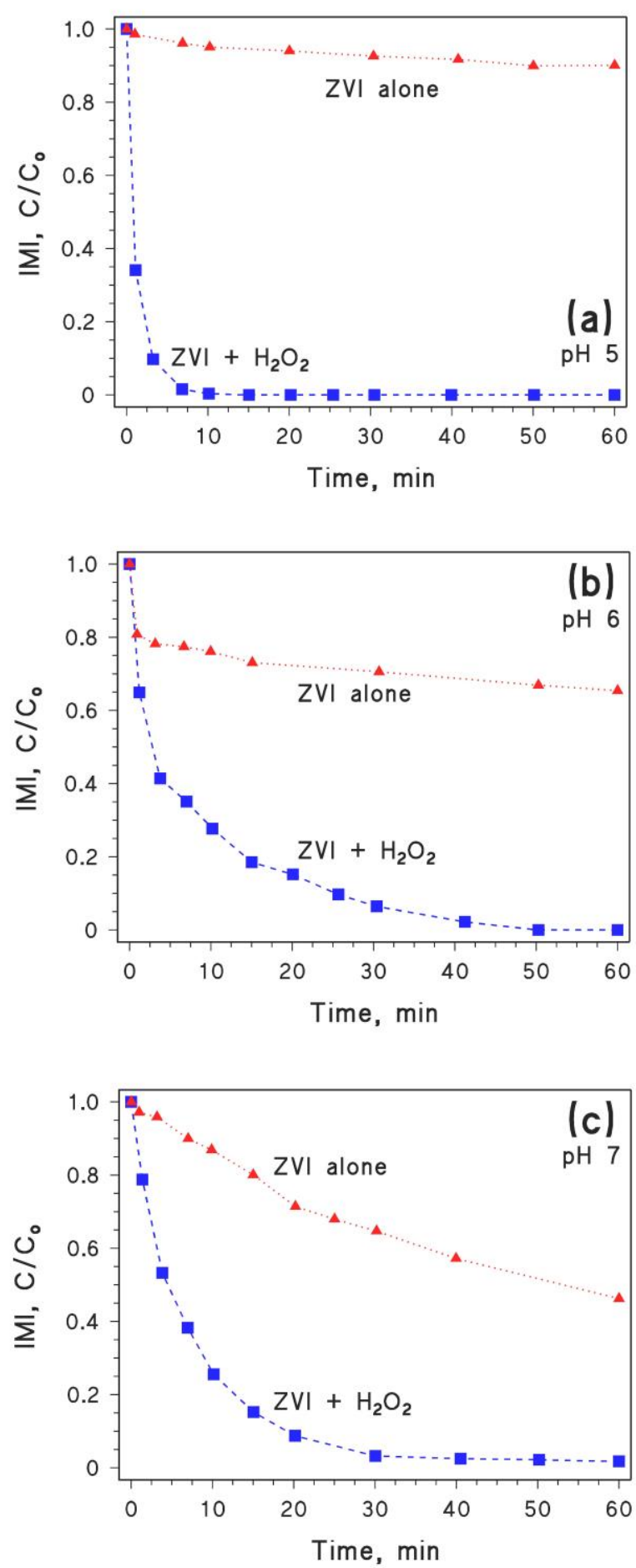

Figure S4. Degradation of $10 \mu \mathrm{mol} \mathrm{L}-1$ imipenem (IMI) in the presence of ZVI $+\mathrm{H}_{2} \mathrm{O}_{2}$ and of ZVI alone. (a) $\mathrm{pH} 5,100 \mu \mathrm{mol} \mathrm{L} \mathrm{H}_{2} \mathrm{O}_{2}, 0.01 \mathrm{~g} \mathrm{~L}^{-1} \mathrm{ZVI}$; (b) $\mathrm{pH}$ 6, $200 \mu \mathrm{mol} \mathrm{L}{ }^{-1} \mathrm{H}_{2} \mathrm{O}_{2}, 0.02 \mathrm{~g} \mathrm{~L}^{-1} \mathrm{ZVI}$; (f) $\mathrm{pH} 7,200 \mu \mathrm{mol} \mathrm{L}^{-1} \mathrm{H}_{2} \mathrm{O}_{2}, 0.04 \mathrm{~g} \mathrm{~L}^{-1} \mathrm{ZVI}$. 
Table S3. Summary of the preliminary ZVI - Fenton degradation experiments carried out with ultra-pure water in the $\mathrm{pH}$ interval 5-7. ZVI and $\mathrm{H}_{2} \mathrm{O}_{2}$ were added only once, at the beginning of the reaction.

\begin{tabular}{cccccc}
\hline \multirow{2}{*}{$\mathbf{p H}$} & $\mathbf{Z V I}, \mathbf{g ~ L}^{-\mathbf{1}}$ & $\mathbf{H}_{\mathbf{2}} \mathbf{O}_{2}, \mathbf{~ m o l ~ L}^{-\mathbf{1}}$ & \multicolumn{2}{c}{ Removal percentage after 60 min } \\
\cline { 3 - 5 } 5 & & & $\mathbf{C F Z}$ & $\mathbf{V N M}$ & IMI \\
5 & 0.01 & $1.0 \times 10^{-4}$ & 99 & 92 & 99 \\
5 & 0.01 & $2.0 \times 10^{-4}$ & 67 & 59 & 82 \\
6 & 0.02 & $2.0 \times 10^{-4}$ & 89 & 83 & 96 \\
6 & 0.02 & $2.0 \times 10^{-4}$ & 54 & 65 & 63 \\
6 & 0.02 & $4.0 \times 10^{-4}$ & 44 & 45 & 75 \\
6 & 0.03 & $2.0 \times 10^{-4}$ & 59 & 68 & 66 \\
7 & 0.03 & $4.0 \times 10^{-4}$ & 49 & 58 & 62 \\
7 & 0.03 & $2.0 \times 10^{-4}$ & 35 & 45 & 57 \\
7 & 0.03 & $4.0 \times 10^{-4}$ & 20 & 21 & 49 \\
\hline
\end{tabular}




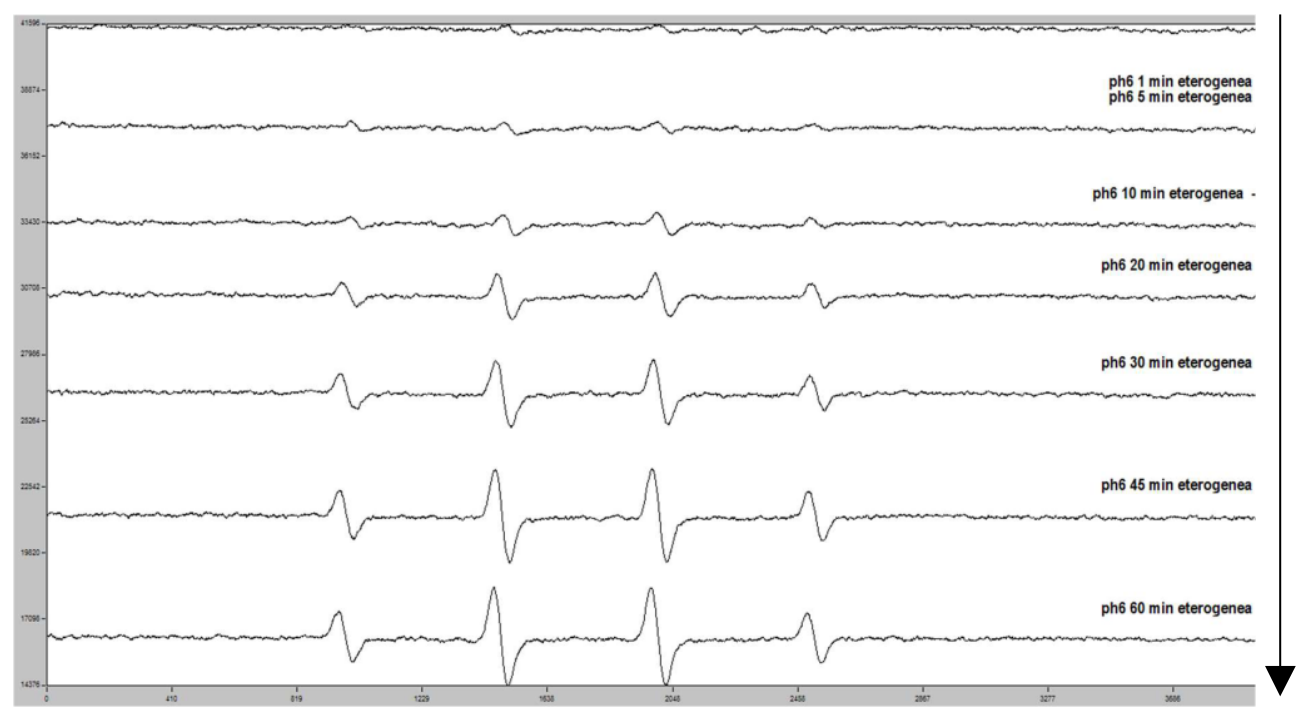

$1 \mathrm{~min}$

$60 \min$

(a)

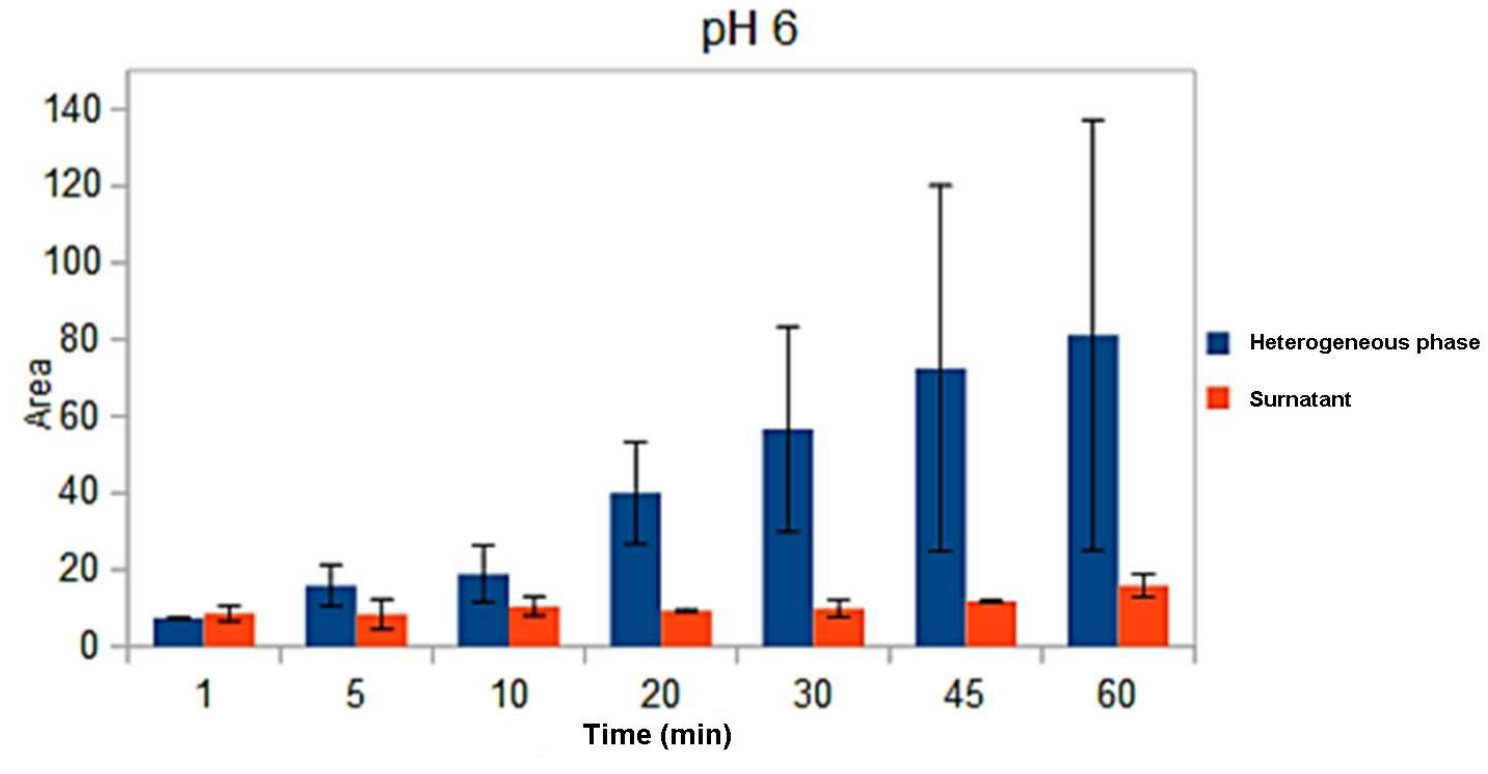

(b)

Figure S5. (a) Time evolution of the EPR spectra of a solution containing $0.06 \mathrm{~mol} \mathrm{~L}^{-1} \mathrm{DMPO}, 0.1$ $\mathrm{g} \mathrm{L}^{-1} \mathrm{ZVI}$ and $0.001 \mathrm{~mol} \mathrm{~L}^{-1} \mathrm{H}_{2} \mathrm{O}_{2}$ at $\mathrm{pH}$ 6, adjusted with a phosphate buffer. The reported EPR signals are those of the DMPO-OH adduct. (b) Comparison between the DMPO-OH EPR signals observed in the ZVI-Fenton system and in the surnatant. In the latter case, ZVI $+\mathrm{H}_{2} \mathrm{O}_{2}$ (without DMPO) was stirred for $1 \mathrm{~h}$, after which the suspension was filtered and DMPO added. Samples were withdrawn after the reported time following DMPO addition. 
Table S4. Summary of the ZVI - Fenton degradation experiments carried out with WWb upon acidification with $\mathrm{H}_{2} \mathrm{SO}_{4}$ at $\mathrm{pH}$ 6. The highlighted conditions are those reported in Figure S6b. Compared to those conditions, worse results were obtained by either increasing or decreasing the $\mathrm{H}_{2} \mathrm{O}_{2}$ concentration/ZVI loading. Note that wastewater has a minimum in its buffer capacity at $4<$ $\mathrm{pH}<6$, thus the amount of $\mathrm{H}_{2} \mathrm{SO}_{4}$ needed to fix $\mathrm{pH}$ to 6 was not much different than that needed to fix $\mathrm{pH}$ to 5 (see Figure S7).

\begin{tabular}{|c|c|c|c|c|c|}
\hline \multirow{2}{*}{ \# } & \multirow{2}{*}{ Total ZVI, g L $\mathrm{L}^{-1}$} & \multirow{2}{*}{ Total $\mathrm{H}_{2} \mathrm{O}_{2}, \mathrm{~mol} \mathrm{~L}^{-1}$} & \multicolumn{3}{|c|}{ Removal percentage after $90 \mathrm{~min}$} \\
\hline & & & CFZ & VNM & IMI \\
\hline 1 & 0.02 & $1.0 \times 10^{-4}$ & 19 & 35 & 57 \\
\hline 2 & 0.03 & $1.0 \times 10^{-4}$ & 0 & 69 & 0 \\
\hline 3 & 0.03 & $2.0 \times 10^{-4}$ & 43 & 39 & 73 \\
\hline 4 & 0.03 & $3.0 \times 10^{-4}$ & 31 & 32 & 57 \\
\hline 5 & 0.04 & $1.0 \times 10^{-4}$ & 23 & 41 & 58 \\
\hline 6 & 0.04 & $2.5 \times 10^{-4}$ & 23 & 33 & 70 \\
\hline 7 & 0.04 & $4.0 \times 10^{-4}$ & 63 & 55 & 88 \\
\hline 8 & 0.05 & $5.0 \times 10^{-4}$ & 25 & 21 & 37 \\
\hline 9 & 0.06 & $2.0 \times 10^{-4}$ & 17 & 24 & 33 \\
\hline 10 & 0.06 & $3.5 \times 10^{-4}$ & 41 & 38 & 63 \\
\hline 11 & 0.08 & $2.0 \times 10^{-4}$ & 21 & 31 & 62 \\
\hline 12 & 0.10 & $4.0 \times 10^{-4}$ & 28 & 29 & 28 \\
\hline
\end{tabular}



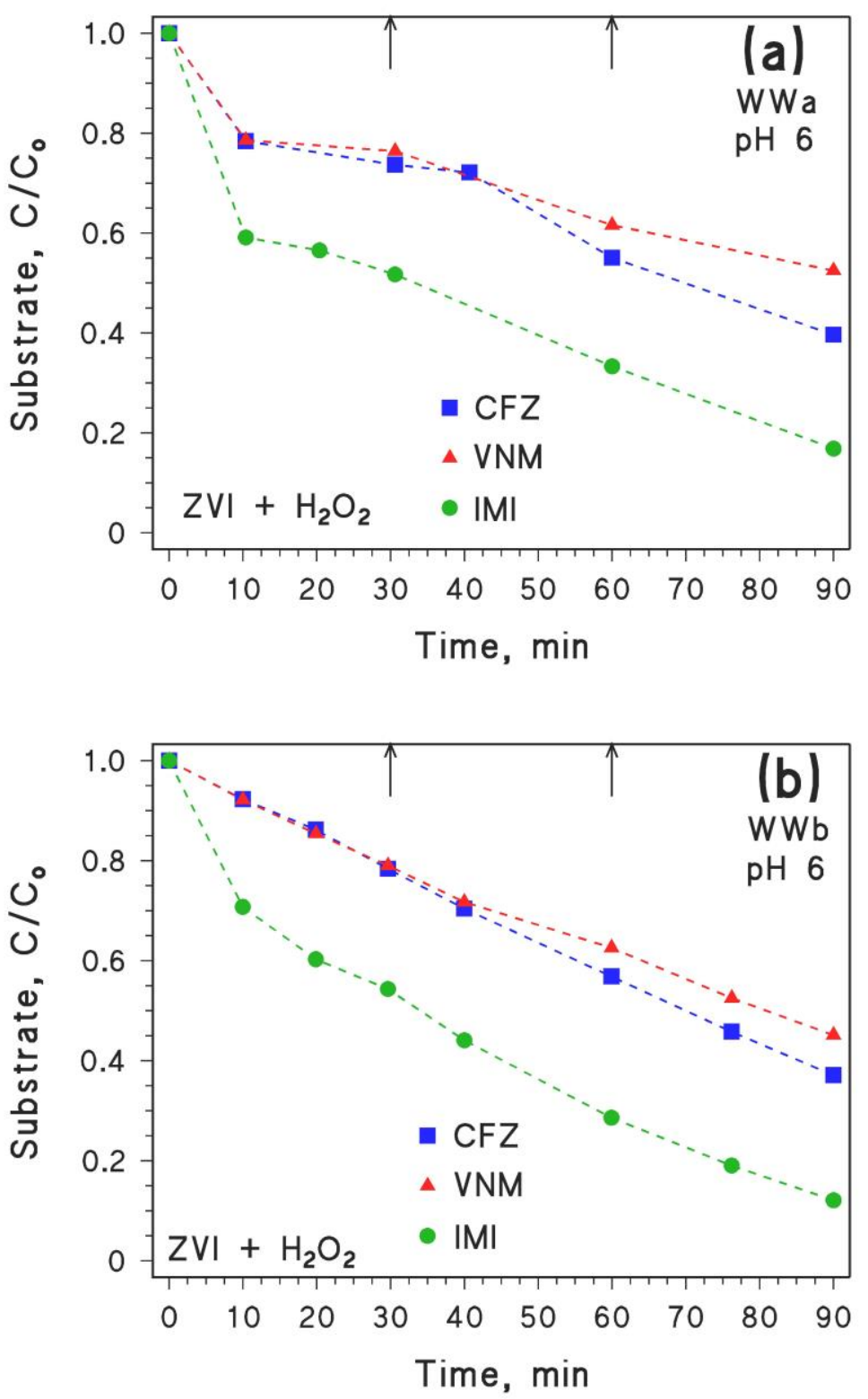

Figure S6. Degradation of a mixture of $4 \mu \mathrm{mol} \mathrm{L}{ }^{-1} \mathrm{CFZ}+4 \mu \mathrm{mol} \mathrm{L}{ }^{-1} \mathrm{VNM}+4 \mu \mathrm{mol} \mathrm{L}{ }^{-1} \mathrm{IMI}$ in wastewater. (a) WWa at $\mathrm{pH} 6$, fixed by $\mathrm{H}_{2} \mathrm{SO}_{4}$ and corrected when necessary during the course of the reaction; $0.04 \mathrm{~g} \mathrm{~L}^{-1} \mathrm{ZVI}$ added in two aliquots (half at $0 \mathrm{~min}$ and half at $30 \mathrm{~min}$ ); $400 \mu \mathrm{mol} \mathrm{L}{ }^{-1}$ $\mathrm{H}_{2} \mathrm{O}_{2}$ added in three aliquots $(300 \mu \mathrm{mol} \mathrm{L}-1$ at $0 \mathrm{~min}, 50 \mu \mathrm{mol} \mathrm{L}-1$ at $30 \mathrm{~min}$, and $50 \mu \mathrm{mol} \mathrm{L}-1$ at 60 min). (b) $\mathrm{WWb}$ at $\mathrm{pH} 6$, fixed by $\mathrm{H}_{2} \mathrm{SO}_{4}$ and corrected when necessary during the course of the reaction; $0.04 \mathrm{~g} \mathrm{~L}^{-1} \mathrm{ZVI}$ added in two aliquots (half at $0 \mathrm{~min}$ and half at $30 \mathrm{~min}$ ); $400 \mu \mathrm{mol} \mathrm{L}{ }^{-1}$ $\mathrm{H}_{2} \mathrm{O}_{2}$ added in three aliquots $\left(300 \mu \mathrm{mol} \mathrm{L}{ }^{-1}\right.$ at $0 \mathrm{~min}, 50 \mu \mathrm{mol} \mathrm{L}-1$ at $30 \mathrm{~min}$, and $50 \mu \mathrm{mol} \mathrm{L} \mathrm{L}^{-1}$ at 60 $\min )$.

The time points at 30 and 60 min (further additions of $\mathrm{H}_{2} \mathrm{O}_{2}$ and, where applicable, ZVI) are highlighted by the vertical arrows. 

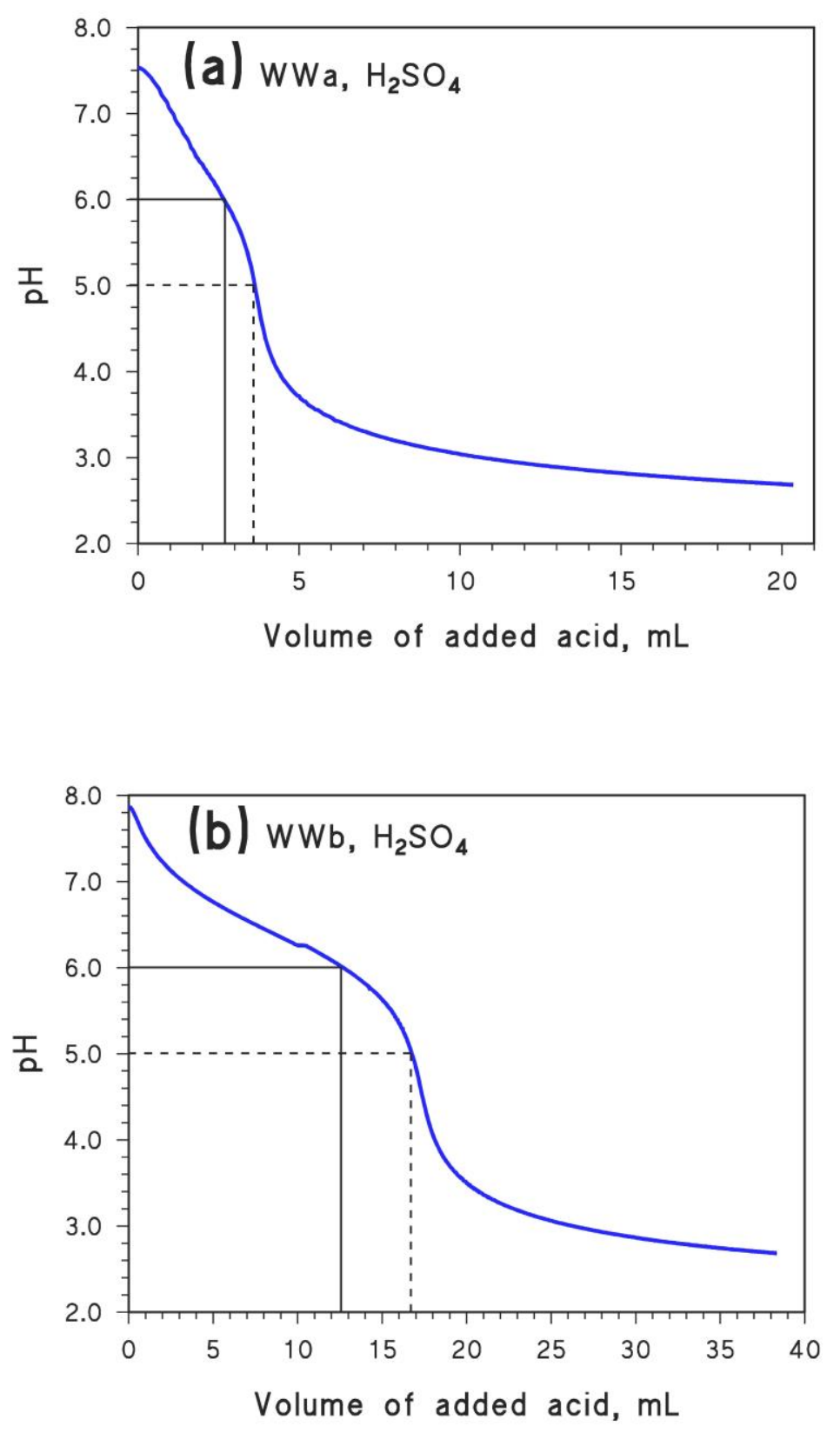

Figure S7. Acid-base titration results of the wastewater samples (WWa, WWb) with $\mathrm{H}_{2} \mathrm{SO}_{4}$ and $\mathrm{H}_{3} \mathrm{PO}_{4}$. (a) Titration of WWa with $4.5 \times 10^{-3} \mathrm{~mol} \mathrm{~L}^{-1} \mathrm{H}_{2} \mathrm{SO}_{4}$. (b) Titration of WWb with $4.5 \times 10^{-3}$ mol L ${ }^{-1} \mathrm{H}_{2} \mathrm{SO}_{4}$. The volumes of acid needed to fix the wastewater $\mathrm{pH}$ to 5 and 6 are highlighted with the dashed and solid lines, respectively. 


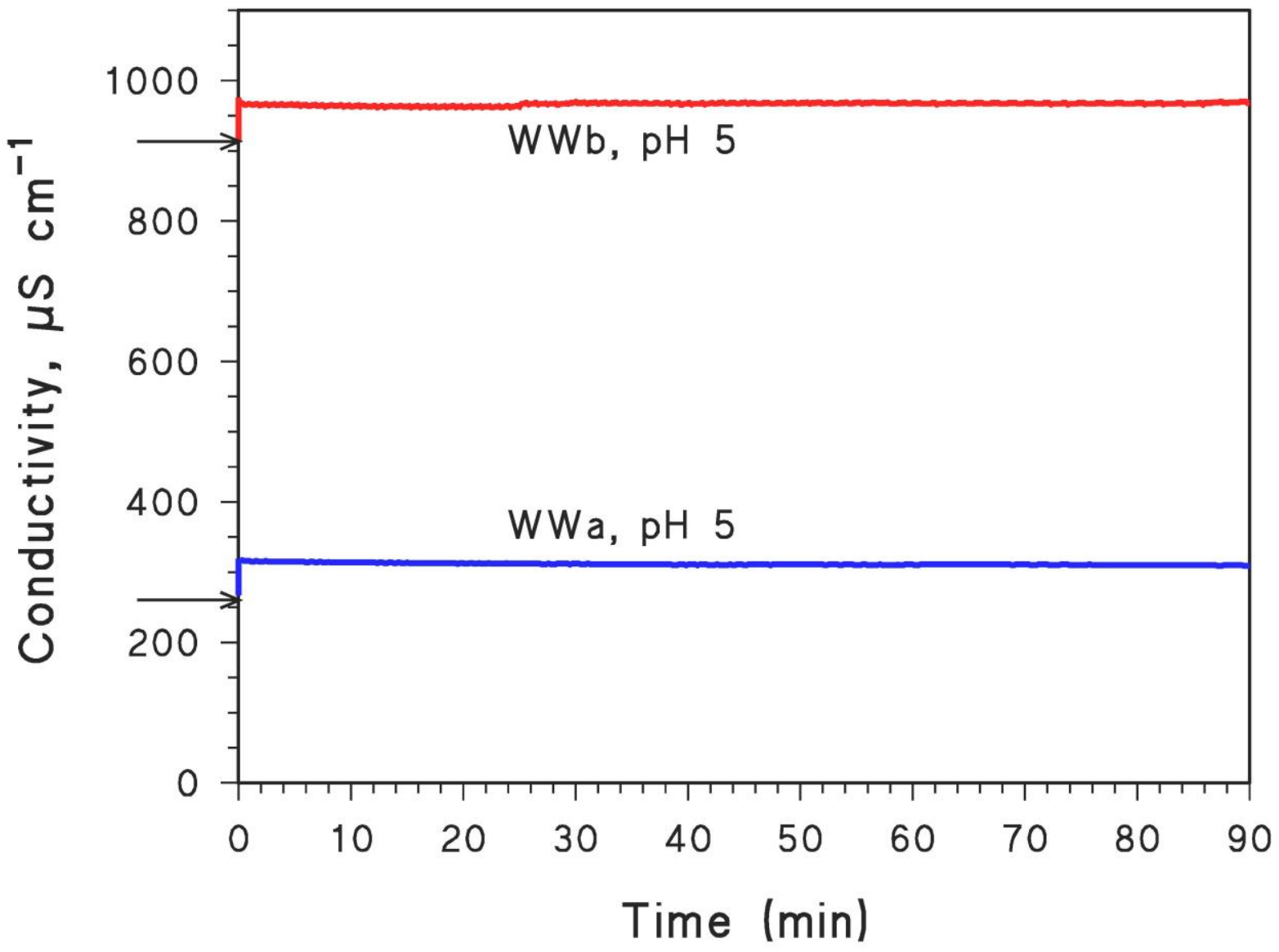

Figure S8. Time trends of conductivity upon degradation of a mixture of $4 \mu \mathrm{mol} \mathrm{L}{ }^{-1} \mathrm{CFZ}+4 \mu \mathrm{mol}$ $\mathrm{L}^{-1} \mathrm{VNM}+4 \mu \mathrm{mol} \mathrm{L}{ }^{-1} \mathrm{IMI}$ in wastewater WWa and WWb. With both wastewaters, the $\mathrm{pH} 5$ was adjusted initially with $\mathrm{H}_{2} \mathrm{SO}_{4}$ and corrected again at $30 \mathrm{~min}$; ZVI loading was $0.02 \mathrm{~g} \mathrm{~L}^{-1} ; \mathrm{H}_{2} \mathrm{O}_{2}$ concentration was $400 \mu \mathrm{mol} \mathrm{L}-1$, added in three aliquots $(300 \mu \mathrm{mol} \mathrm{L}-1$ at $0 \mathrm{~min}, 50 \mu \mathrm{mol} \mathrm{L}-1$ at 30 min, and $50 \mu \mathrm{mol} \mathrm{L} \mathrm{L}^{-1}$ at $60 \mathrm{~min}$ ). The horizontal arrows highlight the conductivity values of the original wastewater. 


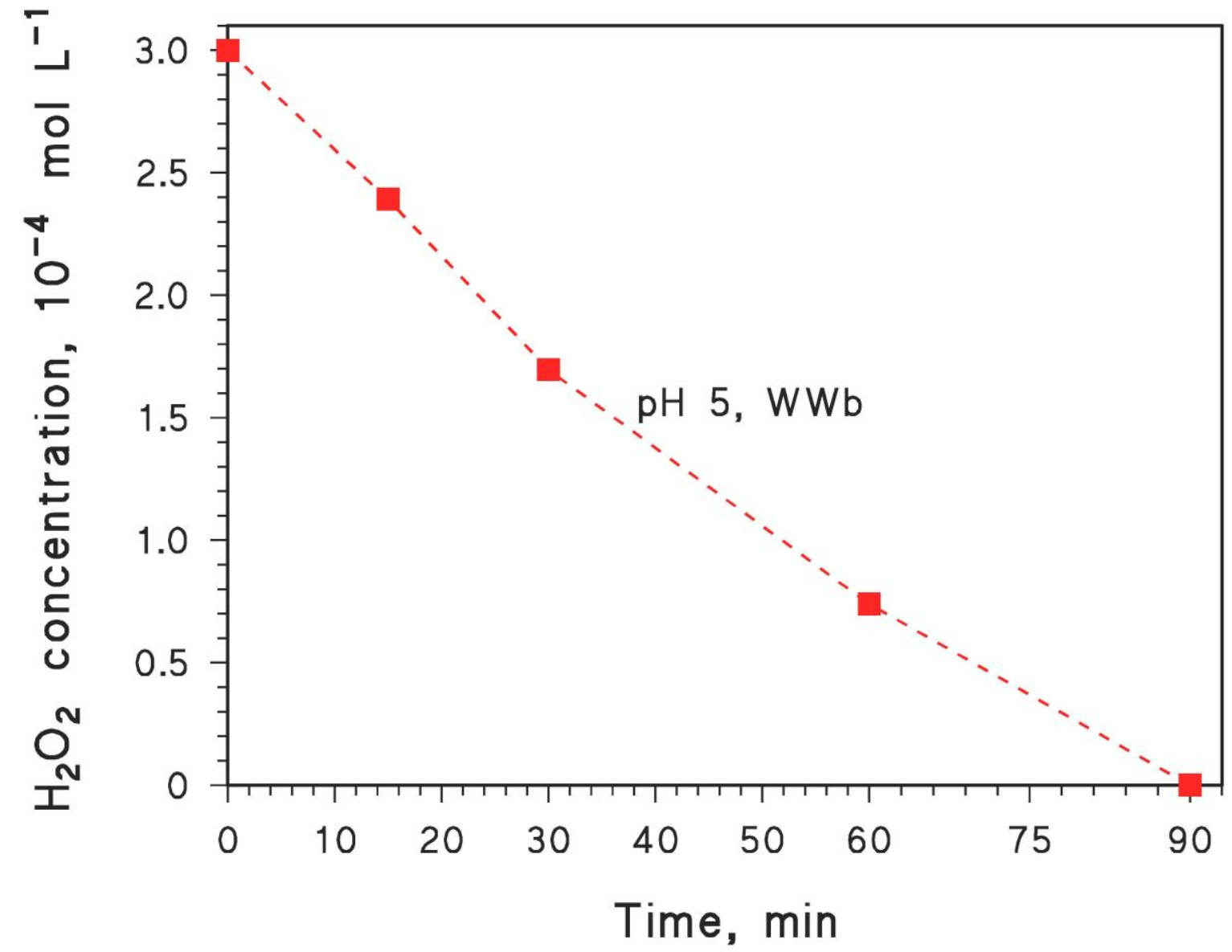

Figure S9. Time trends of $\mathrm{H}_{2} \mathrm{O}_{2}$ upon degradation of a mixture of $4 \mu \mathrm{mol} \mathrm{L}-1 \mathrm{CFZ}+4 \mu \mathrm{mol} \mathrm{L}-1$ $\mathrm{VNM}+4 \mu \mathrm{mol} \mathrm{L}-1$ IMI in secondary wastewater (WWb) at $\mathrm{pH} 5$ (adjusted initially with $\mathrm{H}_{2} \mathrm{SO}_{4}$ and corrected again at $30 \mathrm{~min}$ ). The ZVI loading was $0.02 \mathrm{~g} \mathrm{~L}^{-1}$; the $\mathrm{H}_{2} \mathrm{O}_{2}$ concentration was $400 \mu \mathrm{mol}$ $\mathrm{L}^{-1}$, added in three aliquots $(300 \mu \mathrm{mol} \mathrm{L}-1$ at $0 \mathrm{~min}, 50 \mu \mathrm{mol} \mathrm{L}-1$ at $30 \mathrm{~min}$, and $50 \mu \mathrm{mol} \mathrm{L}-1$ at 60 $\min$ ). 
Table S5. Optimized operational conditions to achieve complete ZVI-Fenton degradation of CFZ,

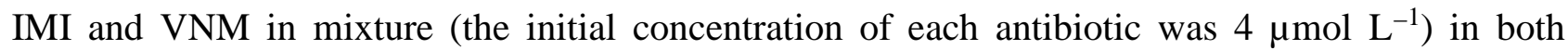
wastewaters (WWa, WWb), at pH 5 with $\mathrm{H}_{2} \mathrm{SO}_{4}$.

\begin{tabular}{|c|c|}
\hline \multirow{2}{*}{ Time, min } & $\mathrm{ZVI}+\mathrm{H}_{2} \mathrm{O}_{2}$ \\
\hline & $\mathrm{H}_{2} \mathrm{SO}_{4}, \mathrm{pH} 5$ \\
\hline \multirow[t]{2}{*}{$\mathbf{0}$} & $\mathrm{H}_{2} \mathrm{O}_{2} 3 \times 10^{-4} \mathrm{M}$ \\
\hline & ZVI $0.02 \mathrm{~g} \mathrm{~L}^{-1}$ \\
\hline \multirow[t]{2}{*}{30} & $\mathrm{H}_{2} \mathrm{O}_{2} 5 \times 10^{-5} \mathrm{M}$ \\
\hline & Correct $\mathrm{pH}$ to 5 \\
\hline 60 & $\mathrm{H}_{2} \mathrm{O}_{2} 5 \times 10^{-5} \mathrm{M}$ \\
\hline 90 & End \\
\hline Notes & Final pH of 5.7-5.8 \\
\hline
\end{tabular}


Table S6. Proposed chemical structures of the quasi-molecular ion $[\mathrm{M}+\mathrm{H}]^{+}$and of three corresponding product ions of each antibiotic investigated and the transformation intermediates, with their retention times (RT)

\begin{tabular}{|c|c|c|c|c|c|}
\hline $\begin{array}{c}\text { Compo } \\
\text { und }\end{array}$ & $\begin{array}{c}\text { RT } \\
(\text { min }) \\
\end{array}$ & Precursor Ion $[\mathrm{M}+\mathrm{H}]^{+}$ & Product Ion 1 & Product Ion 2 & Product Ion 3 \\
\hline CFZ & 12.43 & $\mathrm{~m} / \mathrm{z} 455.1$ & $\mathrm{~m} / \mathrm{z} 323.1$ & $\mathrm{~m} / \mathrm{z} 156.1$ & $m / z 295.1$ \\
\hline $\begin{array}{l}\text { CFZ- } \\
\text { P1a }\end{array}$ & 1.51 & $m / z 442.8$ & $\mathrm{~m} / \mathrm{z} 231.0$ & $\mathrm{~m} / \mathrm{z} 96.0$ & $m / z 372.3$ \\
\hline $\begin{array}{l}\text { CFZ- } \\
\text { P1b }\end{array}$ & 1.84 & $\mathrm{~m} / \mathrm{z} 442.8$ & $\mathrm{~m} / \mathrm{z} 171.0$ & $\mathrm{~m} / \mathrm{z} 231$ & $m / z 99.0$ \\
\hline $\begin{array}{l}\text { CFZ- } \\
\text { P1c }\end{array}$ & 11.80 & $\mathrm{~m} / \mathrm{z} 442.8$ & $m / z 268$ & $m / z 98$ & $m / z 124$ \\
\hline $\begin{array}{c}\text { CFZ- } \\
\text { P2a }\end{array}$ & 2.98 & $\mathrm{~m} / \mathrm{z} 296.1$ & $\mathrm{~m} / \mathrm{z} 140$ & $\mathrm{~m} / \mathrm{z} 85$ & $\mathrm{~m} / \mathrm{z} 168$ \\
\hline $\begin{array}{l}\text { CFZ- } \\
\text { P2b }\end{array}$ & 4.02 & $m / z 296.1$ & $m / z 169$ & $m / z 86$ & $m / z 113$ \\
\hline
\end{tabular}




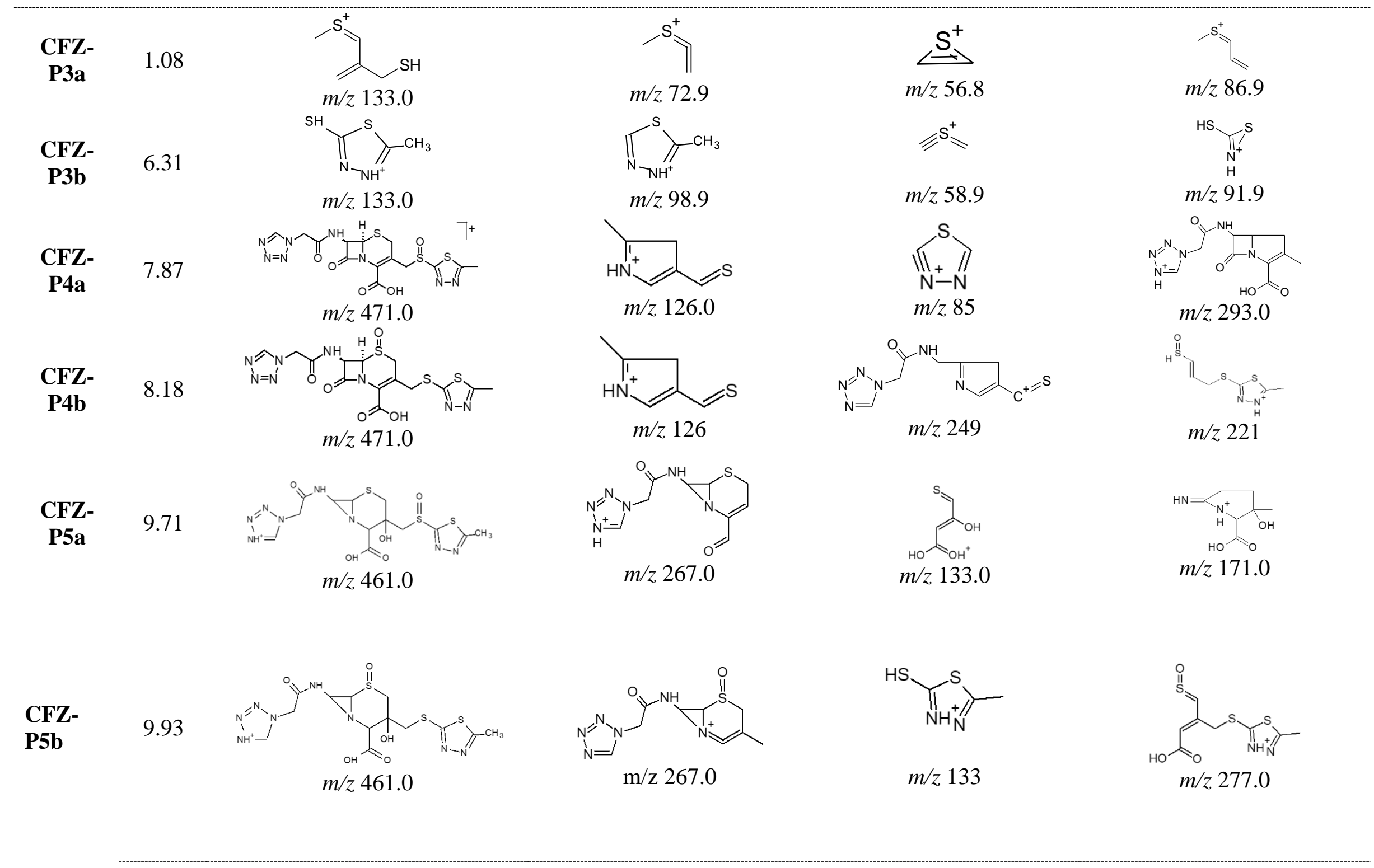




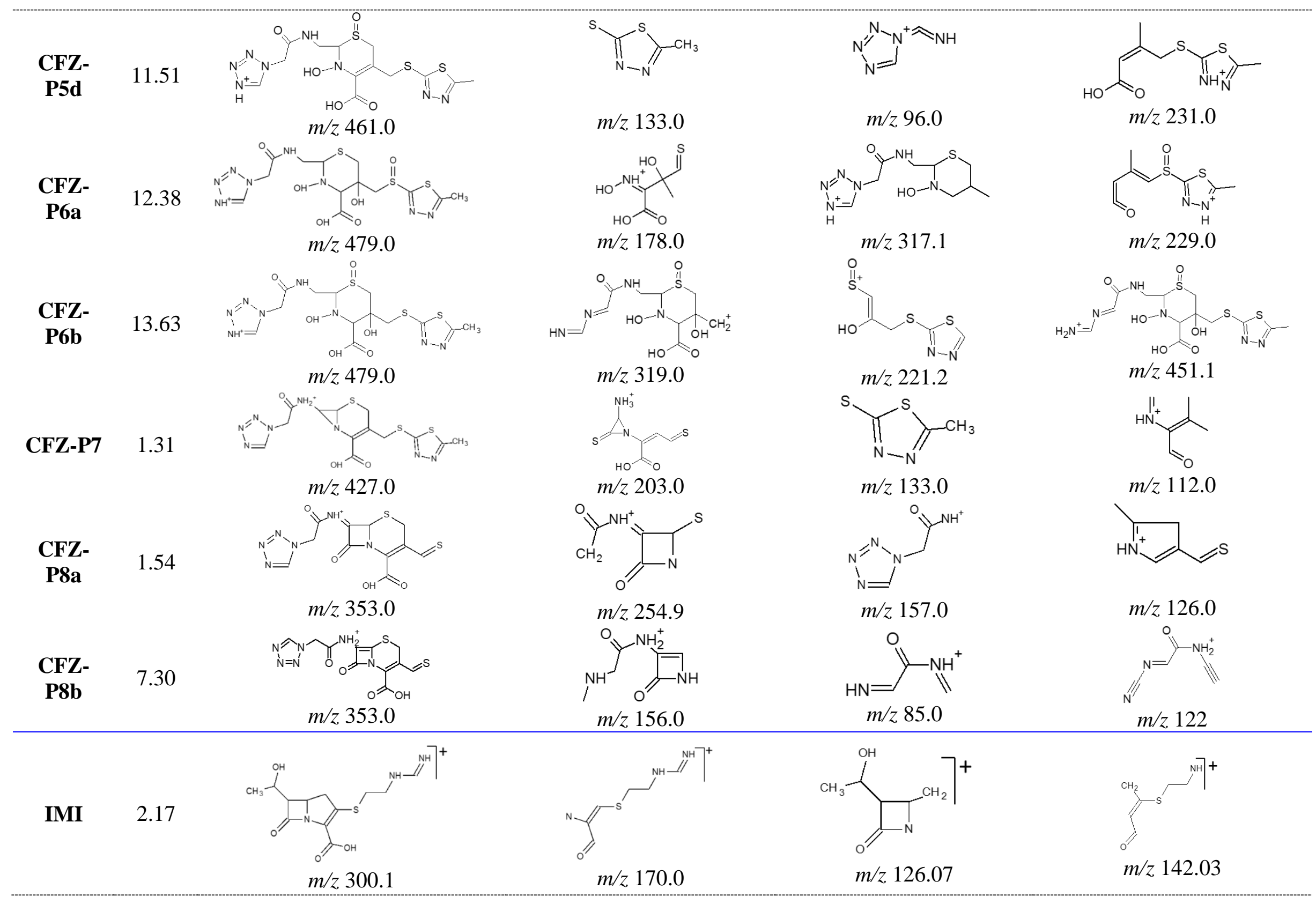




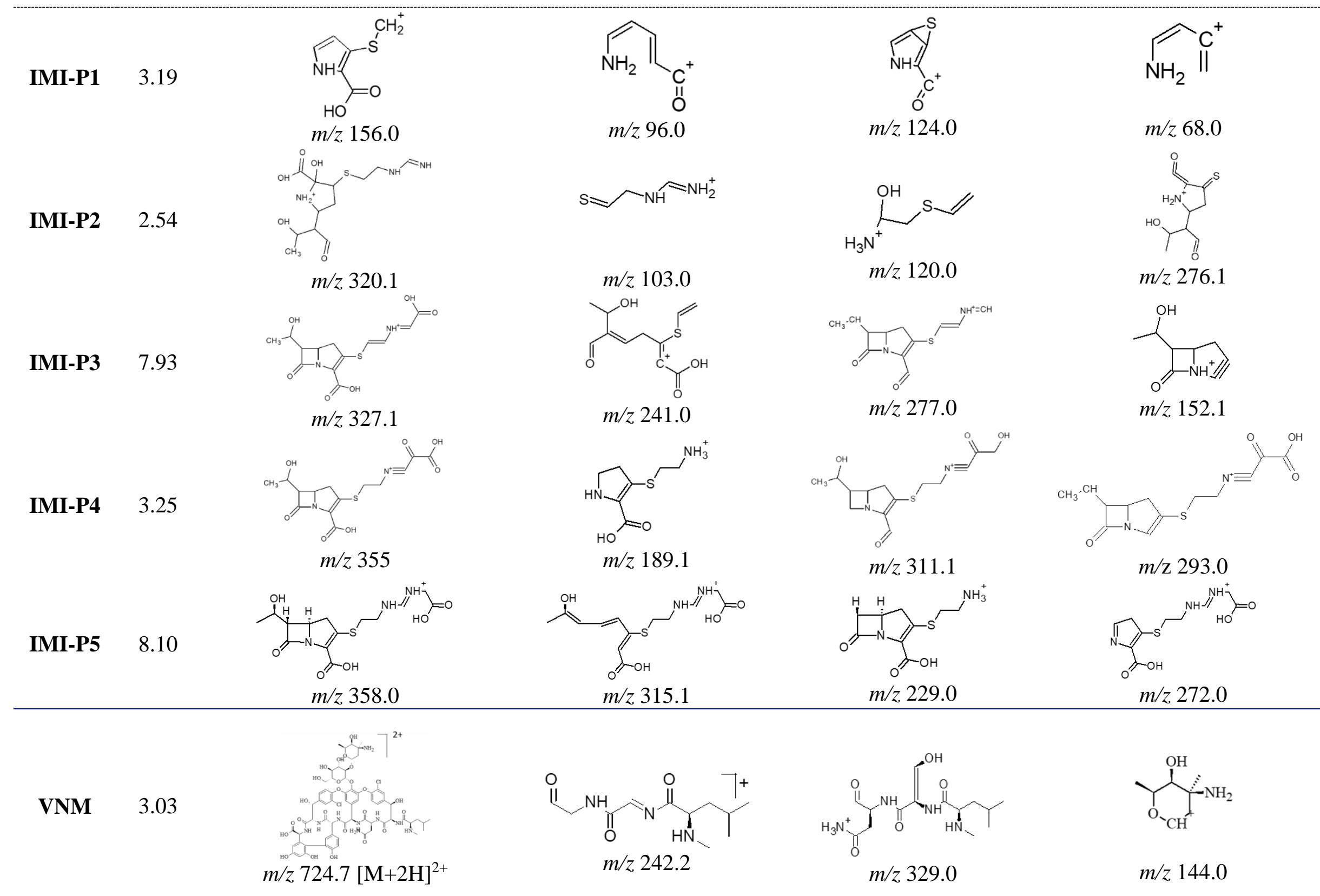




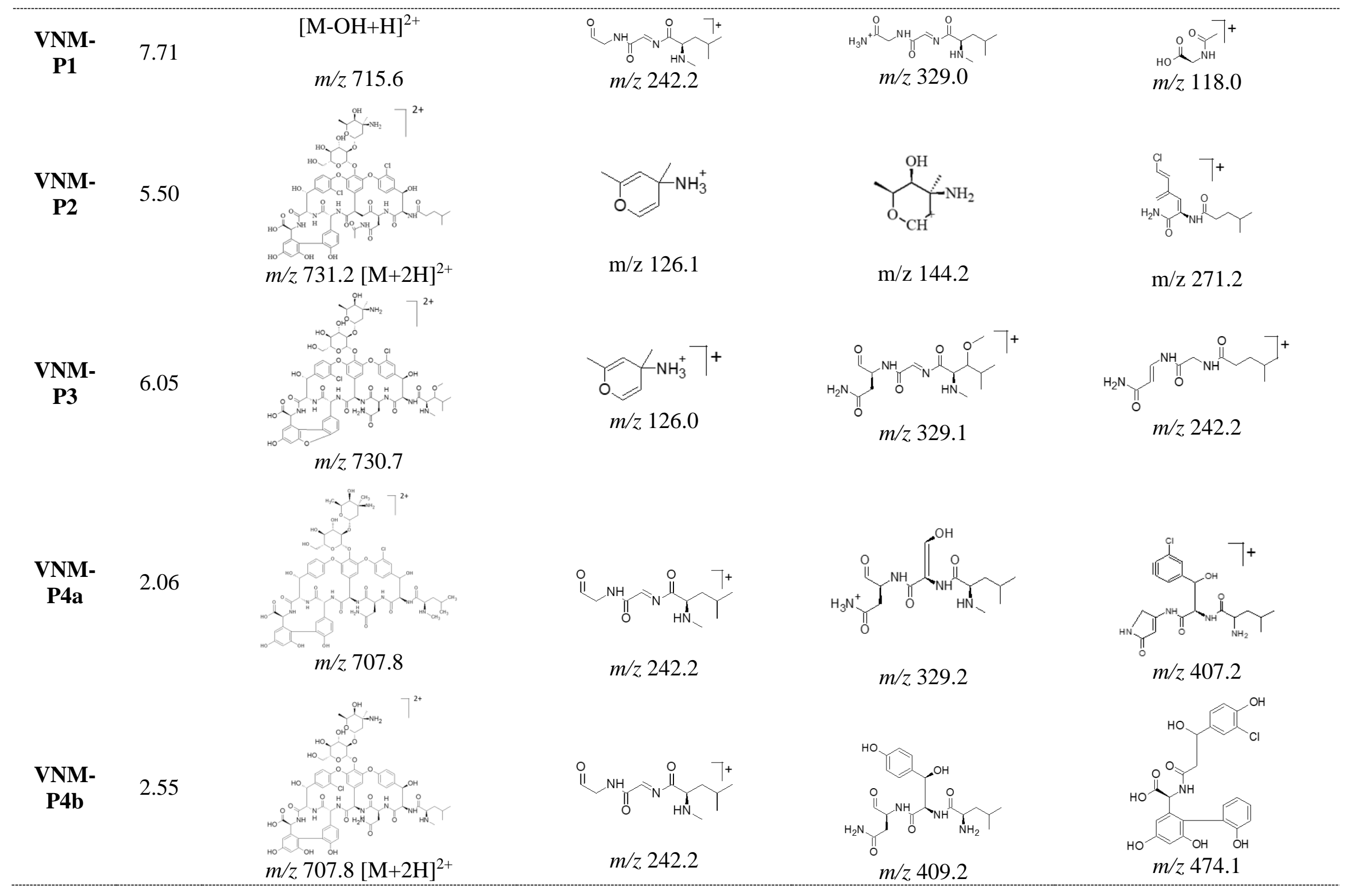




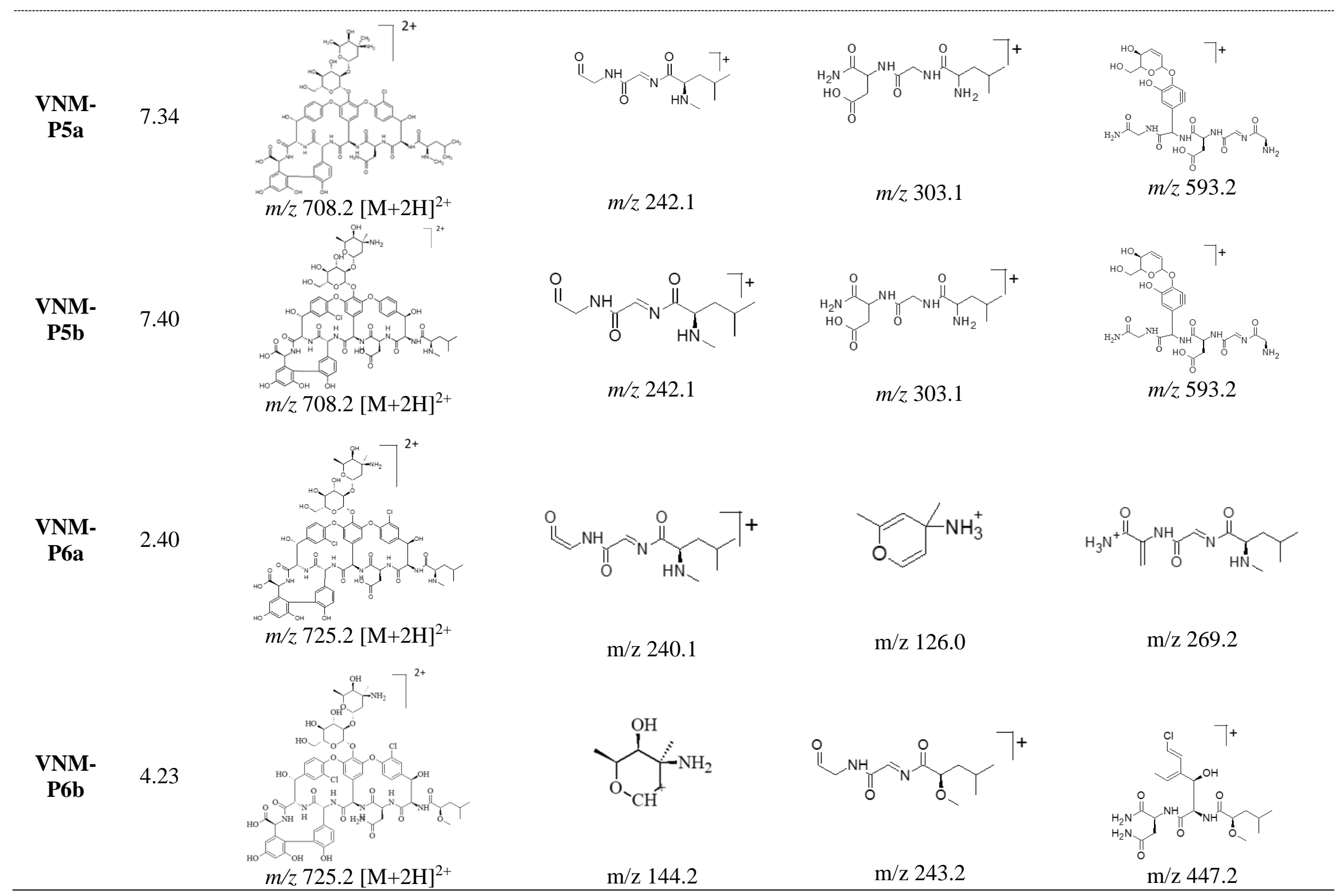




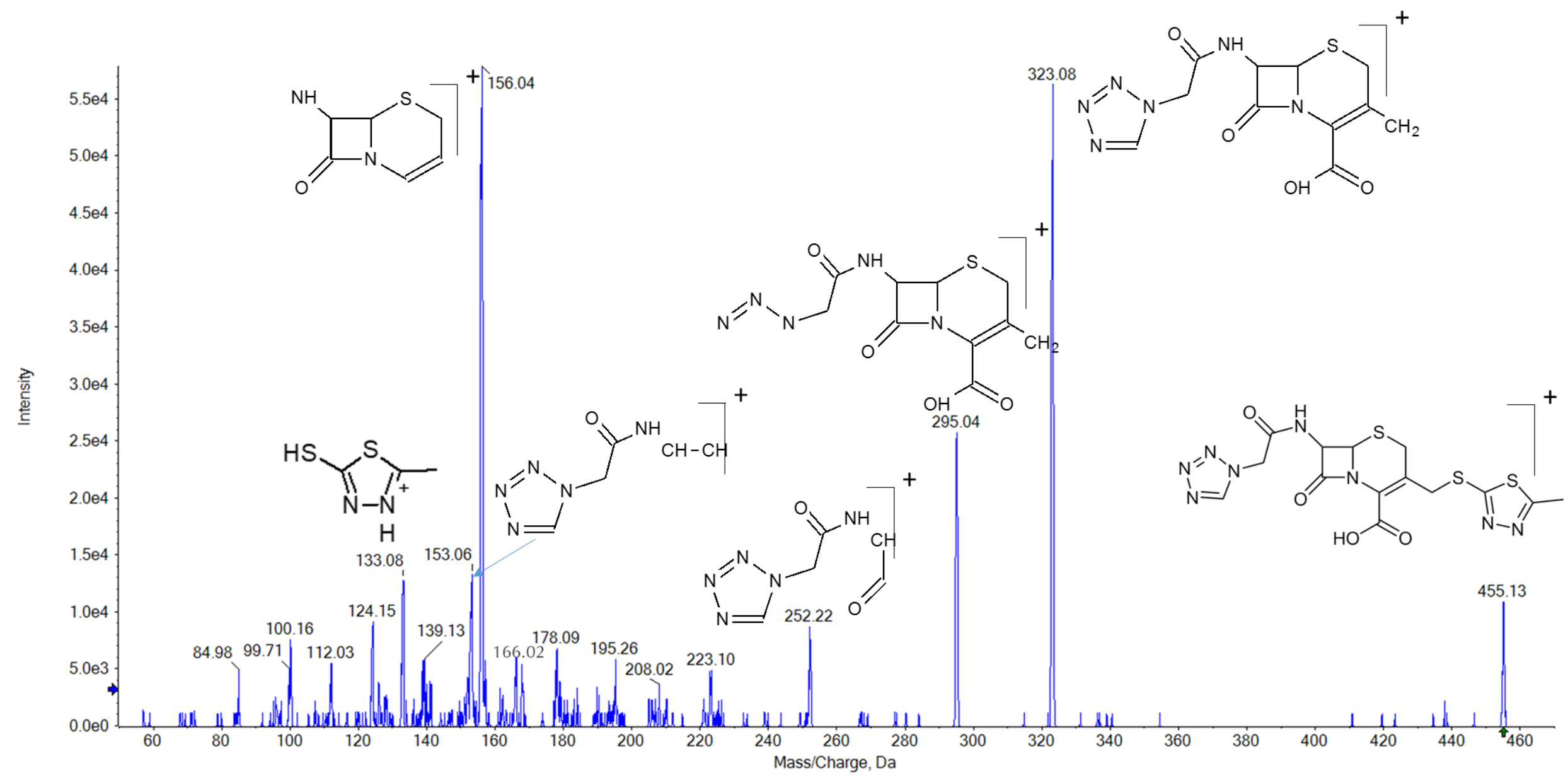

Figure S10. ESI (PI) MS/MS spectrum of CFZ. 


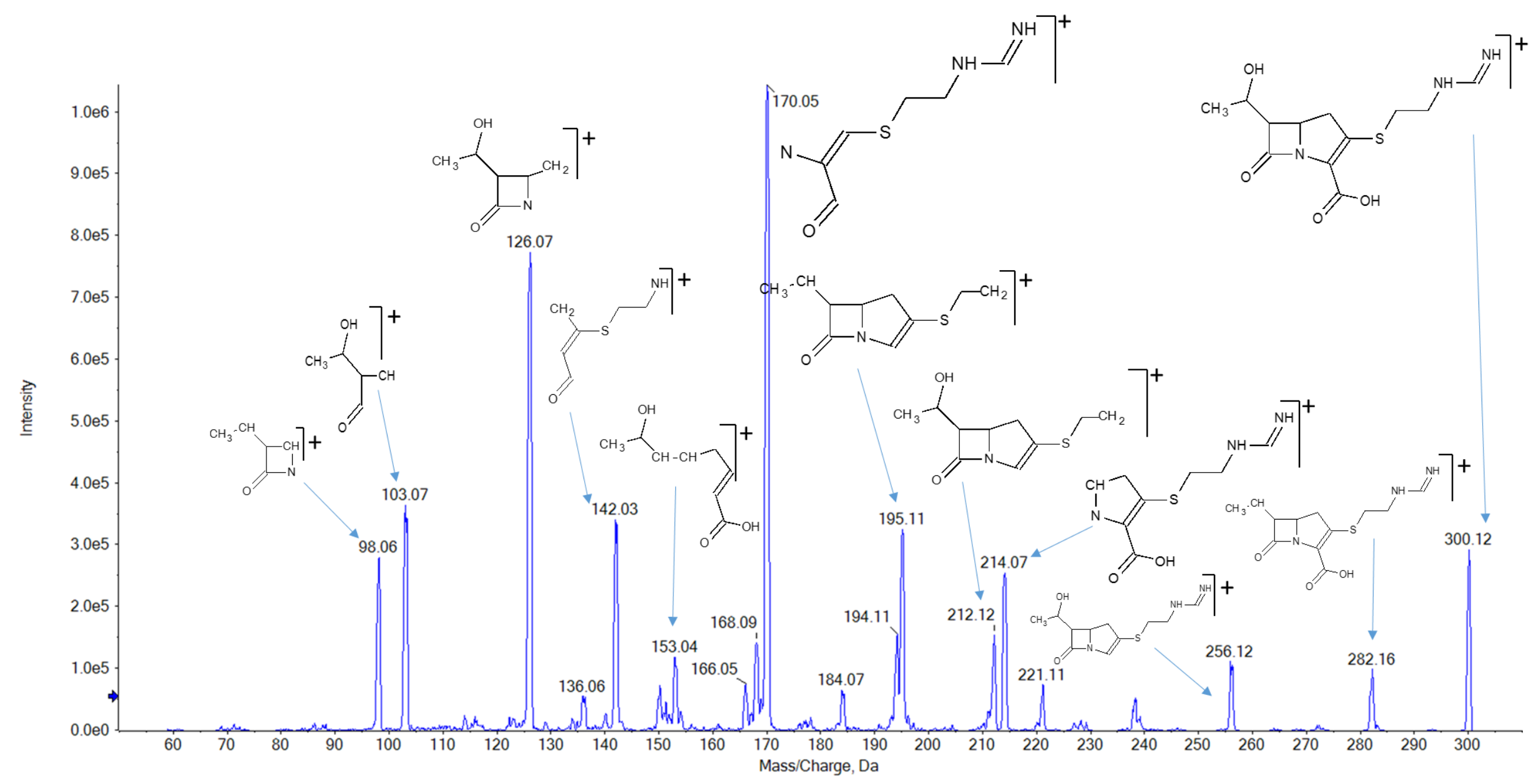

Figure S11. ESI (PI) MS/MS spectrum of IMI. 


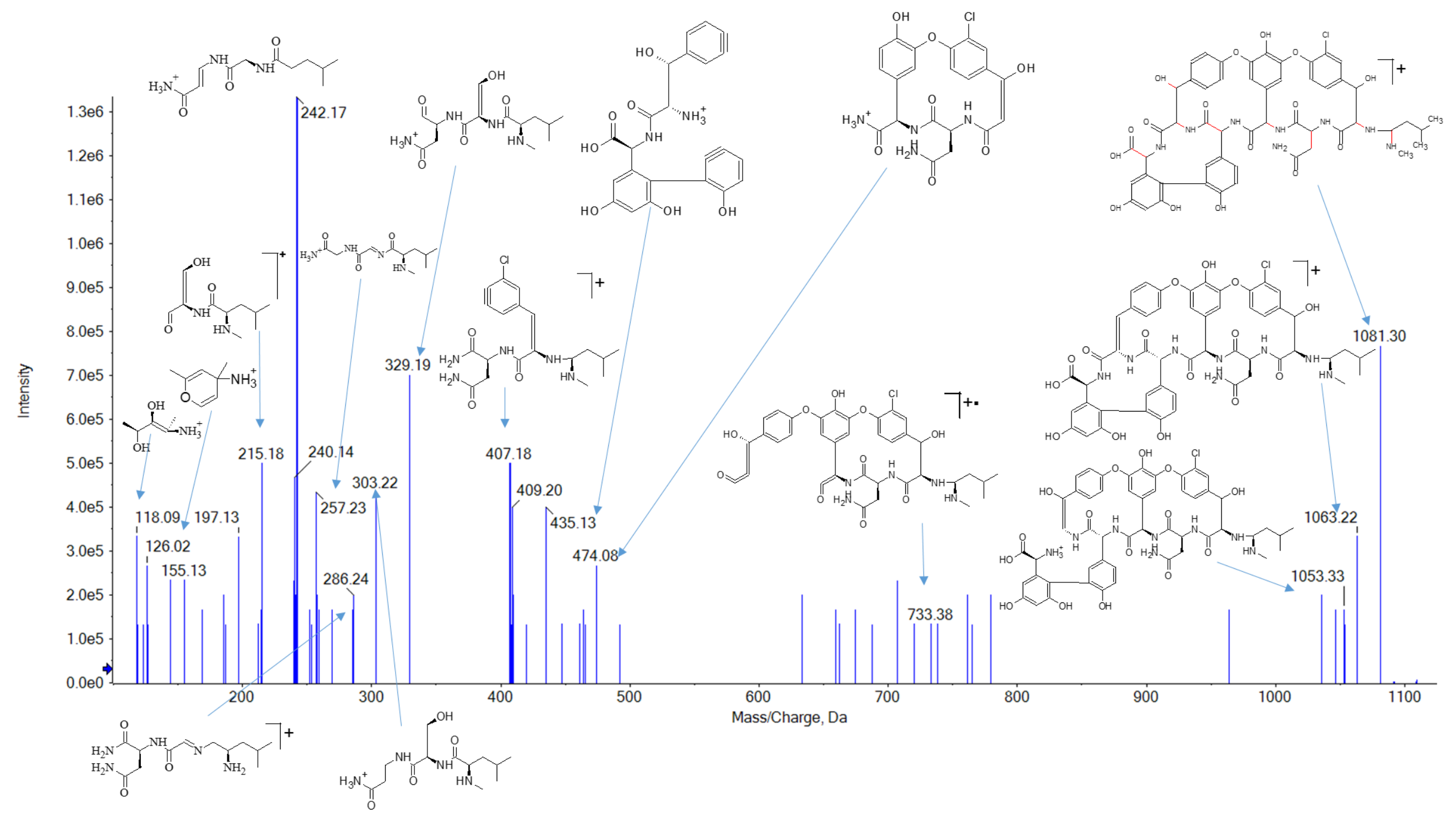

Figure S12. ESI (PI) MS/MS spectrum of VNM. 


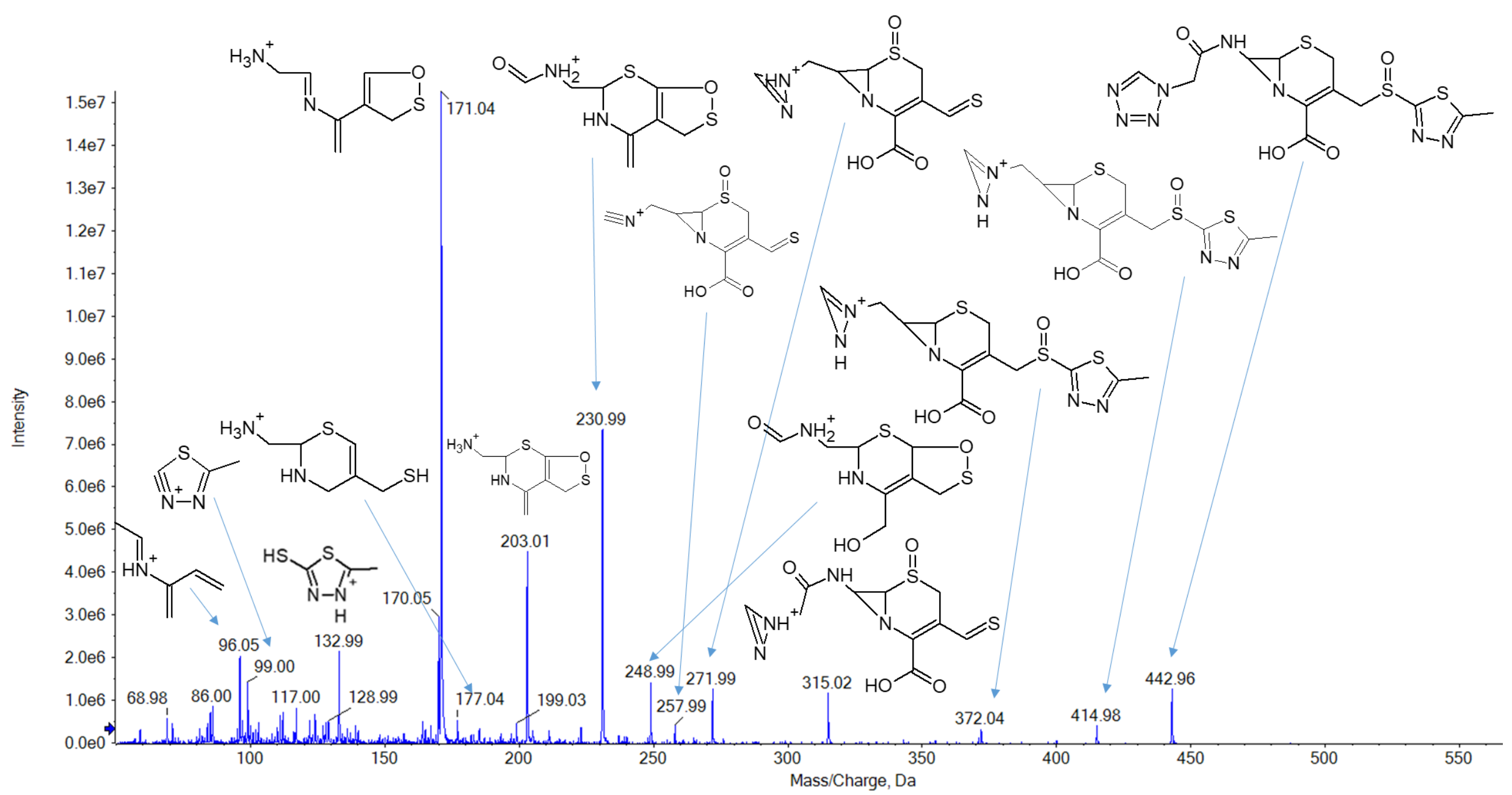

Figure S13. ESI (PI) MS/MS spectrum of CFZ-P1a. 


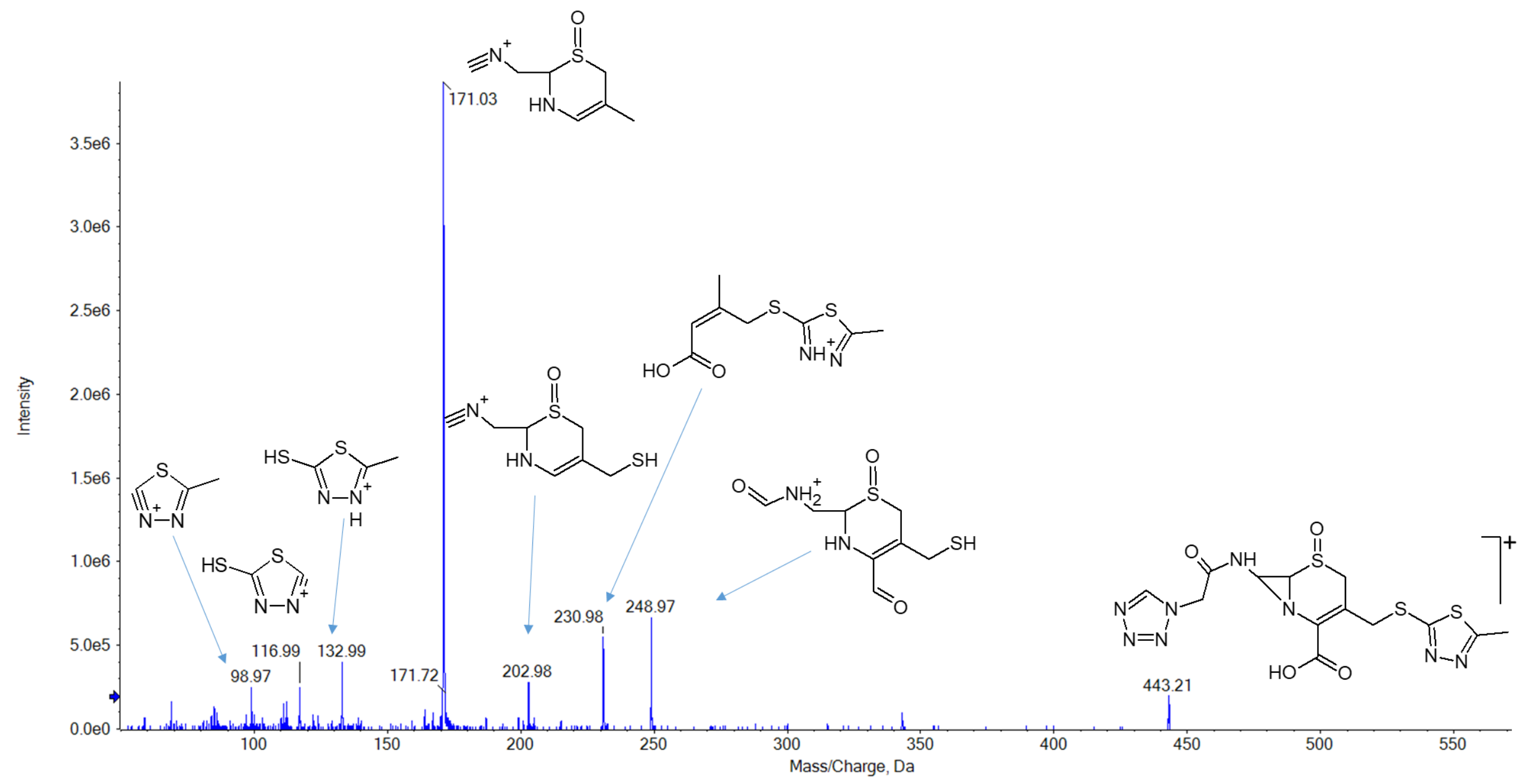

Figure S14. ESI (PI) MS/MS spectrum of CFZ-P1b. 


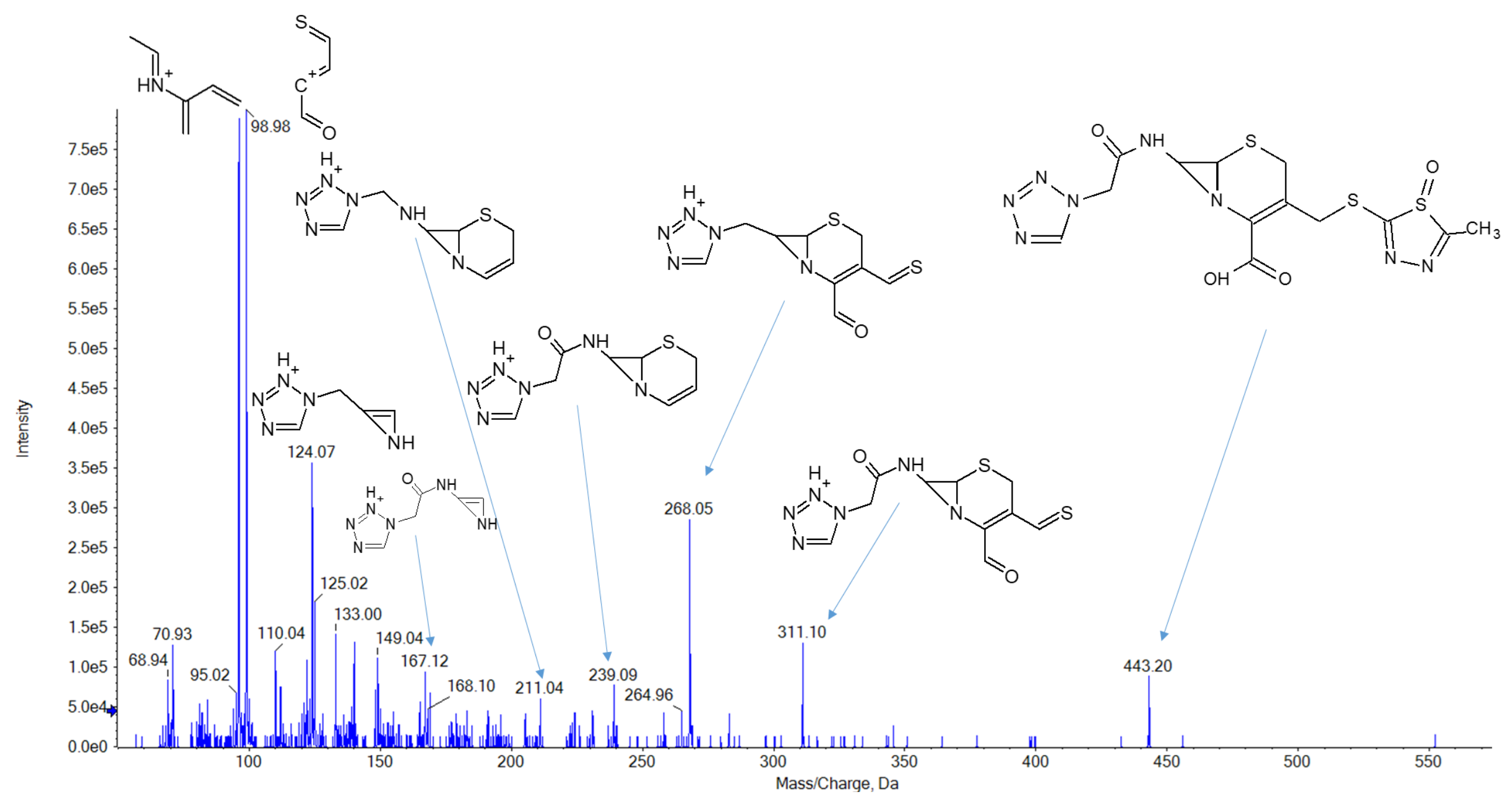

Figure S15. ESI (PI) MS/MS spectrum of CFZ-P1c. 


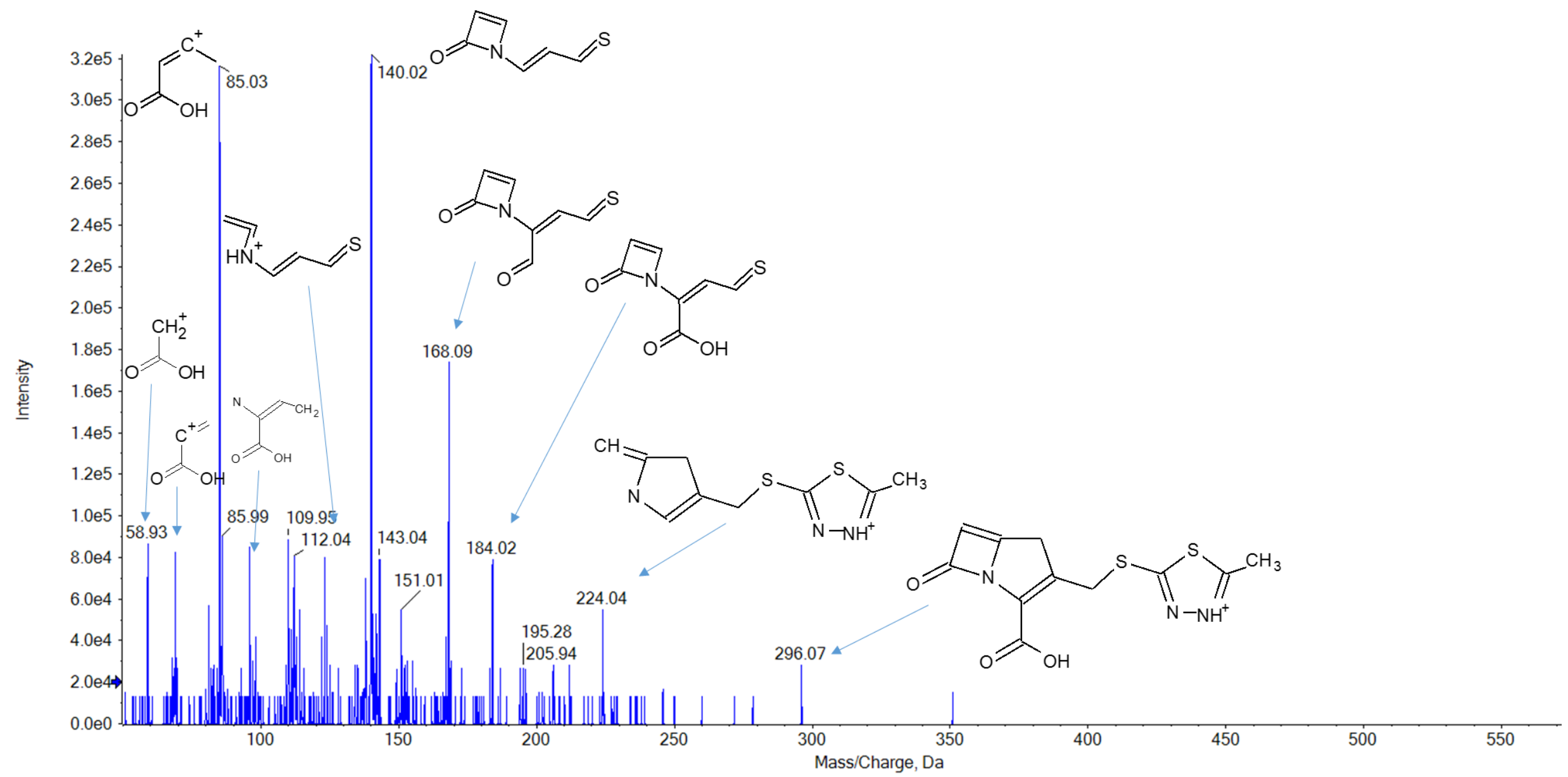

Figure S16. ESI (PI) MS/MS spectrum of CFZ-P2a. 


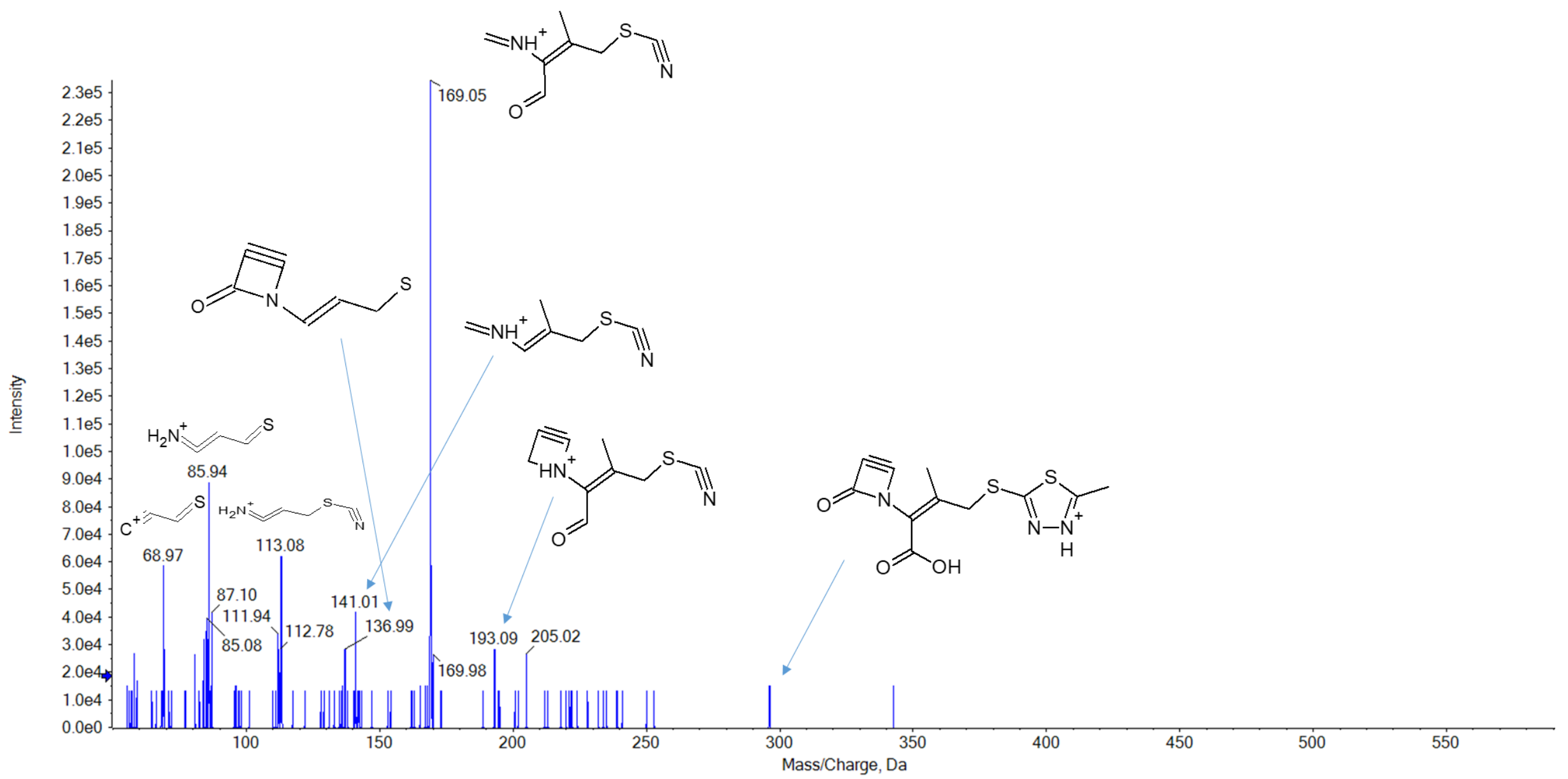

Figure S17. ESI (PI) MS/MS spectrum of CFZ-P2b. 


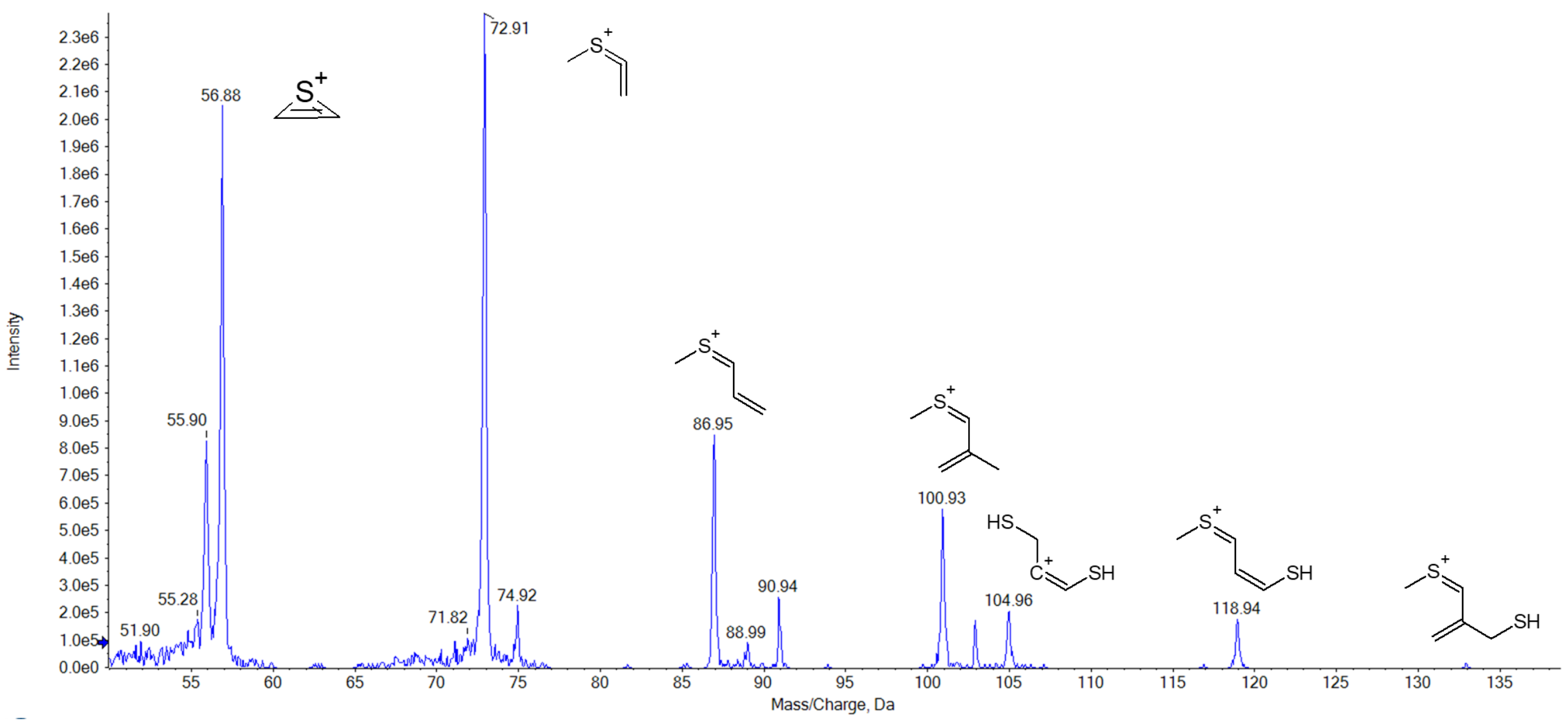

Figure S18. ESI (PI) MS/MS spectrum of CFZ-P3a. 


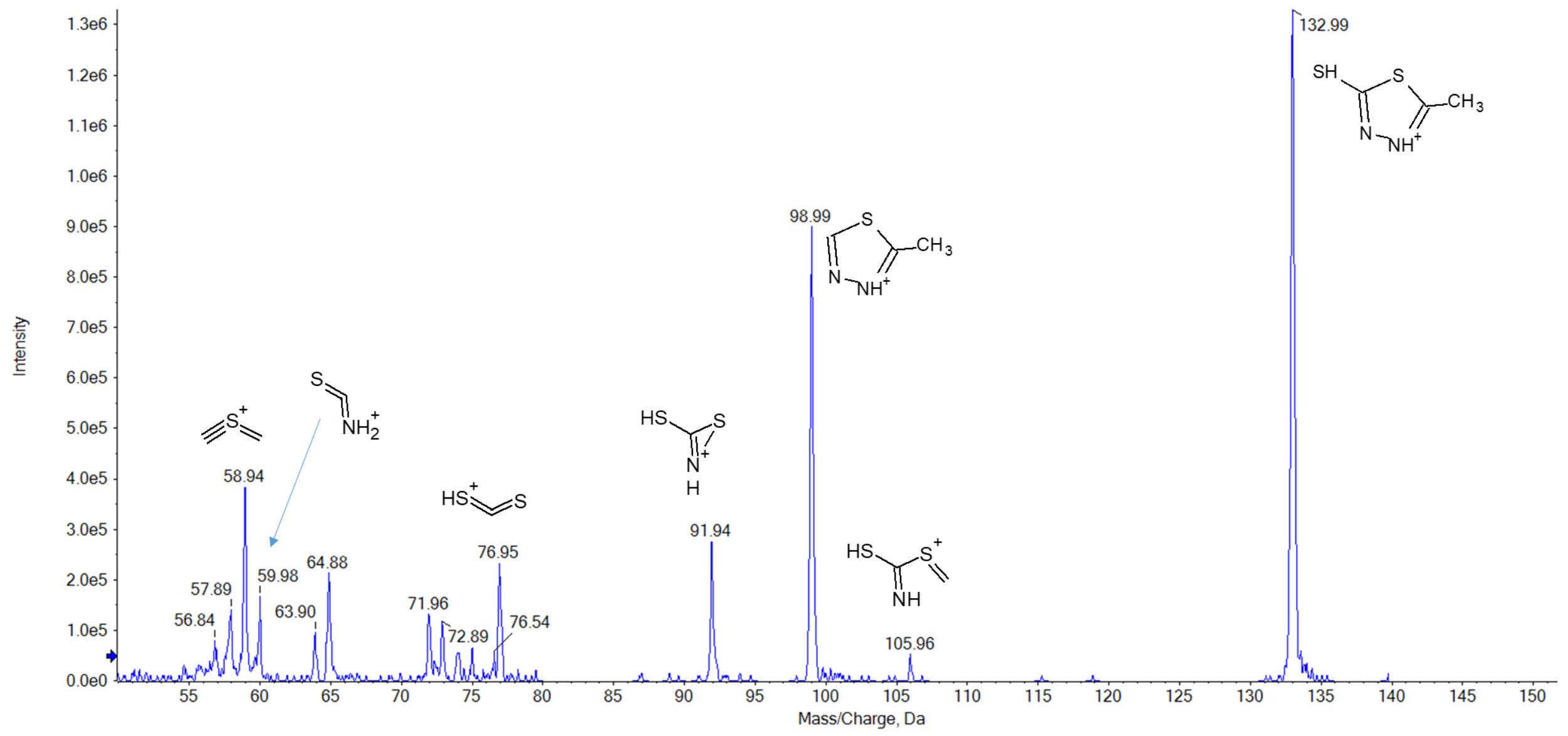

Figure S19. ESI (PI) MS/MS spectrum of CFZ-P3b. 


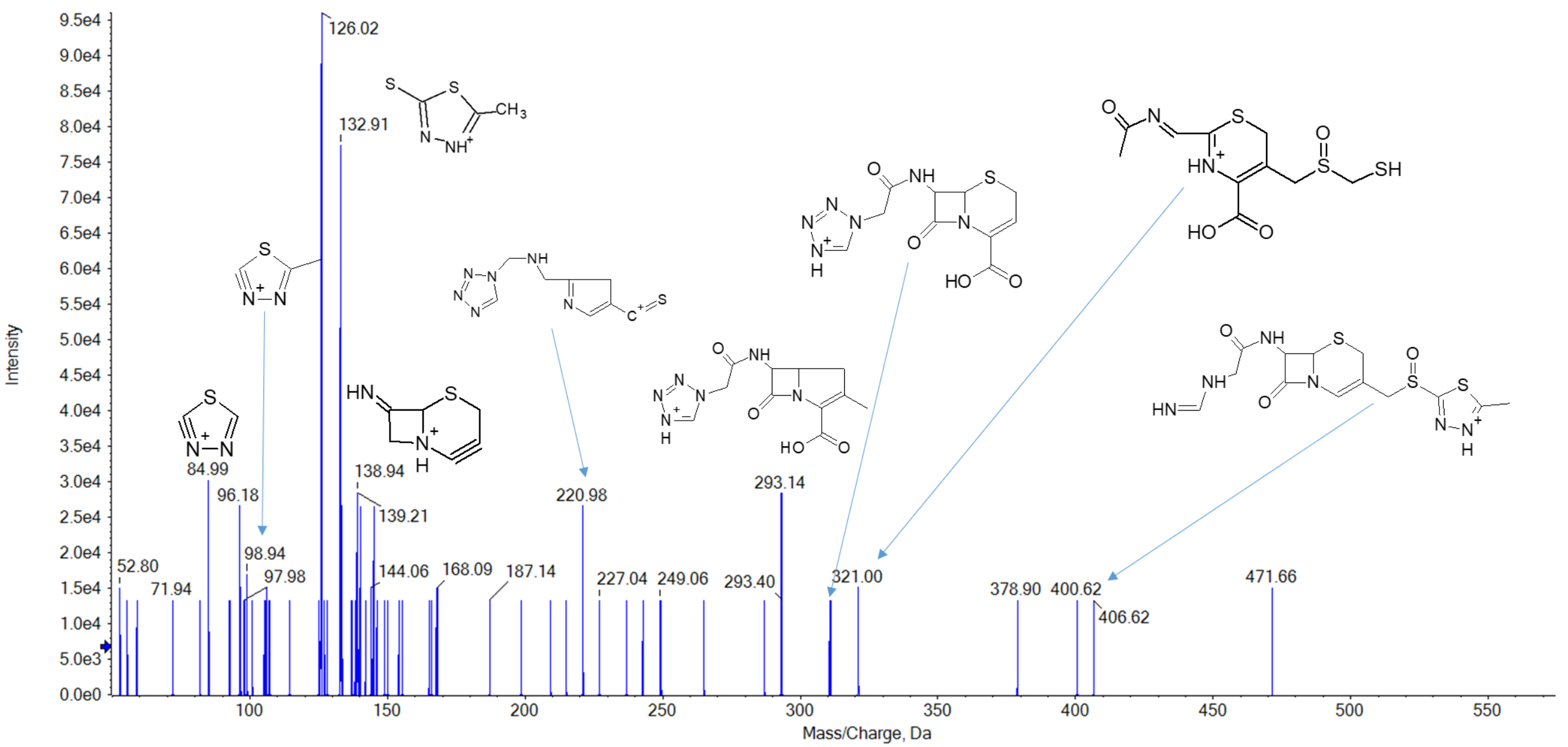

Figure S20. ESI (PI) MS/MS spectrum of CFZ-P4a. 


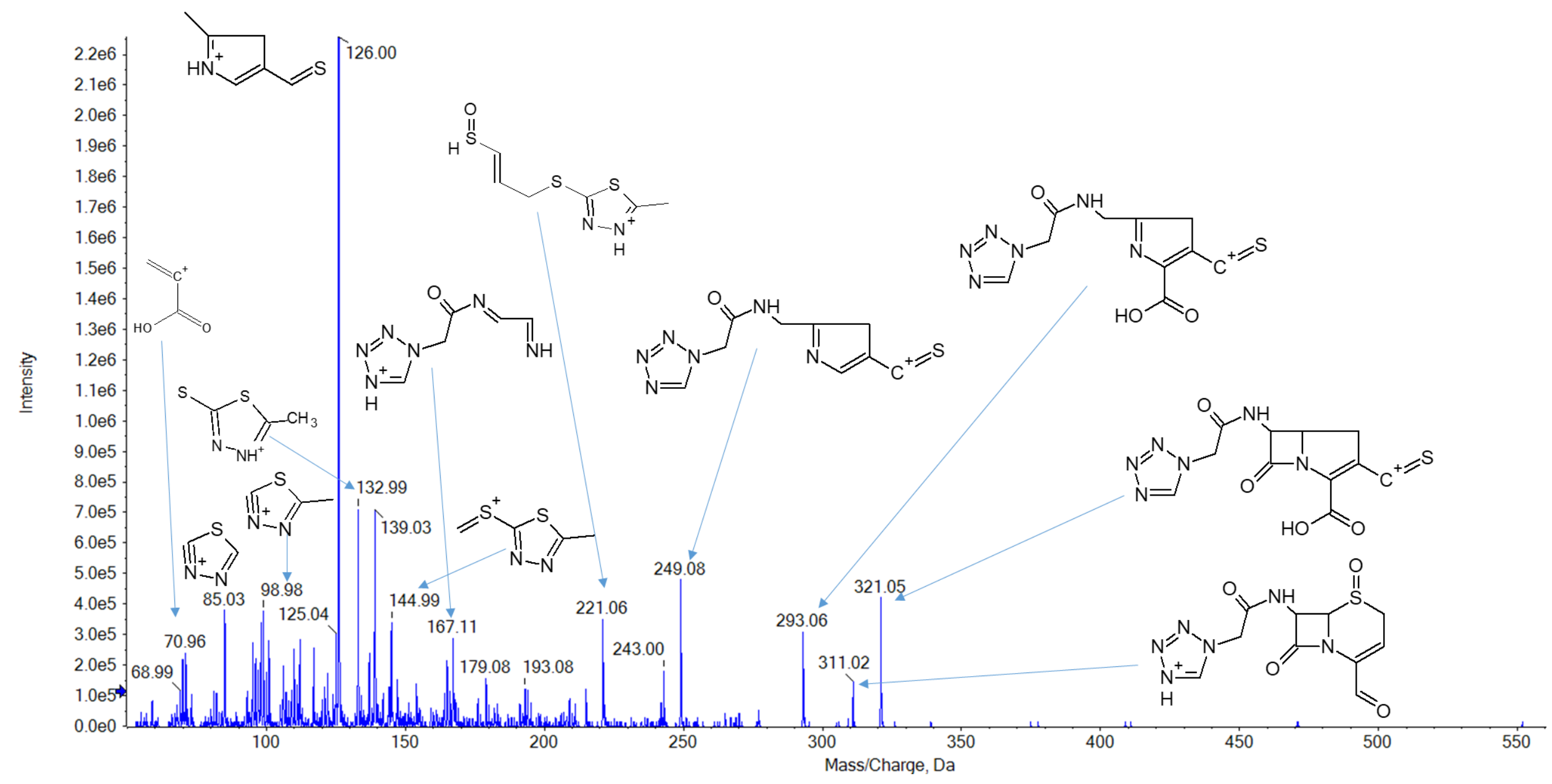

Figure S21. ESI (PI) MS/MS spectrum of CFZ-P4b. 


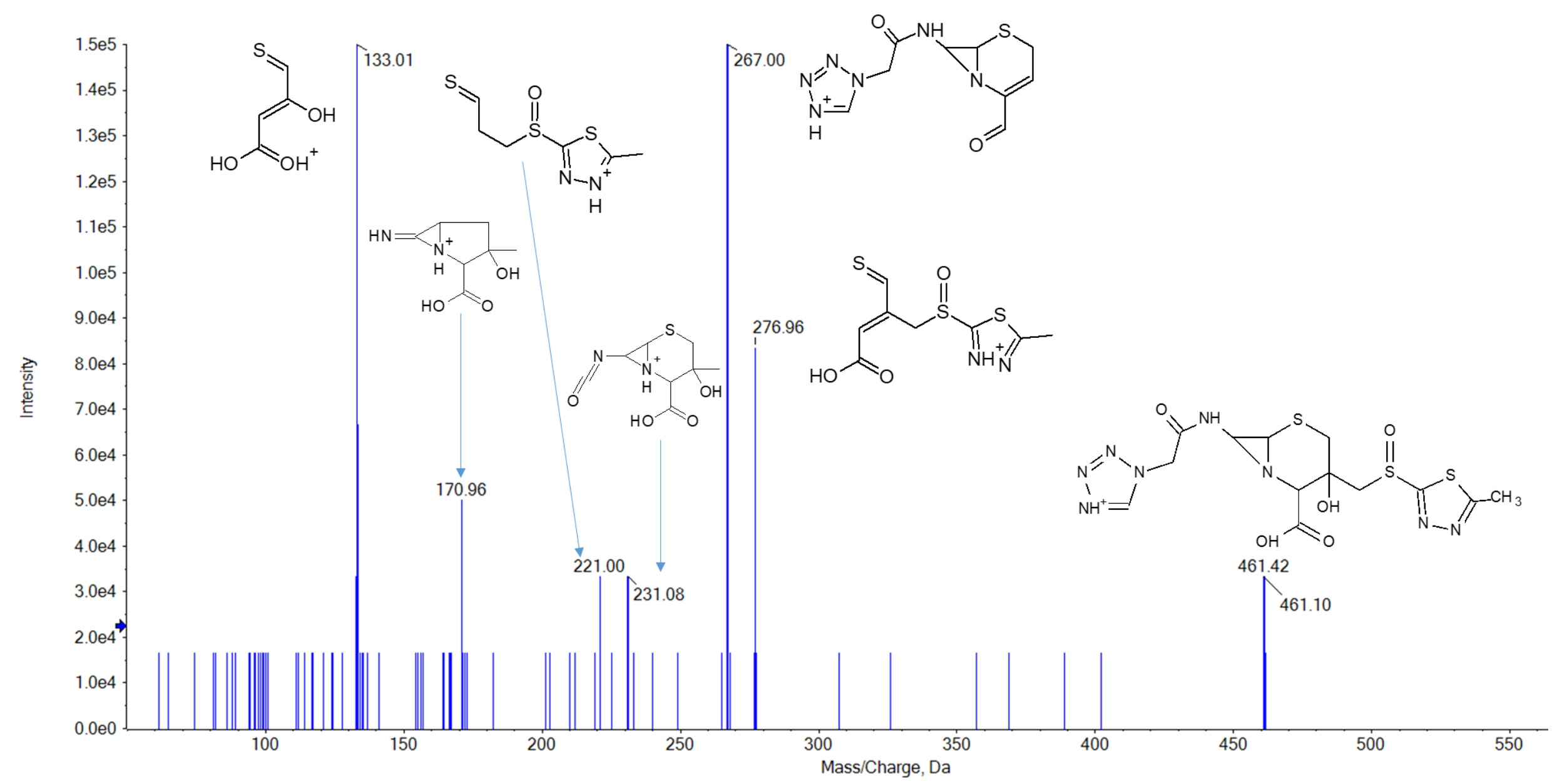

Figure S22. ESI (PI) MS/MS spectrum of CFZ-P5a. 


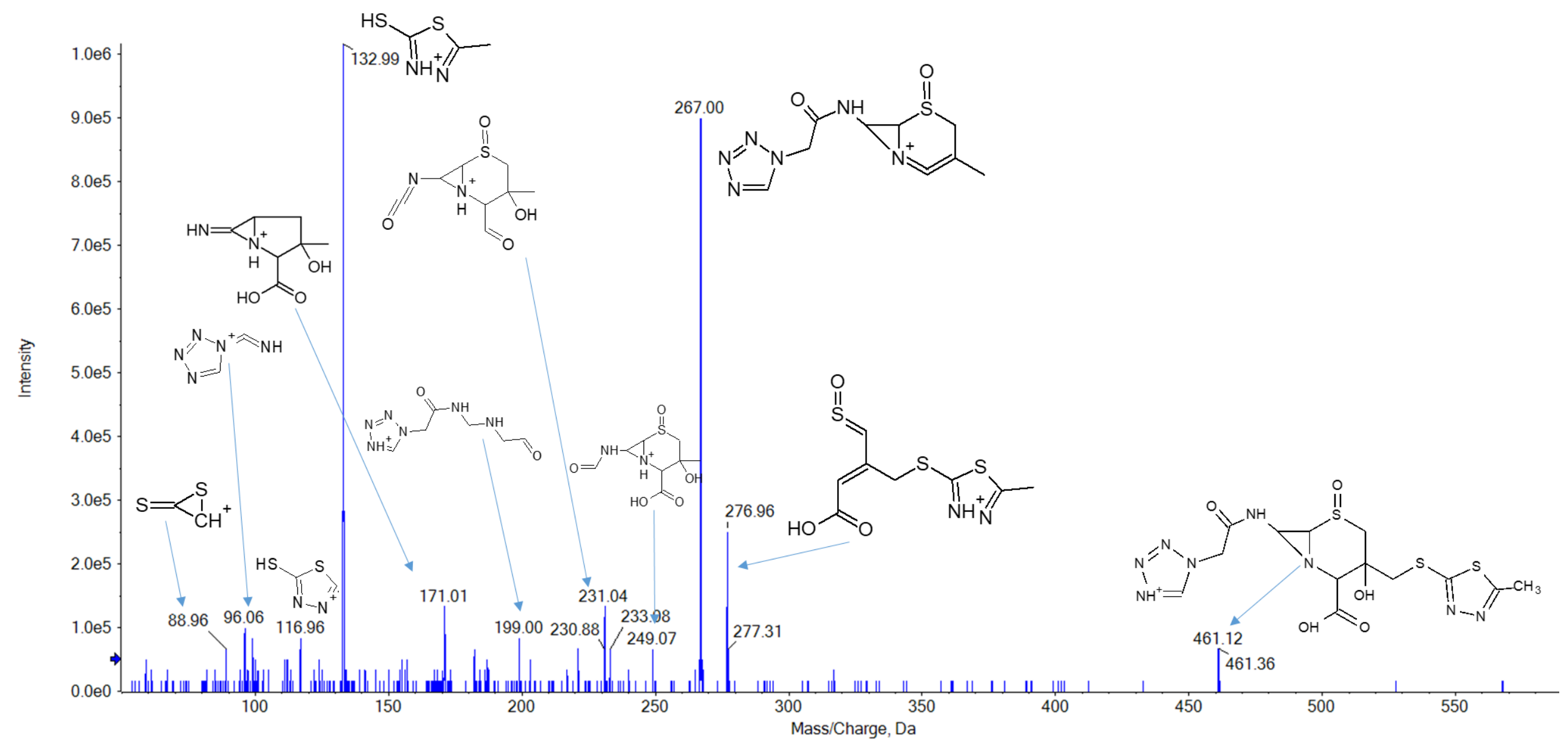

Figure S23. ESI (PI) MS/MS spectrum of CFZ-P5b. 


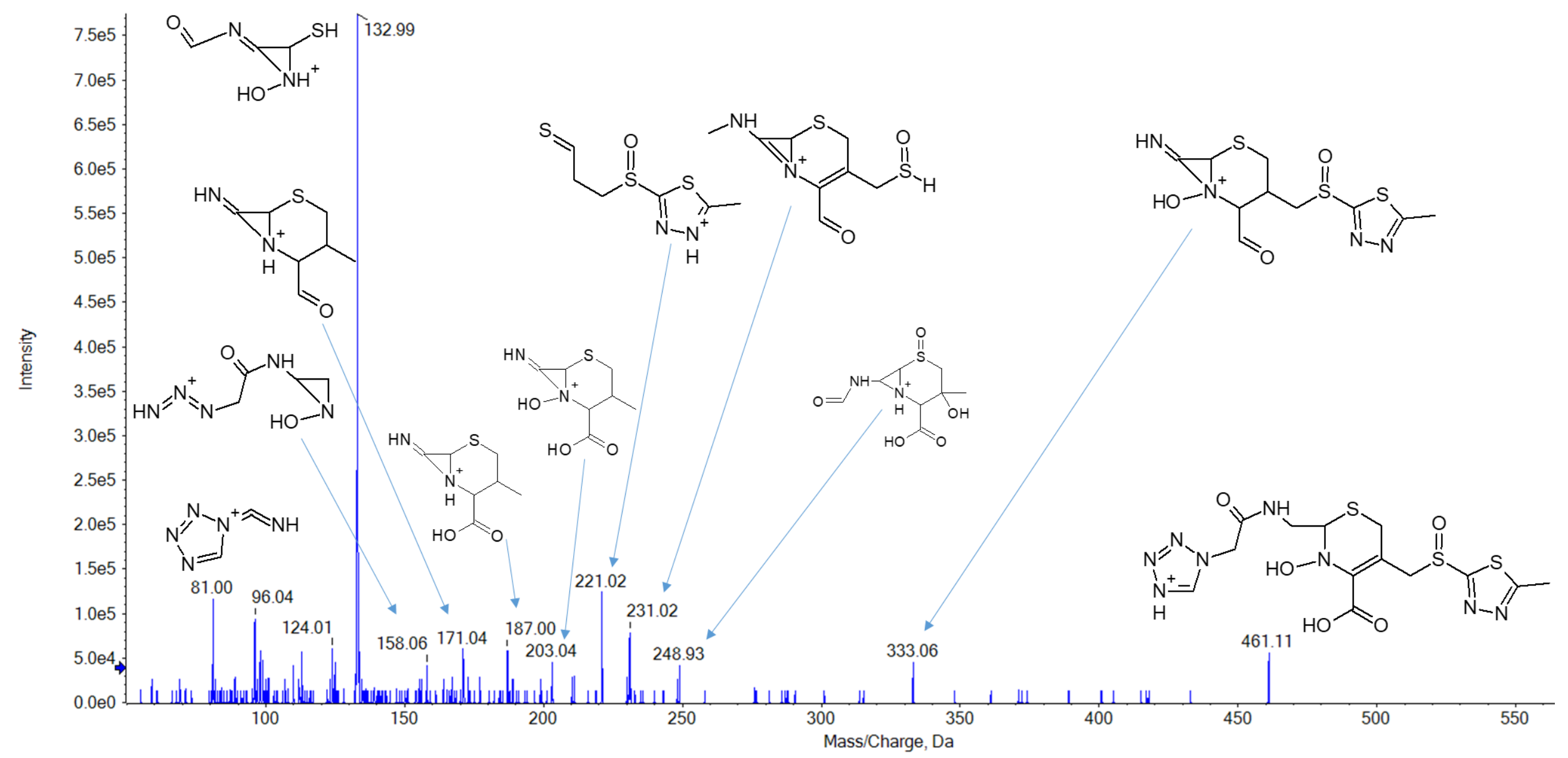

Figure S24. ESI (PI) MS/MS spectrum of CFZ-P5c. 


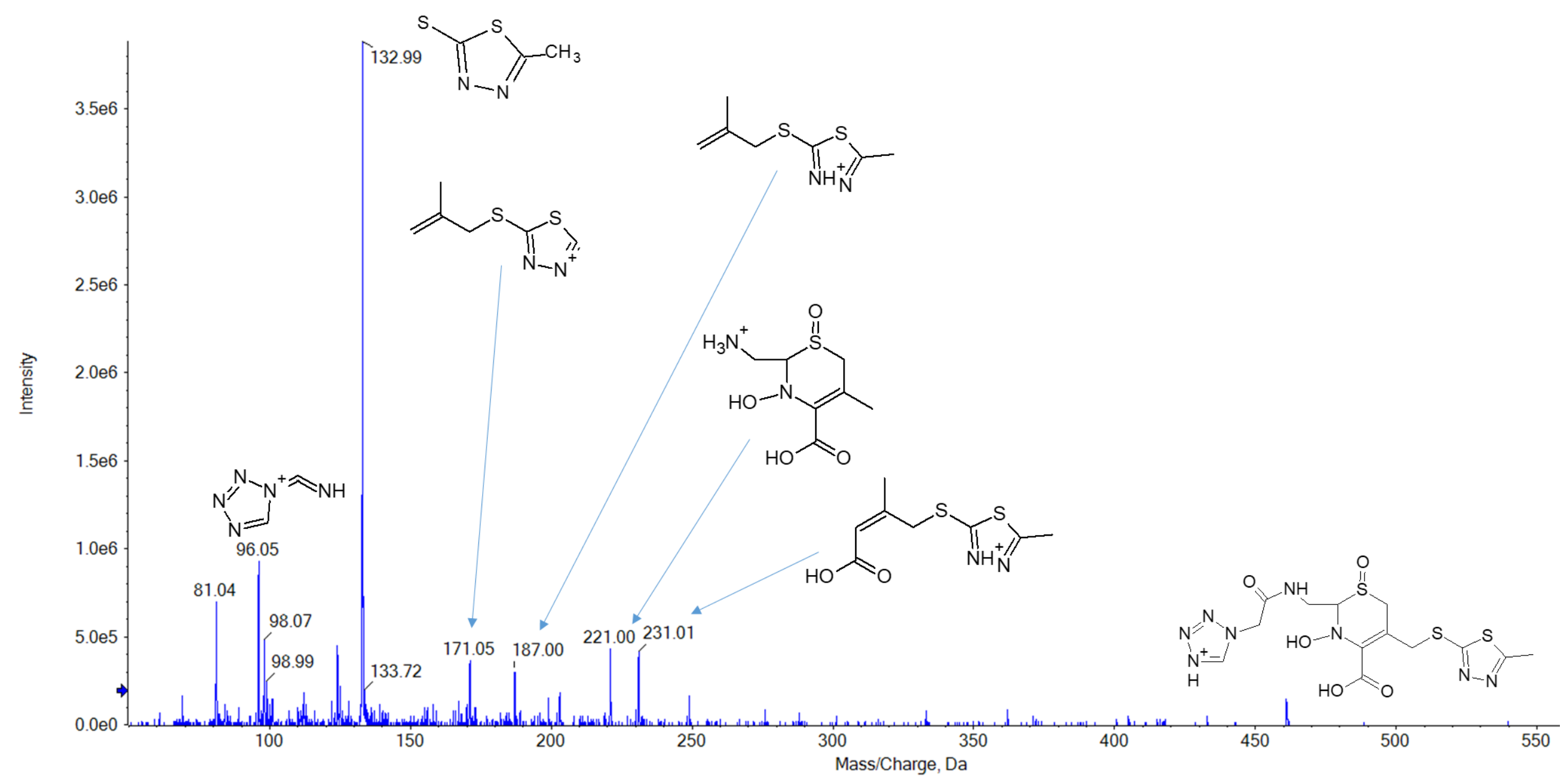

Figure S25. ESI (PI) MS/MS spectrum of CFZ-P5d. 


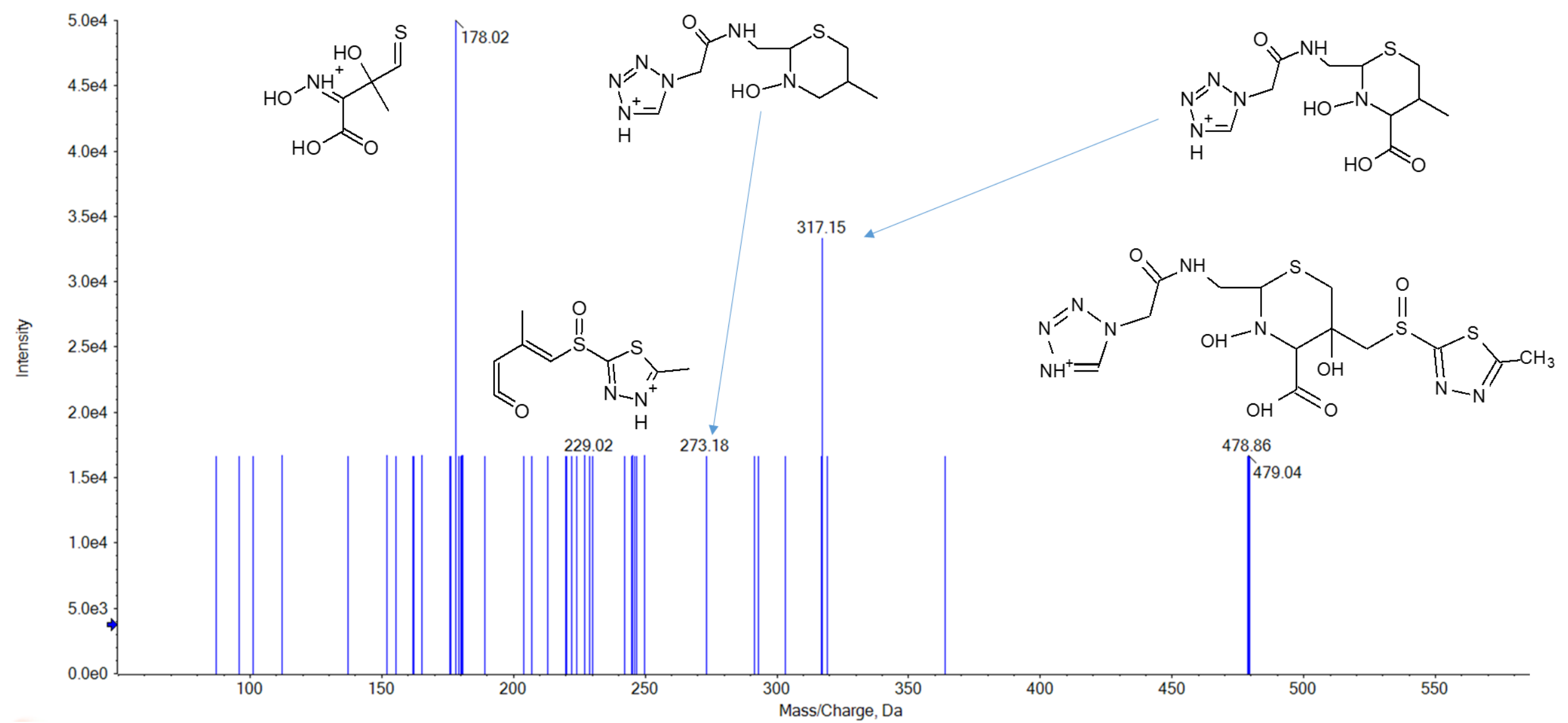

Figure S26. ESI (PI) MS/MS spectrum of CFZ-P6a. 


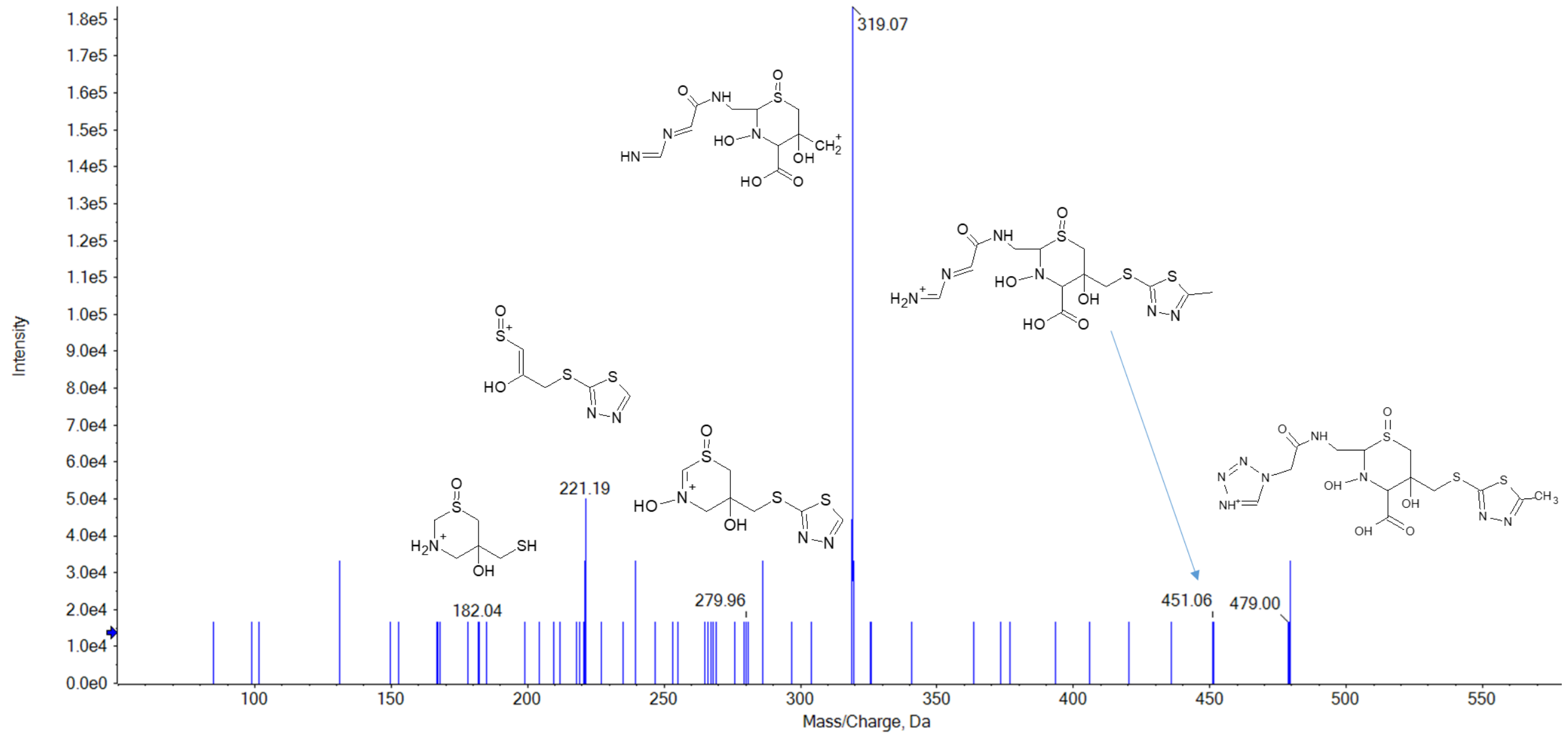

Figure S27. ESI (PI) MS/MS spectrum of CFZ-P6b. 


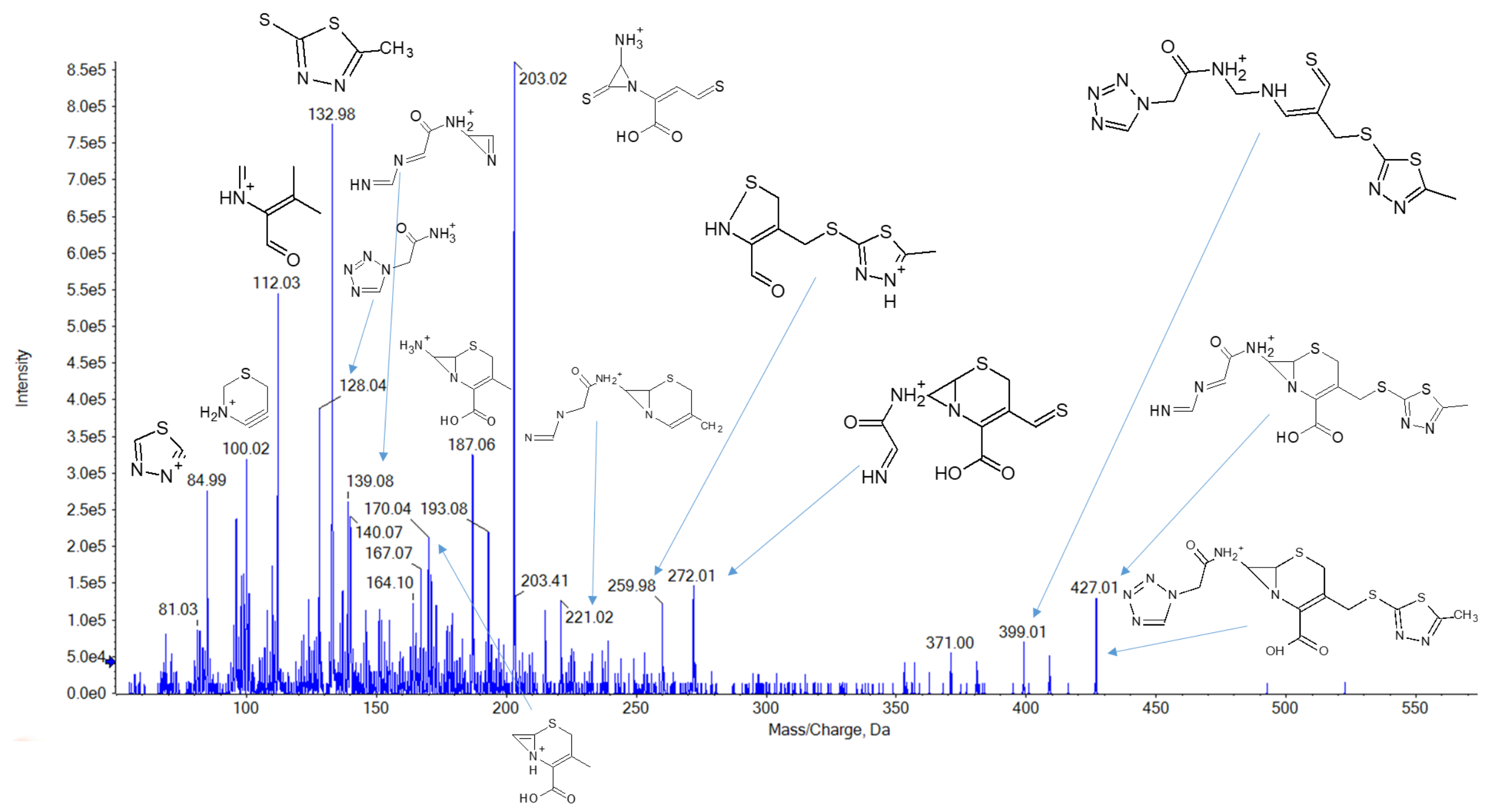

Figure S28. ESI (PI) MS/MS spectrum of CFZ-P7. 


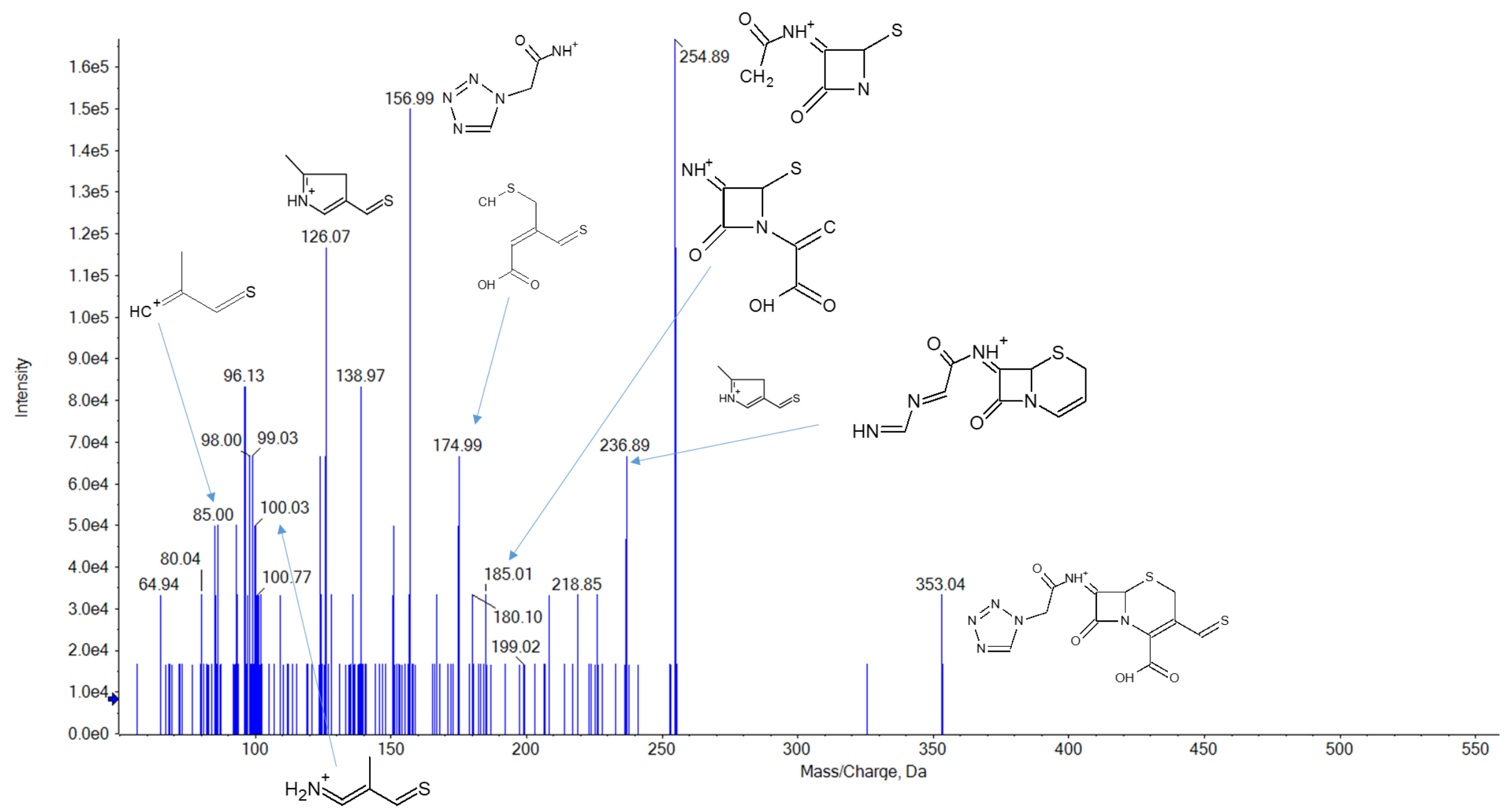

Figure S29. ESI (PI) MS/MS spectrum of CFZ-P8a. 


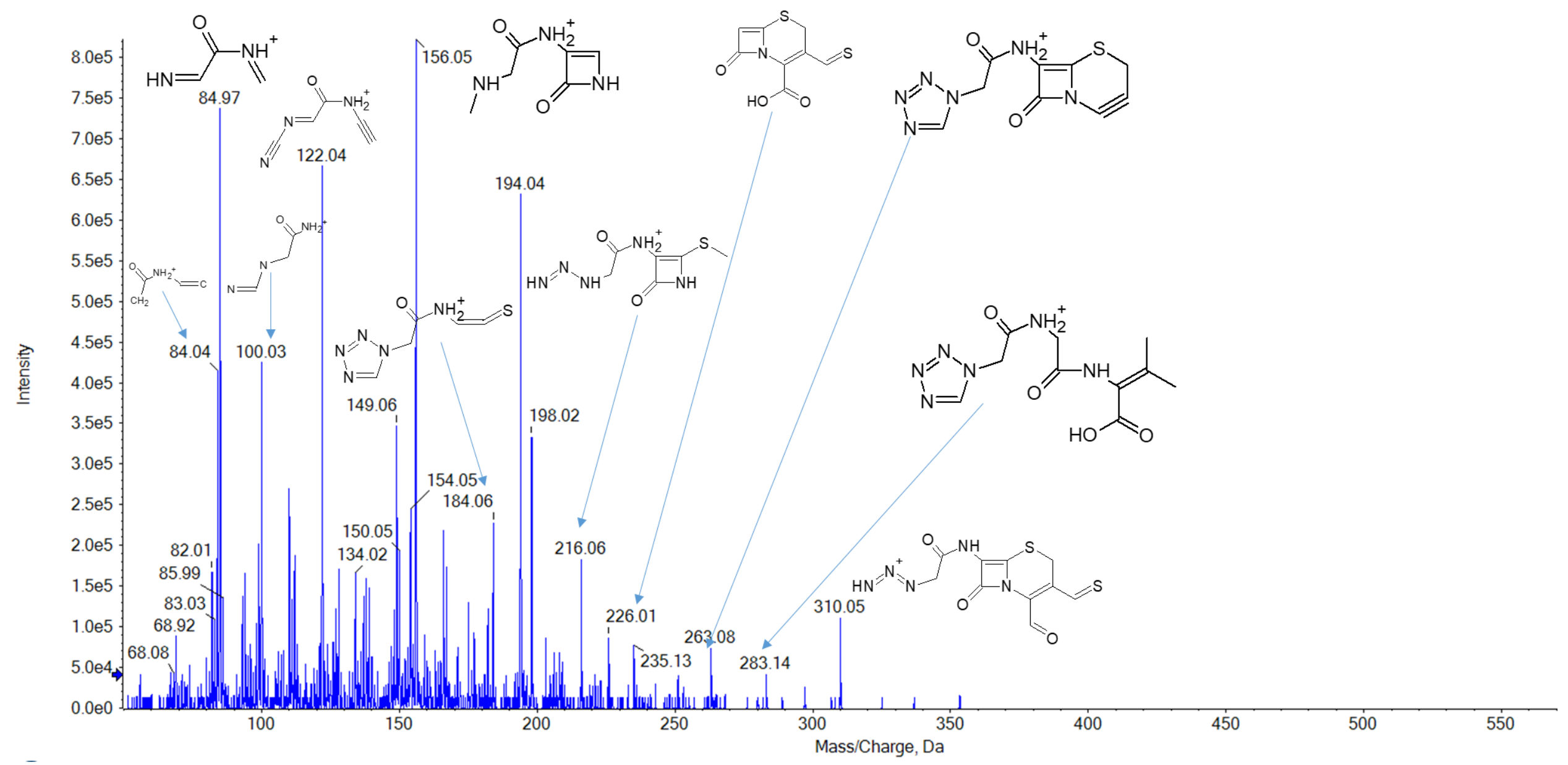

Figure S30. ESI (PI) MS/MS spectrum of CFZ-P8b. 


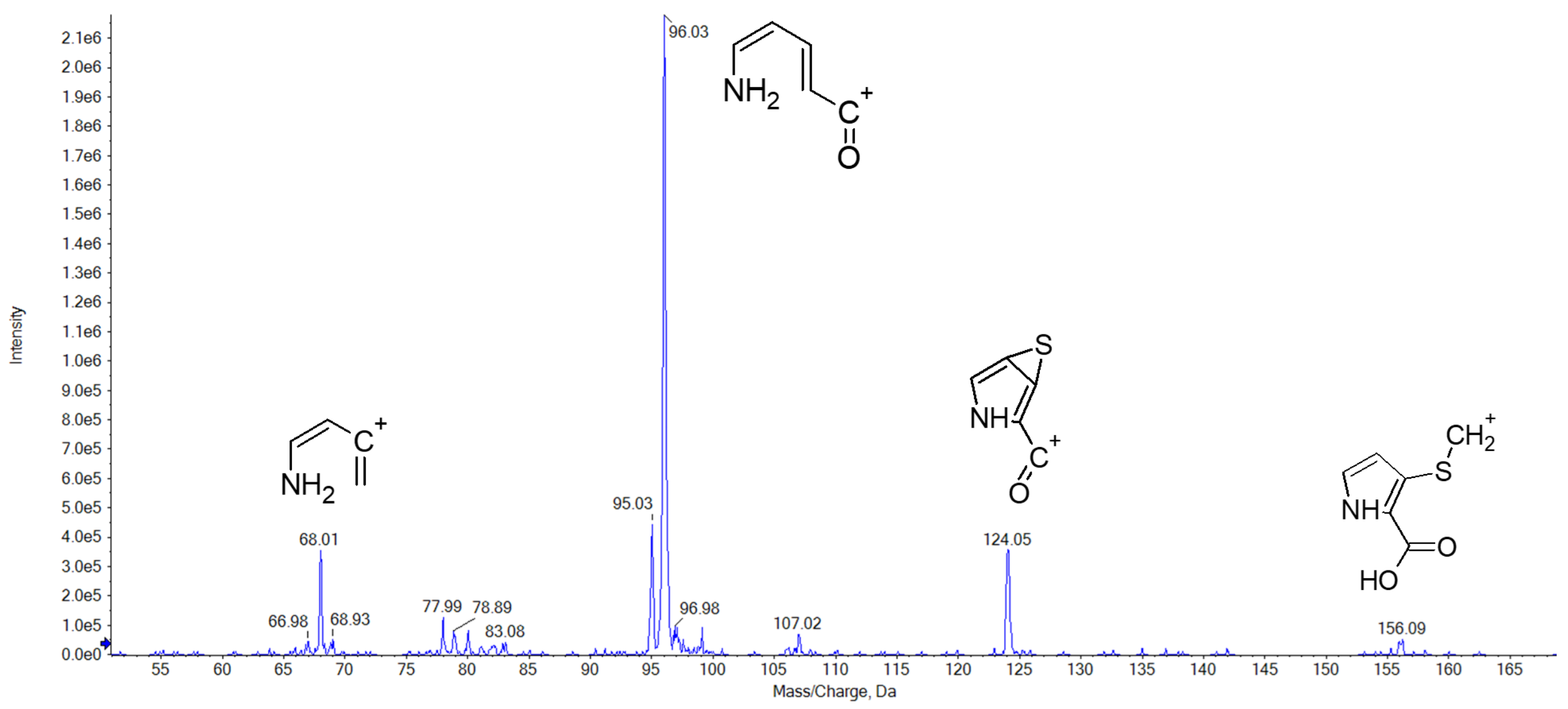

Figure S31. ESI (PI) MS/MS spectrum of IMI-P1. 


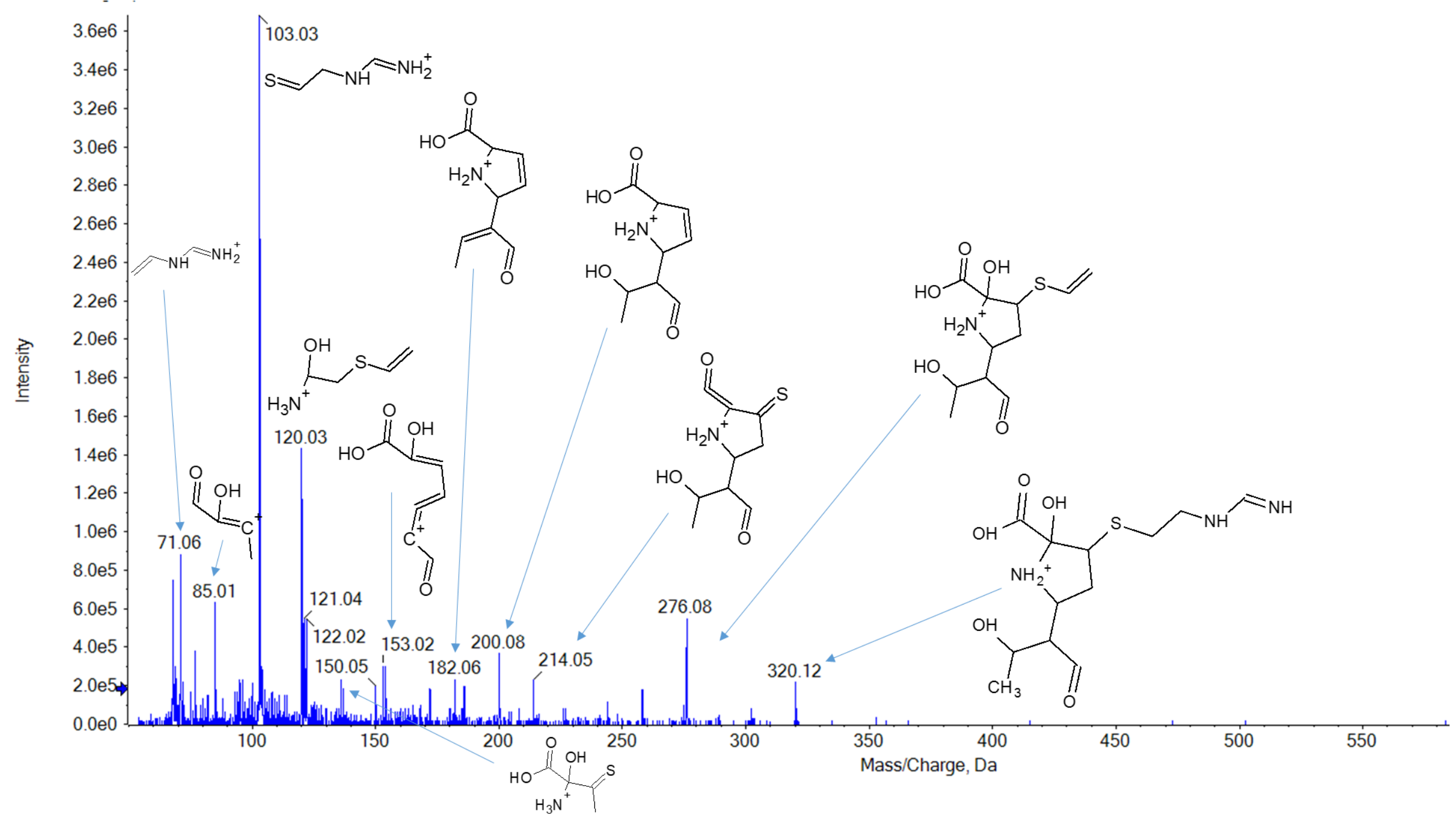

Figure S32. ESI (PI) MS/MS spectrum of IMI-P2. 


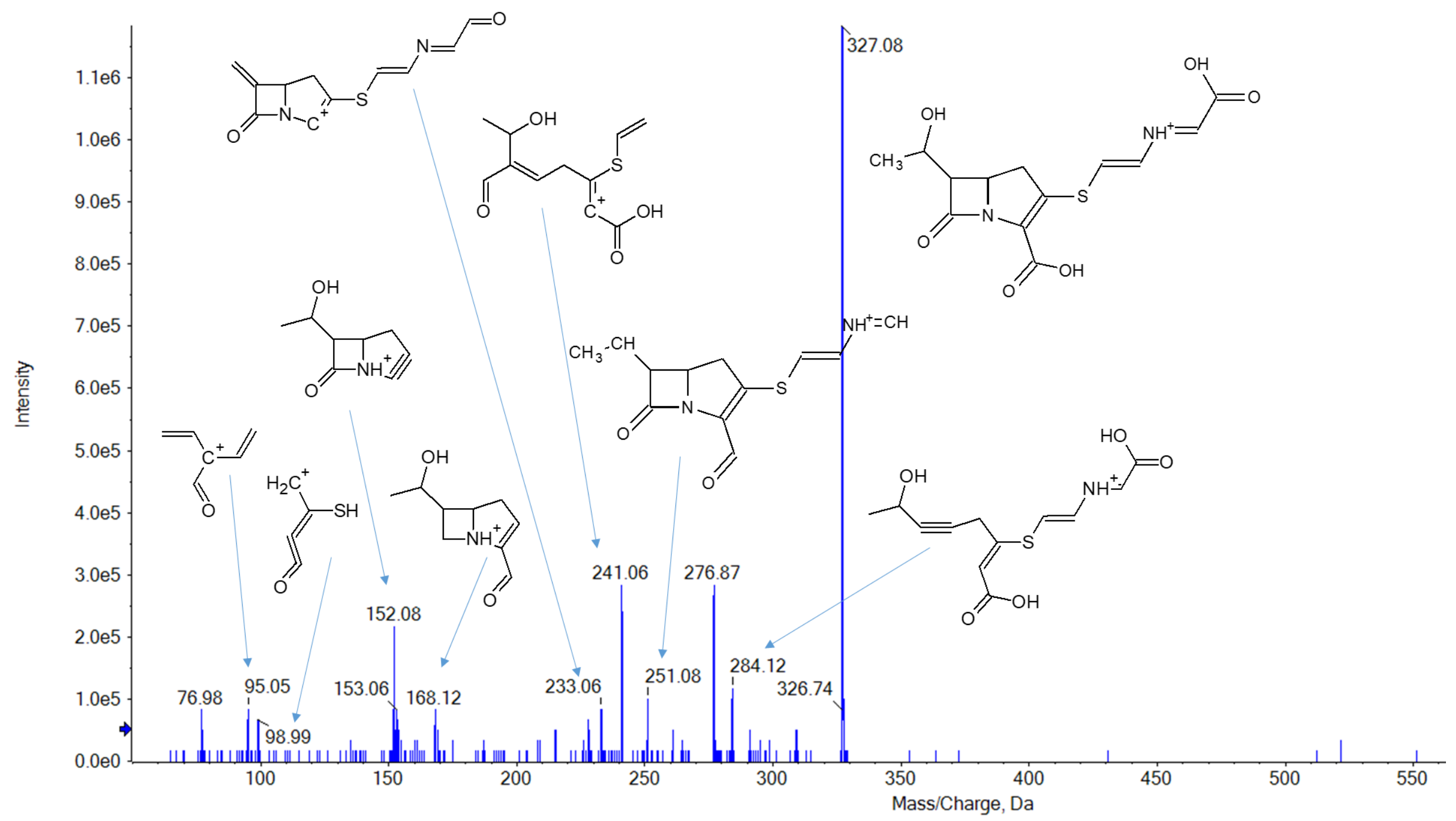

Figure S33. ESI (PI) MS/MS spectrum of IMI-P3. 


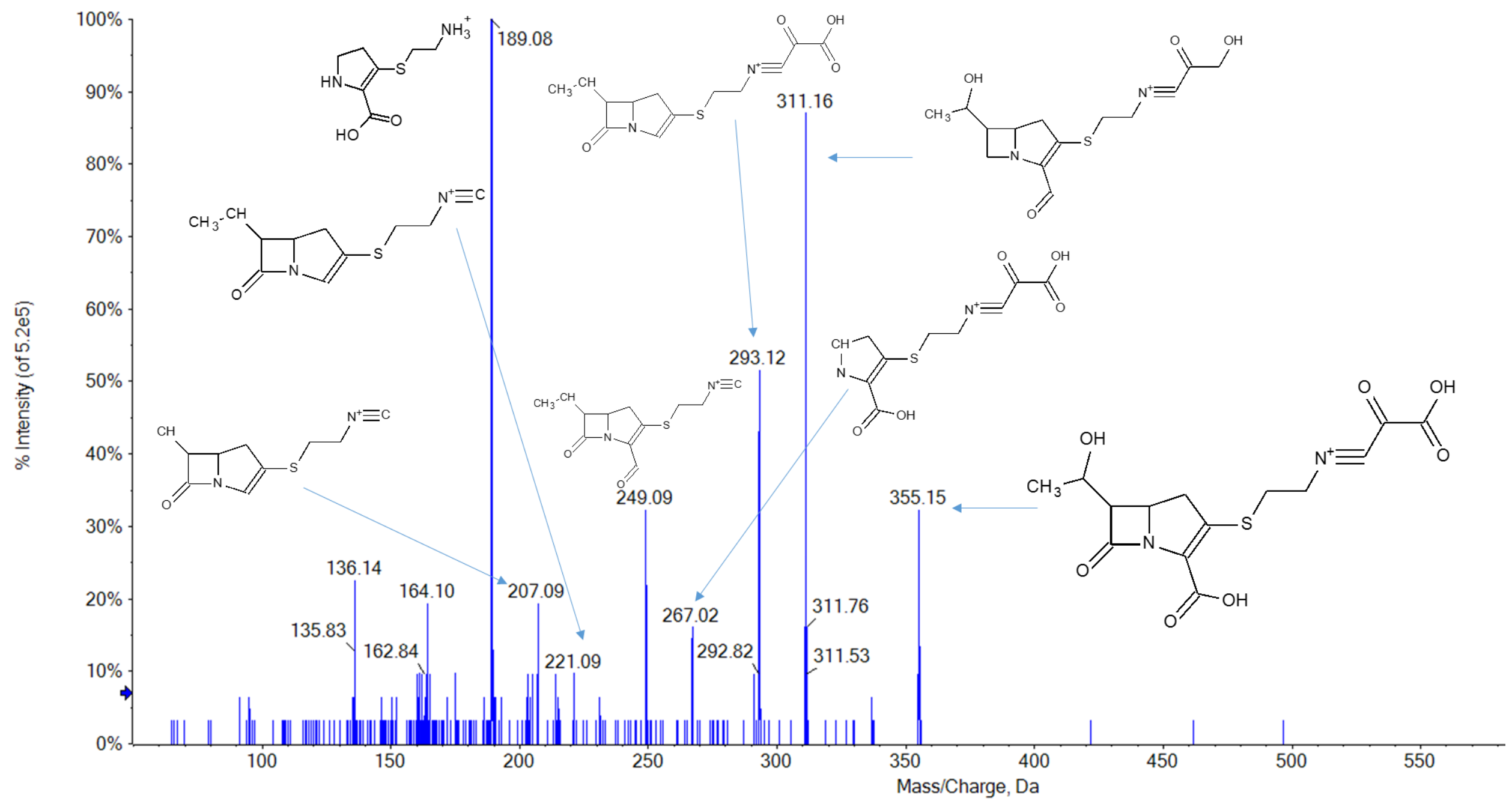

Figure S34. ESI (PI) MS/MS spectrum of IMI-P4. 


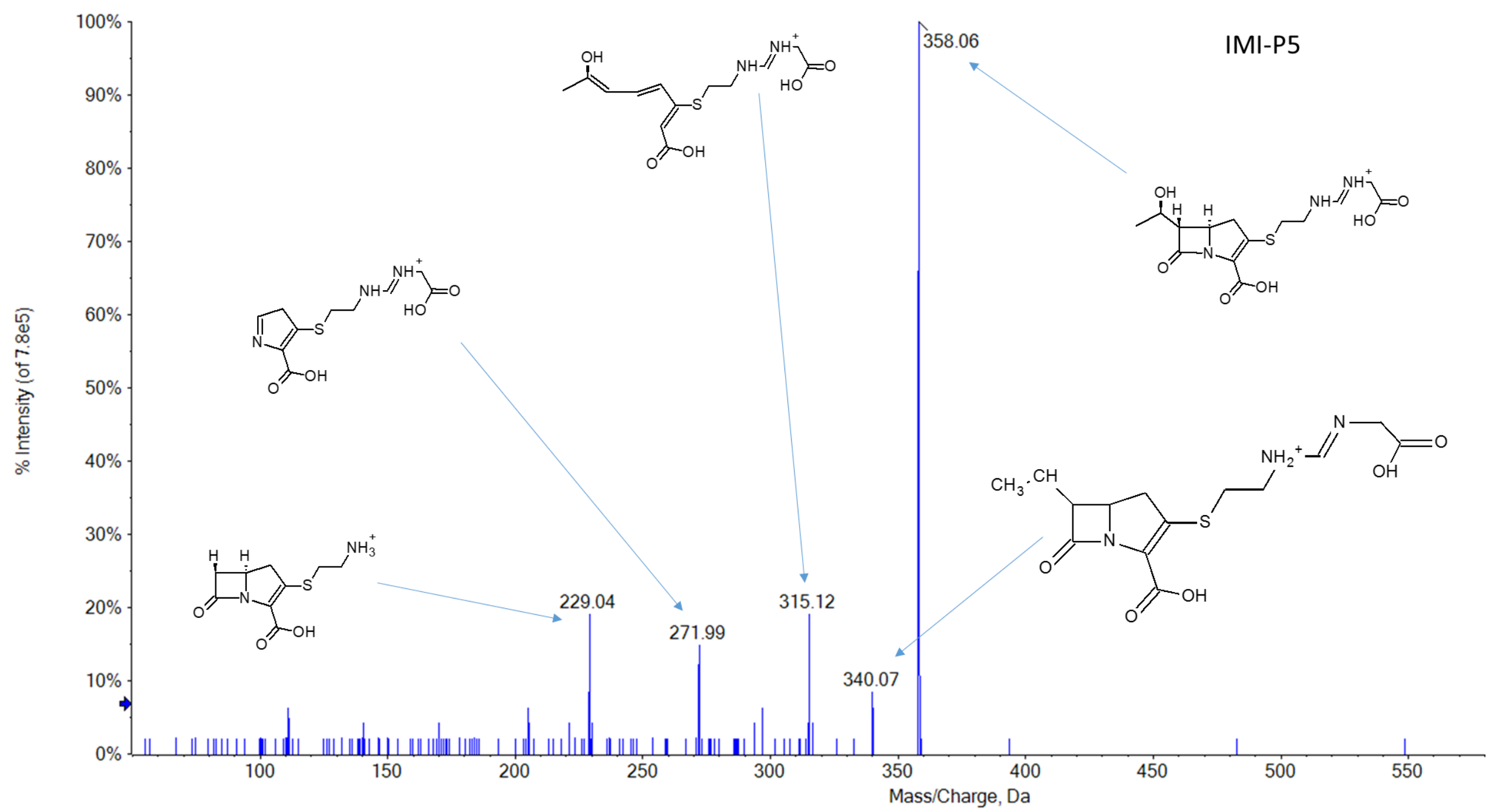

Figure S35. ESI (PI) MS/MS spectrum of IMI-P5. 


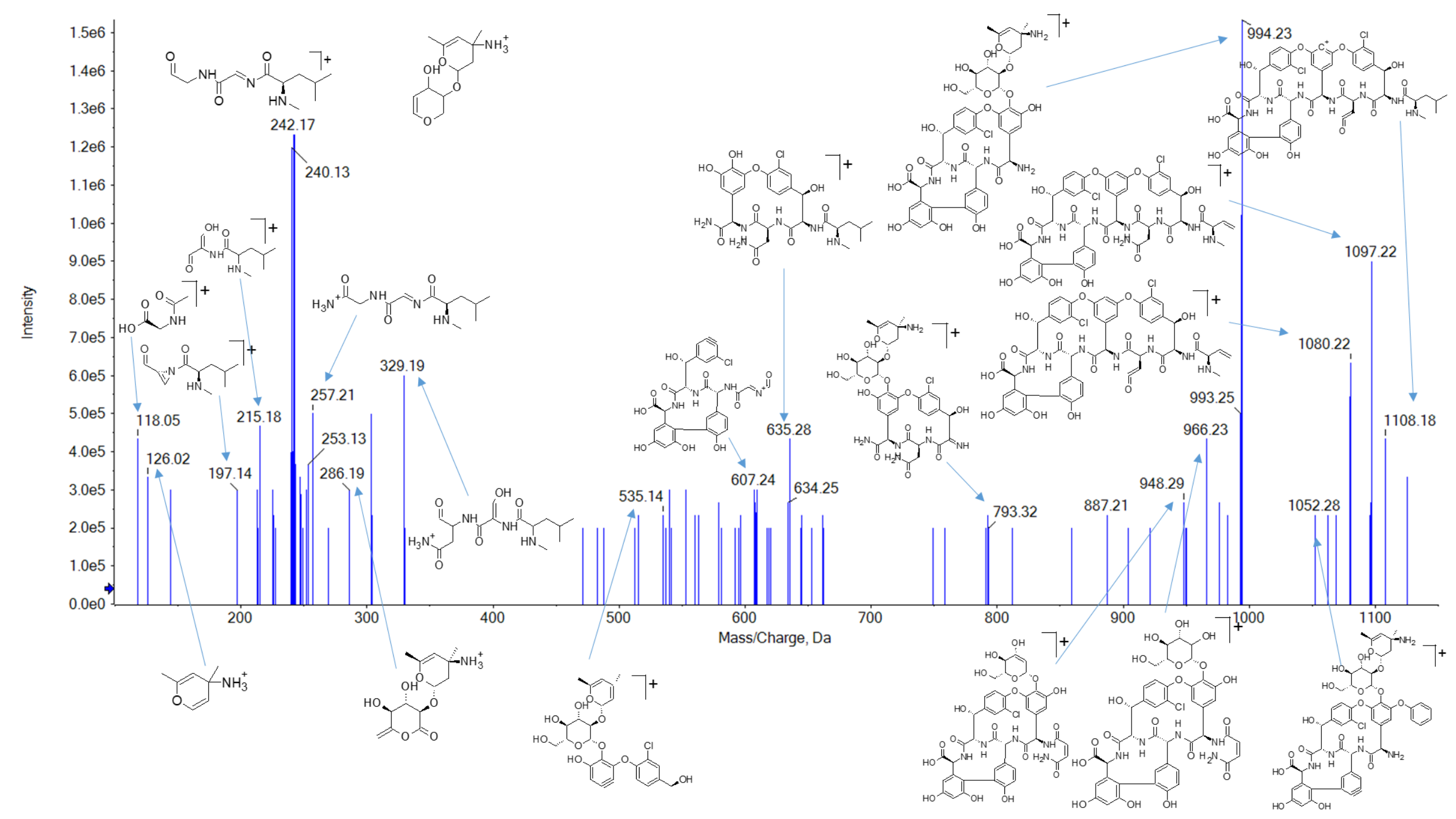

Figure S36. ESI (PI) MS/MS spectrum of VNM-P1. 


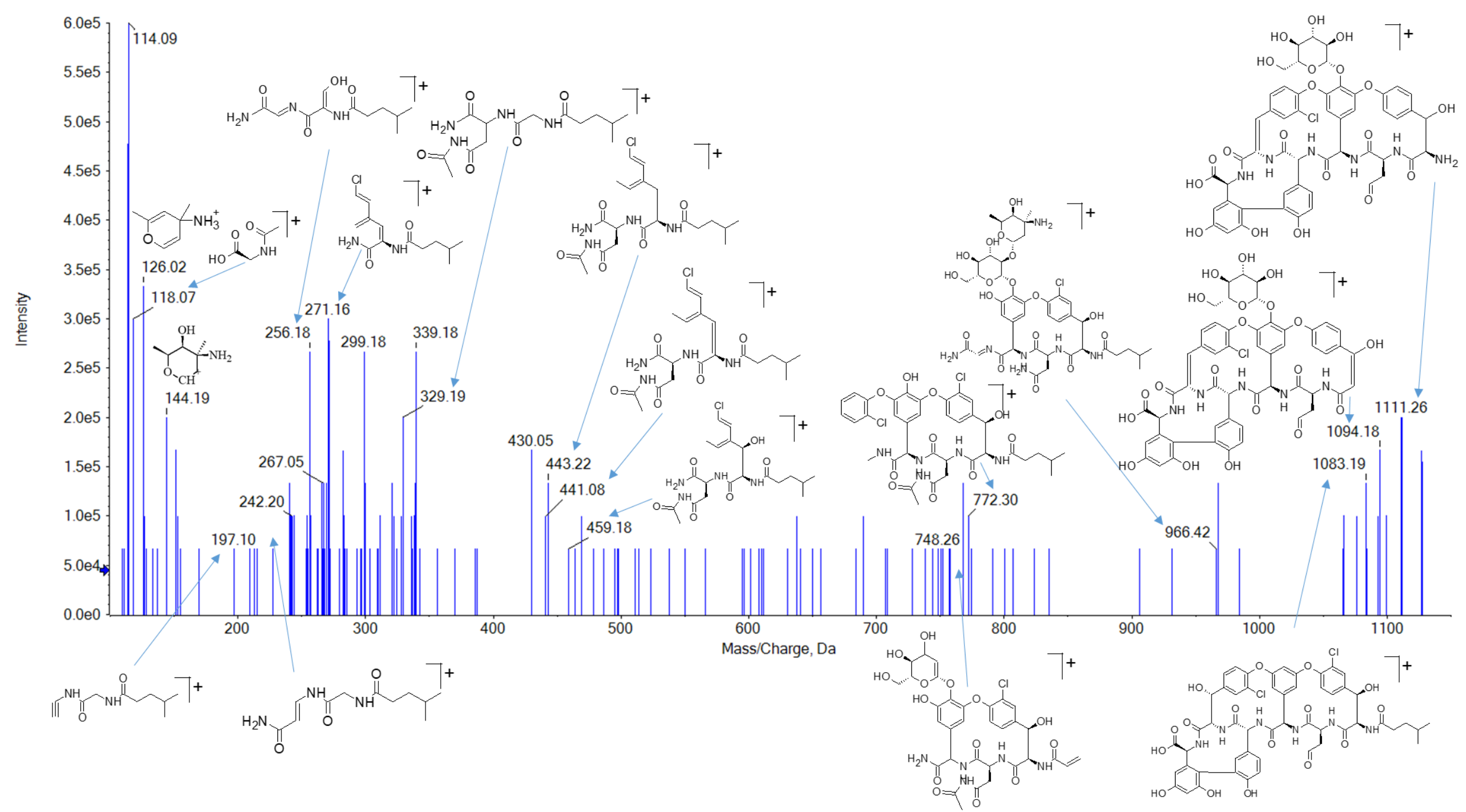

Figure S37. ESI (PI) MS/MS spectrum of VNM-P2. 


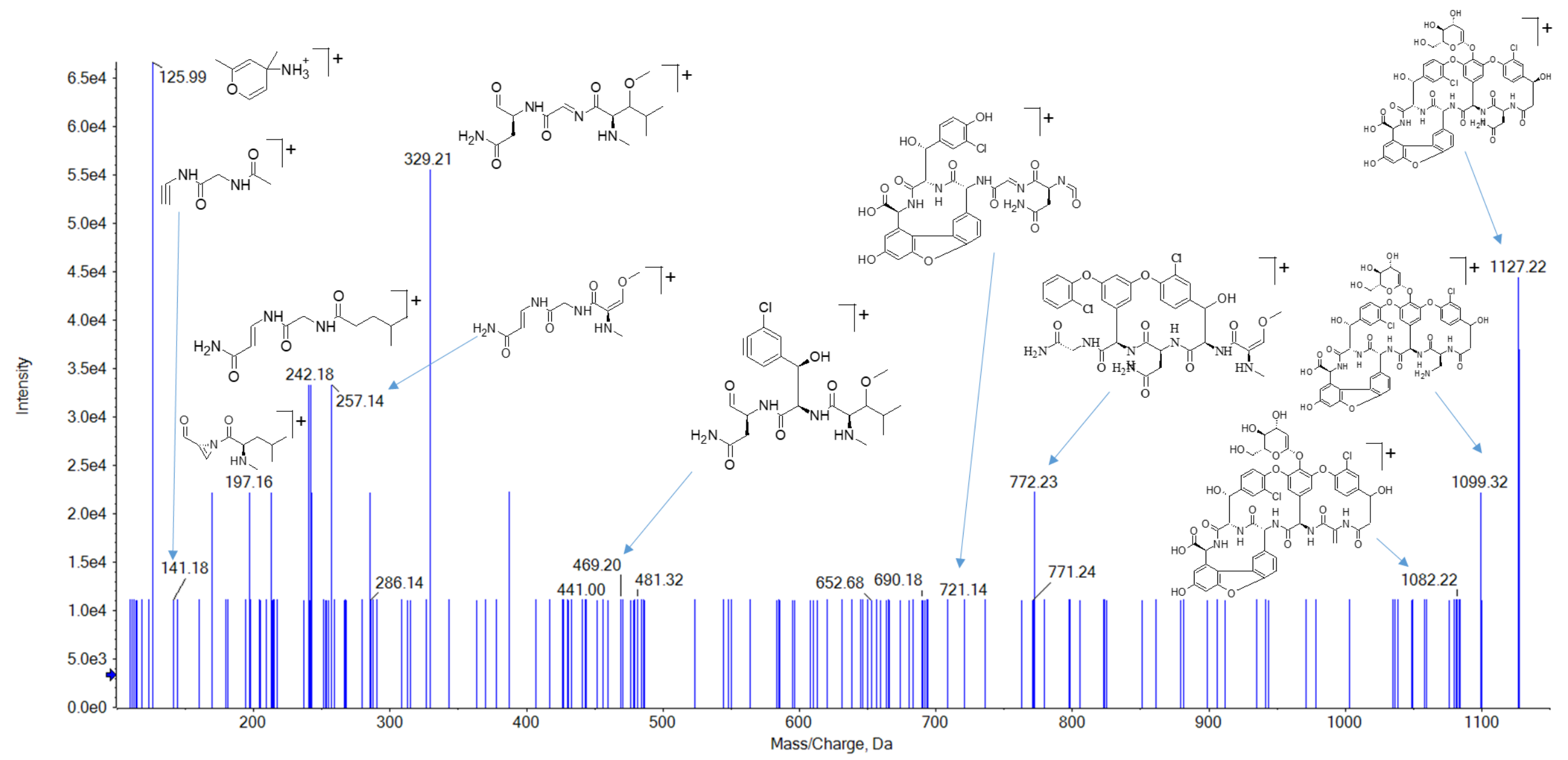

Figure S38. ESI (PI) MS/MS spectrum of VNM-P3. 


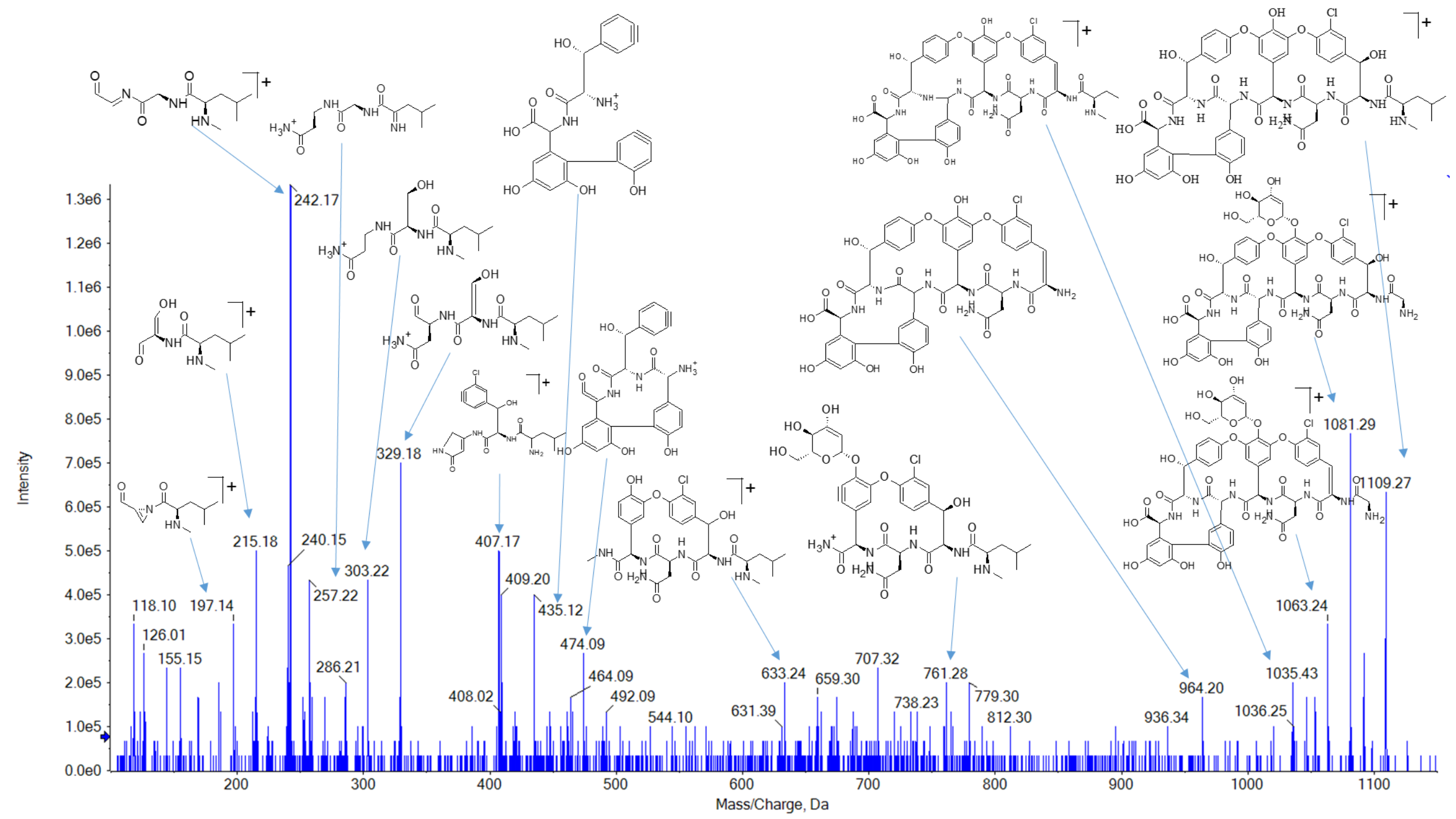

Figure S39. ESI (PI) MS/MS spectrum of VNM-P4a. 

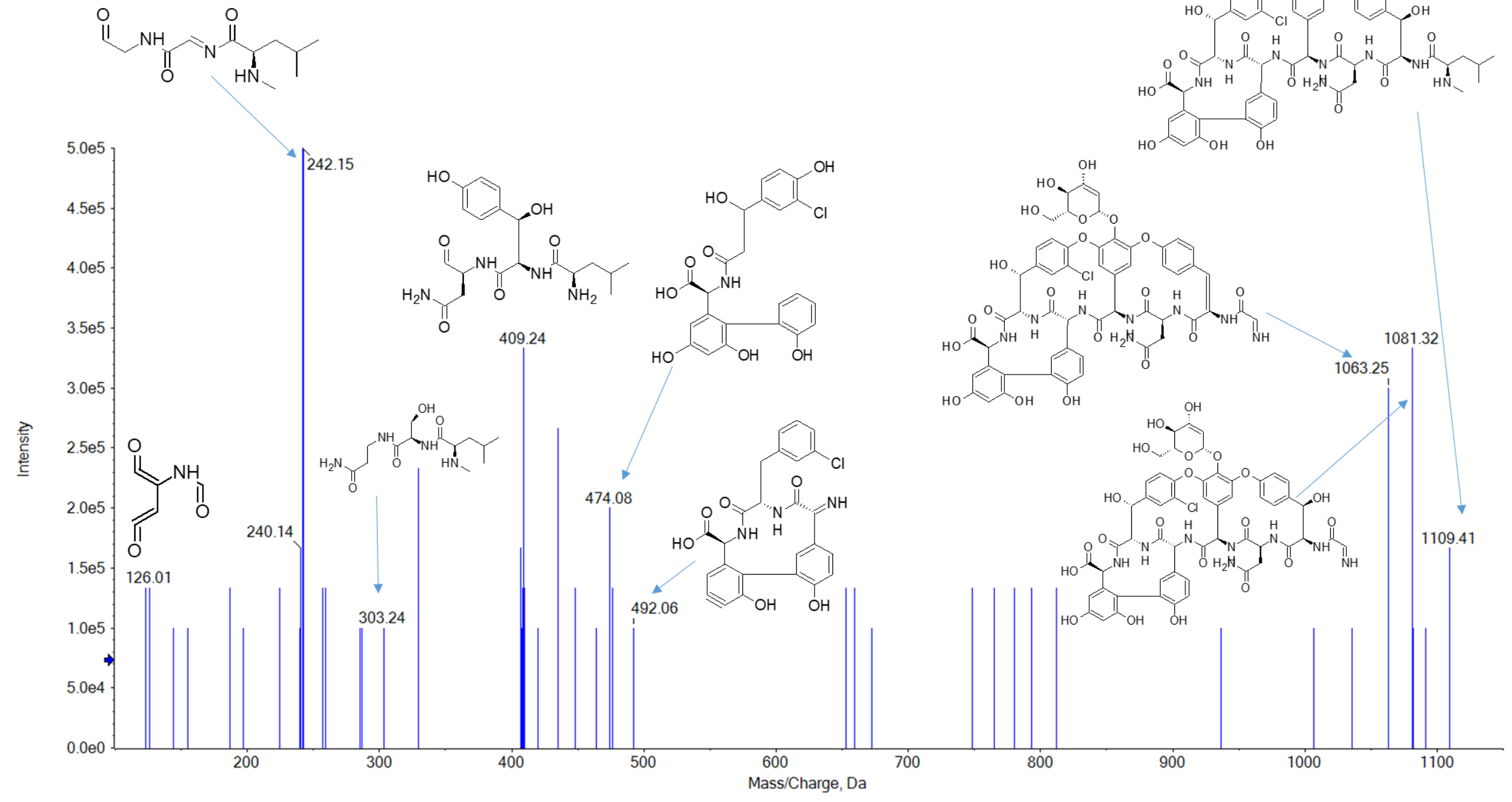

Figure S40. ESI (PI) MS/MS spectrum of VNM-P4b. 


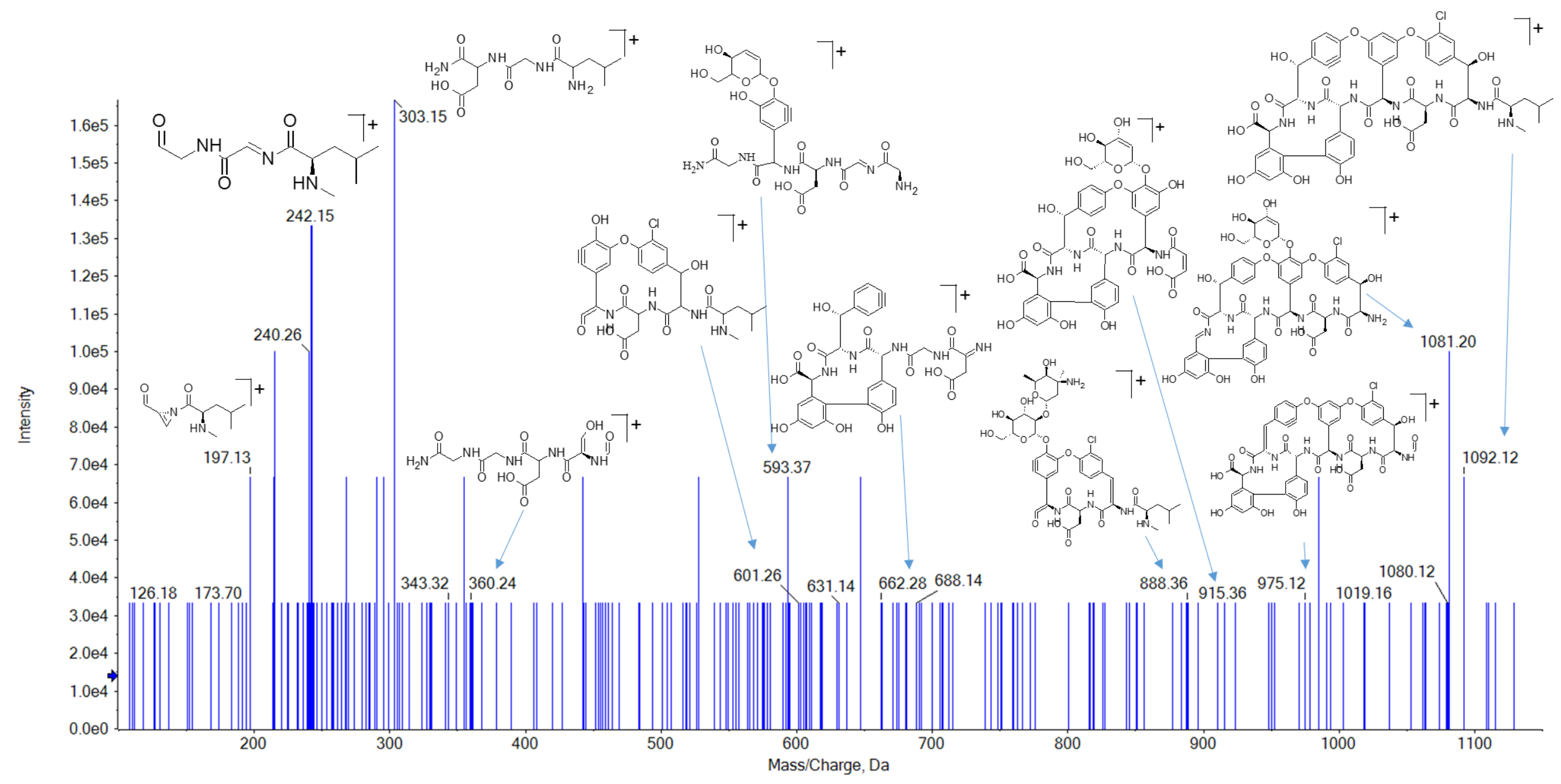

Figure S41. ESI (PI) MS/MS spectrum of VNM-P5a. 


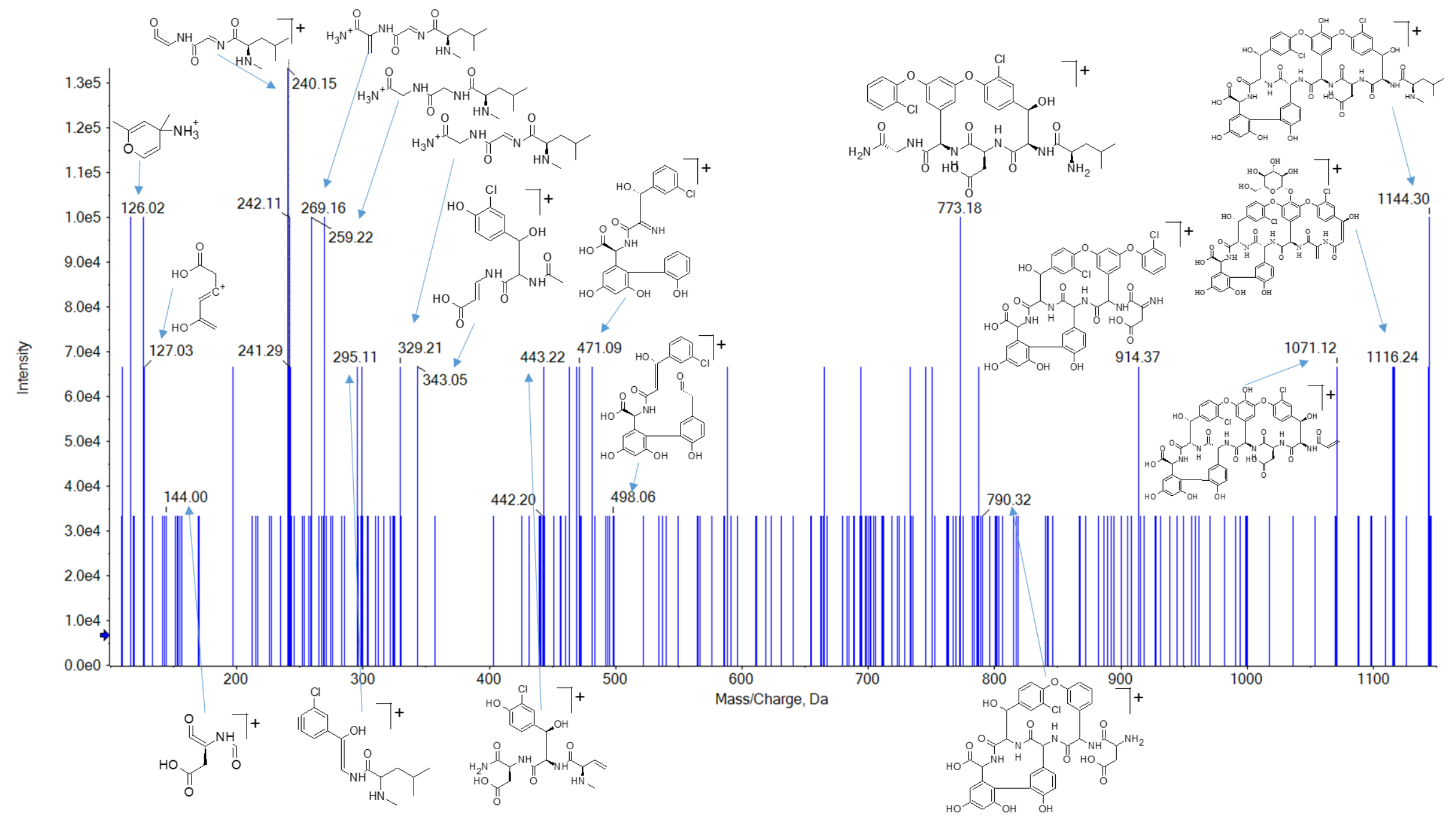

Figure S42. ESI (PI) MS/MS spectrum of VNM-P6a. 


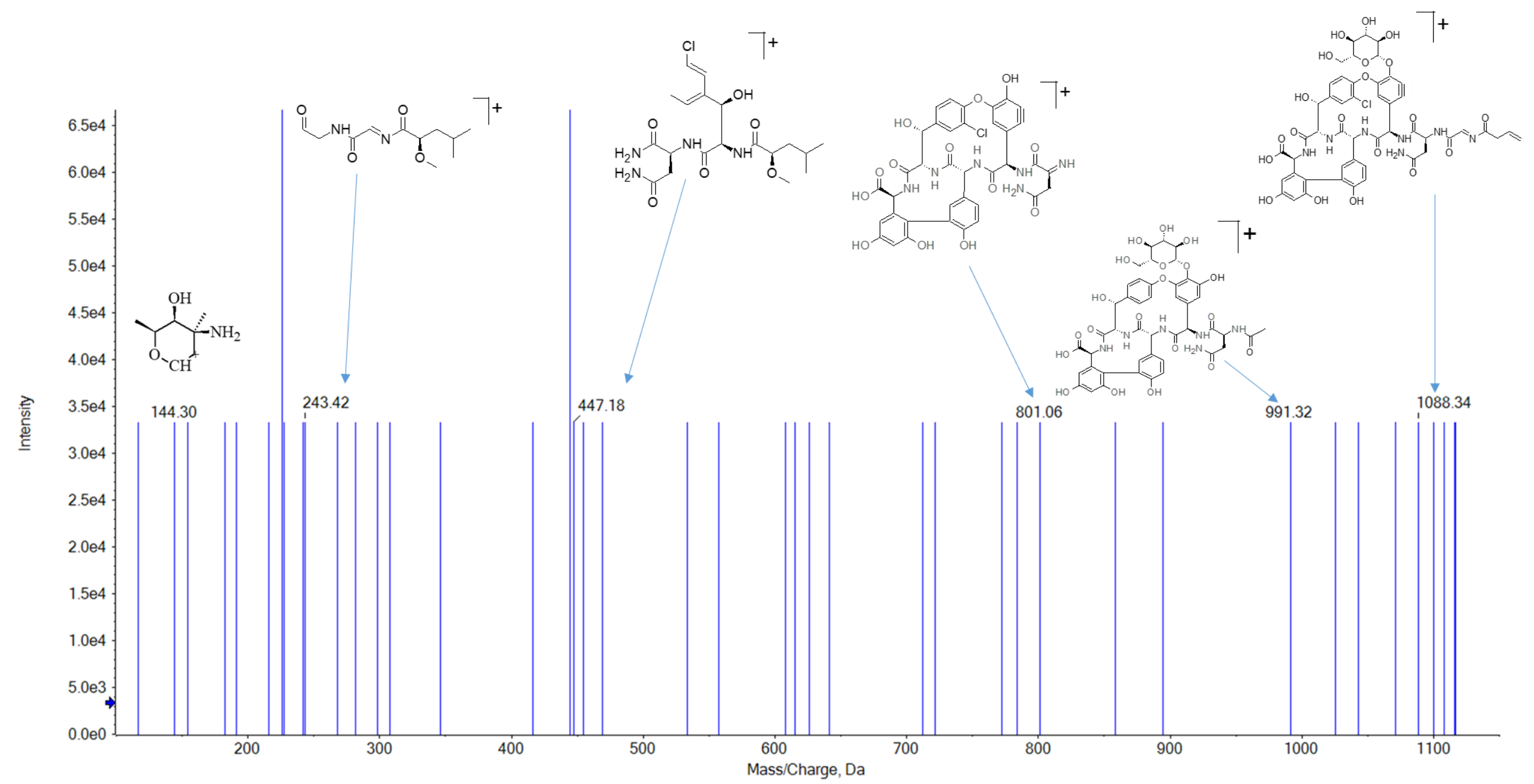

Figure S43. ESI (PI) MS/MS spectrum of VNM-P6b. 

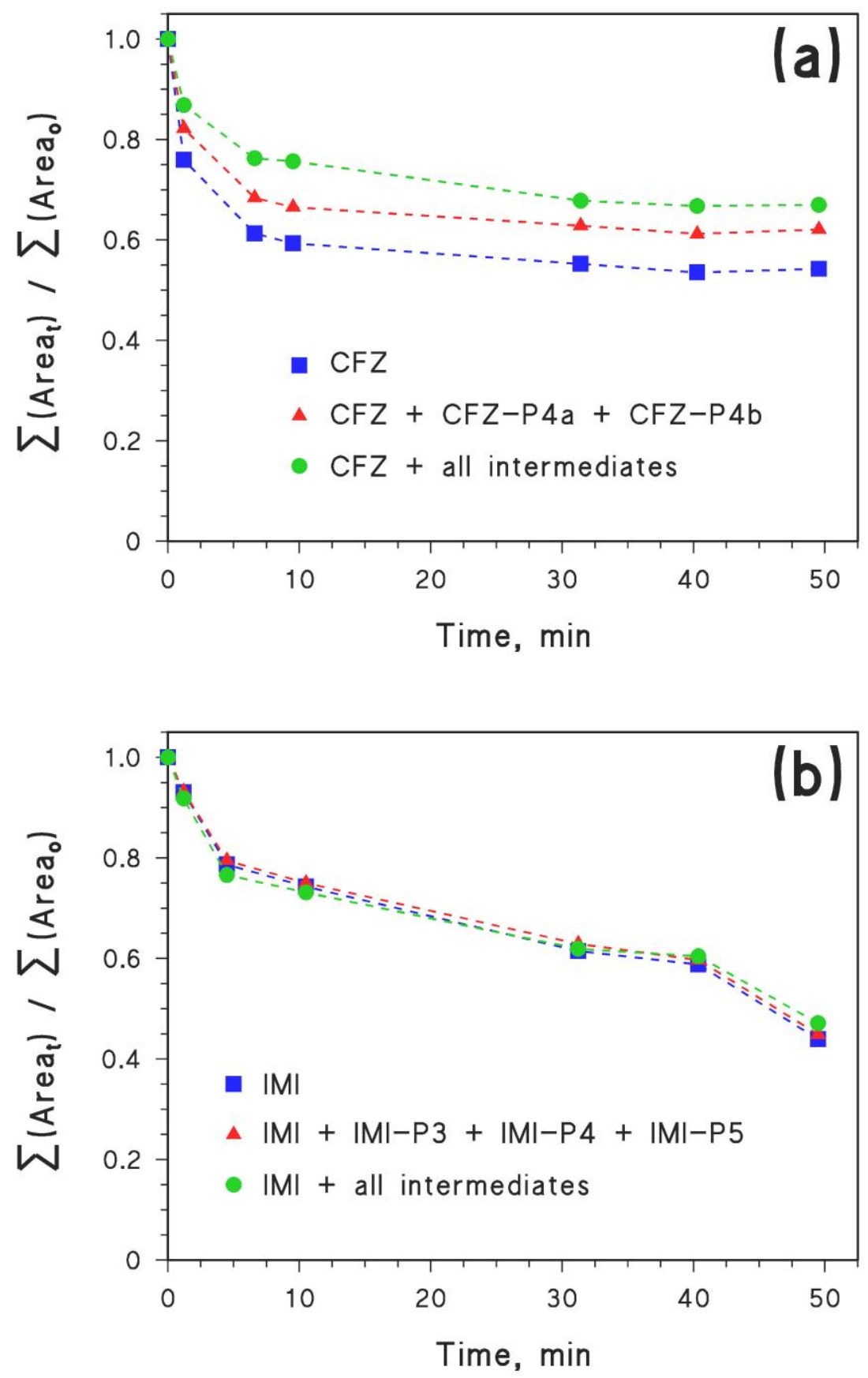

Figure S44. Time trends of the normalized peak areas of: (i) initial antibiotic; (ii) antibiotic plus the detected intermediates that retain an intact $\beta$-lactam ring; (iii) antibiotic plus all the detected intermediates. (a) cefazolin (CFZ); (b) imipenem (IMI).

Fenton conditions: $3 \times 10^{-4}$ mol L-1 antibiotic, $3 \times 10^{-4}$ mol L-1 $\mathrm{H}_{2} \mathrm{O}_{2}$ added twice (at 0 min and at 30 $\min$ ), $0.03 \mathrm{~g} \mathrm{~L}^{-1} \mathrm{ZVI}, \mathrm{pH} 5$ by $\mathrm{H}_{2} \mathrm{SO}_{4}$. 